\begin{abstract}
UNIVERSIDADE DE SÃO PAULO
FACULDADE DE FILOSOFIA, CIÊNCIAS E LETRAS DE RIBEIRÃO PRETO

DEPARTAMENTO DE FÍSICA
\end{abstract}

BEATRIZ TOMAZI

Protótipo experimental para aquisição de imagens por espalhamento de raios $\mathrm{X}$

Ribeirão Preto - SP

2019 


\title{
Protótipo experimental para aquisição de imagens por espalhamento de raios $\mathrm{X}$
}

\author{
Dissertação apresentada à Faculdade de \\ Filosofia, Ciências e Letras de Ribeirão Preto \\ da Universidade de São Paulo, como parte das \\ exigências para obtenção do título de mestre em \\ ciências. \\ Area de concentração: \\ Física Aplicada à Medicina e Biologia. \\ Orientador: \\ Prof. Dr. Martin Eduardo Poletti
}

\author{
(versão corrigida) \\ Ribeirão Preto - SP
}


Autorizo a reprodução e divulgação total ou parcial deste trabalho, por qualquer meio convencional ou eletrônico, para fins de estudo e pesquisa, desde que citada a fonte.

\section{FICHA CATALOGRÁFICA}

Tomazi, Beatriz

Protótipo experimental para aquisição de imagens por espalhamento de raios X / Beatriz Tomazi; orientador Martin Eduardo Poletti. Ribeirão Preto-SP, 2019.

86 f.:il

Dissertação (Mestrado - Programa de Pós-graduação em Física Aplicada à Medicina e Biologia) - Faculdade de Filosofia, Ciências e Letras de Ribeirão Preto da Universidade de São Paulo, 2019.

1.Imagens por espalhamento de raios X; 2. Espalhamento; 3 . Contraste e CNR 
Nome: TOMAZI, B

Título: Protótipo experimental para aquisição de imagens por espalhamento de raios $\mathrm{X}$

Dissertação apresentada à Faculdade de Filosofia, Ciências e Letras de Ribeirão Preto da Universidade de São Paulo, como parte das exigências para obtenção do título de mestre em ciências.

Aprovada em:

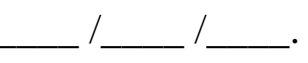

\section{Banca Examinadora}

Prof. Dr./ Prof. ${ }^{\text {a }}$ Dra. : Instituição:

Julgamento : Assinatura:

Prof. Dr./ Prof. ${ }^{a}$ Dra. : Instituição:

Julgamento : Assinatura:

Prof. Dr./ Prof. ${ }^{\text {a }}$ Dra. : Instituição:

Julgamento : Assinatura: 


\section{Agradecimentos}

À minha família, meus pais e irmã, Lair Roque Tomazi, Ana Rosa Tomazi e Patrícia Tomazi por todo apoio, amor e respeito em todos os momentos da minha vida.

Às minhas amigas e irmãs que adquiri ao longo do tempo Laís Forner, Aline Vaz de Melo e Paula Sanches por todos estes anos de convivência e companheirismo.

Ao meu orientador Professor Dr. Martin Eduardo Poletti por todos os ensinamentos durante minha graduação e mestrado.

Ao técnico Elderes de Paula pela paciência e ajuda nos experimentos.

Aos meus amigos do Laboratório de Física das Radiações e Dosimetria, Michel Gobo, Leonardo Soares, Daniel Balbin, Júlio Godeli, Flávia Franco, Alessandra Perez e Jéssica Graff pelas discussões e contribuições durante todo o mestrado.

À Universidade de São Paulo por me proporcionar grandes momentos e por todo o apoio que me foi dado.

À CAPES, pelo apoio financeiro. 


\section{Resumo}

\section{TOMAZI, Beatriz. Protótipo experimental para aquisição de imagens por espalhamento}

de raios X. 2019. 86f. Dissertação (Mestrado - Programa de pós graduação em Física Aplicada à Medicina e Biologia) - Faculdade de Filosofia, Ciências e Letras de Ribeirão Preto, Universidade de São Paulo - SP, 2019.

Recentes pesquisas mostram que a componente espalhada por um objeto pode ser utilizada para formar imagens médicas, complementares às imagens convencionais. O objetivo geral deste trabalho é avaliar a técnica da formação de imagem por espalhamento de raios $\mathrm{X}$ por meio da análise do contraste e razão contraste ruído (contrast noise ratio, CNR) entre materiais, utilizando um detector de radiografia computadorizada e espectros de raios $\mathrm{X}$ clínicos. Neste estudo, foi implementado um algoritmo para a realização dos cálculos analíticos que preveem a imagem por espalhamento, baseados no método determinístico, seguindo um modelo tridimensional, possibilitando o estudo e estimativa dos borramentos geométricos e físicos nos perfis radiais da imagem. No sistema experimental, foram utilizados espectros de raios $\mathrm{X}$ incidentes de $50 \mathrm{kV}$ (filtração adicional de 2,2 $\mathrm{mm}$ de $\mathrm{Al}$ e 0,6 $\mathrm{mm}$ de $\mathrm{Cu}$ ) e $80 \mathrm{kV}$ (filtração adicional de 2,2 $\mathrm{mm}$ de $\mathrm{Al}$ e $0,6 \mathrm{~mm}$ de $\mathrm{Cu}$; e 2,5 $\mathrm{mm}$ de $\mathrm{Al}$ ), proporcionando a análise de diferentes amostras compostas por materiais equivalentes ao tecido homogêneas (PMMA, água e nylon) e heterogêneas (de forma cilíndrica compostas por PMMA com um objeto inserido de $5 \mathrm{~mm}$ de água, com espessura total de $2 \mathrm{~cm}$ ). Os resultados analíticos mostraram significantes variações nos perfis radiais da imagem causadas pelos borramentos angular e espectral, apresentando grandes distorções de acordo com a variação do espectro incidente de raios $\mathrm{X}$, mostrando uma forte dependência com a largura espectral, energia média do feixe e forma do espectro de raios X. Os resultados de contraste e CNR se mostraram superiores na maior parte ao longo do raio do detector comparado ao primário, resultando em valores de até 11 vezes maior utilizando o espectro de $80 \mathrm{kV}$ (filtração adicional de 2,5 $\mathrm{mm}$ ) nos intervalos de $0,4 \mathrm{~cm}$ à 2,6 cm do raio do detector. Estes resultados são úteis para a utilização desta técnica em 
ambiente clínico e otimização das regiões de integração dos perfis ao longo do raio do detector, as quais resultam em maiores contrastes e $\mathrm{CNR}$, relevantes para a formação da imagem. 


\section{Abstract}

TOMAZI, Beatriz. Experimental prototype for image acquisition by $\mathbf{X}$-ray scattering. 2019. 86f. Dissertation (Master Degree - Postgraduate Program in Physics Applied to Medicine and Biology) - Faculdade de Filosofia, Ciências e Letras de Ribeirão Preto, Universidade de São Paulo - SP, 2019.

Recent research shows that the component scattered by an object can be used to form medical images, complementary to conventional images. The current work aims to evaluate the $\mathrm{X}$-ray imaging scatter technique, through the analysis of contrast and contrast-noise ratio $(C N R)$ between different materials, using a computed radiography image receptor and clinicals X-ray spectra. In this study, an algorithm was implemented to carry out analytical studies that allowed the dissemination of a data base, determining the three dimensional model, allowing the accomplishment of studies and estimates of geometric and physical results in the radial profiles of the image. For the experimental system, were used incident X-ray spectra of $50 \mathrm{kV}$ (additional filtration of $2.2 \mathrm{~mm} \mathrm{Al}$ and $0.6 \mathrm{~mm} \mathrm{Cu}$ ) and $80 \mathrm{kV}$ (additional filtration of $2.2 \mathrm{~mm}$ $\mathrm{Al}$ and $0.6 \mathrm{~mm} \mathrm{Cu}$ and $2.5 \mathrm{~mm} \mathrm{Al}$ ), providing the analysis of different samples composed of homogeneous (PMMA, water and nylon) and heterogeneous (cylindrical form composed of $P M M A$ with an inserted object of $5 \mathrm{~mm}$ of water, with a total thickness of $2 \mathrm{~cm}$ ) tissue equivalent materials. The analytical results showed significant variations in the radial profiles of the image caused by the angular and spectral blurring, presenting great distortions according to the variation of the X-ray incident spectrum, showing a strong dependence on the spectral width, average energy of the beam and shape of the spectrum of X-rays. The contrast and CNR results showed superior values mostly along the detector radius compared to the primary, resulting in values up to 11 times higher using the $80 \mathrm{kV}$ spectrum (additional $2.5 \mathrm{~mm}$ filtration) at the intervals of 0.4 to $2.6 \mathrm{~cm}$ from the radius of the detector. These results are useful for the use of this technique in clinical environment and optimization of the regions of integration of 
the profiles along the radius of the detector, which result in higher contrast and CNR, relevant for the formation of the image. 


\section{Lista de figuras}

2.1. Sistema simplificado de um tubo de raios $X$ (HENDEE, RITENOUR e HOFFMANN, 2002).

2.2. Exemplo espectros de raios $X$ com diferentes filtrações, proveniente de um alvo de $\mathrm{W}$ e tensão aplicada de $80 \mathrm{kV}$ (adquiridos pelo software SpekCalc (POLUDNIOWSKI, LANDRY, et al., 2009b)).

2.3. Ilustração dos processos de interação dos elétrons com o núcleo atômico do alvo. A energia dos raios X produzido depende da distância de interação entre o elétron e o núcleo do alvo (OKUNO et al.,1986).

2.4. Aproximação esquemática do modelo de Bohr para a produção de radiação característica em um átomo do alvo. O elétron (1) colide com um elétron ligado da camada K, ejetando-o (2). Um elétron da camada L preenche a vacância deixada na camada K (3), e a diferença de energia dessas camadas resulta na emissão de radiação característica (4). Sequência númerica para ocorrer a emissão de radiação característica 1, 2, 3 e 4 (OKUNO et al., 1986).

2.5. Representação esquemática do efeito fotoelétrico (OKUNO et al., 1986).

2.6. Representação esquemática do espalhamento Rayleigh, o qual há uma troca de momento, porém a energia se conserva na interação do fóton com um elétron ligado (OKUNO et al., 1986).

2.7. Curvas do fator de forma do espalhamento elástico e a função de espalhamento incoerente em função do momento transferido $\chi$ para o PMMA. As curvas são representadas por (I) $F_{M A I}(\chi)$ (HUBBELL, VEIGELE, et al., 1975); (II) $F_{m o l}(\chi)$ a função de interferência multiplicativa foi retirada dos dados de Tartari et al. (2002) e (III) $S(\chi)$ (HUBBELL, VEIGELE, et al., 1975). Ambas as curvas foram normalizadas pela raiz da massa molecular $\sqrt{M}$ do composto.

2.8. Comparação da seção de choque atômica medida com a calculada por Klein-Nishina em função da energia do fóton incidente em diferentes materiais. A energia $h v_{e q}$ corresponde à energia a qual a seção de choque atômica de Klein-Nishina e a medida são equivalentes (PODGORSAK, 2010).

2.9. Ciclo de um sistema de radiografia computadorizada. a) Utilizando uma placa de fósforo fotoestimulável (Photoestimulable phosphor, PSP). b) A exposição por raios X gera a imagem latente, onde os elétrons são armadilhados em um estado metaestável. c) A imagem é lida através da varredura de um feixe laser para liberar PSL, o qual é coletada por um guia de luz e detectada por um tubo fotomultiplicador, posteriormente, d) residuos de elétrons armadilhados são removidos com uma fonte de luz de alta intensidade, e a placa pode ser reutilizada.

3.1. Representação simplificada do modelo adotado no algoritmo. Uma infinidade de raios é gerada por uma fonte extensa de tamanho $Y$ à uma distância $D_{0}$ de um colimador de abertura $\phi$. Os raios delimitados pelo colimador interagem com uma amostra composta por material equivalente ao tecido de espessura 
$T$. Ao espalharem a um ângulo $\theta$ em relação à radiação incidente, atingem um pixel de um detector plano localizado à $D_{2}+T / 2$ do centro da amostra (origem do sistema de coordenadas).

3.2. Representação da fonte extensa como um conjunto de fontes pontuais. Em a) a fonte de tamanho $\mathrm{Y}$ é dividida em $\mathrm{n}$ elementos, o qual em b) é representado por $\mathrm{n}$ fontes pontuais onde um número $\mathrm{n}_{\mathrm{i}} \mathrm{de}$ raios são traçados ao atingir os elementos de área dA do colimador, levando em conta a divergência dos raios.

3.3. Representação do caminho percorrido por um fóton até a superfície da amostra 36

3.4. Sistema de seleção dos voxels ativos. a) Uma amostra contendo um material de estudo é composta por voxels de dimensões $\left(\frac{M}{m_{x}}\right) x\left(\frac{N}{m_{y}}\right) x\left(\frac{T}{m_{z}}\right) \mathrm{cm}$, o qual são definidos como ativos aqueles que, $\mathrm{b}$ ) contendo um plano xy em seu centro, é interceptado por um raio. 38

3.5. Caminho percorrido pelo fóton após interagir com o material do voxel e atingir um pixel do detector à distância $\left(D_{2}+T-z\right)$ do centro espalhador .

3.6. Diagrama simplificado do algoritmo implementado em MATLAB®.

3.7. Distribuição da $\Psi_{S}$ em função da posição ao longo de um eixo central do detector de uma imagem $10 \times 10 \mathrm{~cm}^{2}$ variando a modelagem do fator de forma, para um feixe monoenergético de $80 \mathrm{keV}$. Em a) a representação utilizando o fator de forma do modelo atômico independente e o fator de forma molecular para o PMMA, e suas respectivas imagens planares em b) e c). Analogamente, à direita, em d) para o tecido adiposo, e suas respectivas imagens planares em e) e f).....

3.8. Diagrama simplificado de um sistema para aquisição de imagens por espalhamento de raios $X$, utilizando um detector plano, localizado a uma distância $D_{2}$ do centro de uma amostra de espessura $T$, a qual é irradiada por um feixe de raios $\mathrm{X}$ originado de a) uma fonte de tamanho $Y$, b) o feixe que atinge a amostra possui tamanho definido pela abertura do colimador $\phi$ localizado a uma distância $D_{0}$ da fonte e $D_{1}$ do centro da amostra (BEATH e CUNNINGHAM, 2009).

3.9. Perfil radial intrínseco do PMMA, em kerma colisional no ar normalizado pelo número de fótons incidentes em função da posição ou raio de um eixo central do detector. A energia do feixe incidente é de $40 \mathrm{keV}$ e o centro da amostra se encontra à $32 \mathrm{~cm}$ do detector plano. A posição do pico principal se encontra em $1,59 \mathrm{~cm}$ e a FWHM resulta em $0,67 \mathrm{~cm}$.

3.10. Fotografia da configuração experimental utilizada para aquisição das imagens por espalhamento de raios $X$.

3.11. Imagem de uma amostra de nylon $(2 \mathrm{~cm}$ ), irradiada por um espectro de $80 \mathrm{kV}$ (filtração adicional de $2,5 \mathrm{~mm}$ de $\mathrm{Al}$ ), em formato DICOM transportada para o software ImageJ, o qual é utilizado para a extração do perfil radial da imagem por meio do plugin radial profile.

3.12 Estudo da propriedade de transferência do sinal em diferentes qualidades do feixe. Em a) as curvas ajustadas à uma função logarítimica e em b) inseridas em mono-log 
3.13 Perfis radiais de imagens adquiridas experimentalmente pela componente espalhada dos raios $\mathrm{X}$, expressos em PV e $\mathrm{K} / \mathrm{K}_{0}$, para uma amostra heterogênea de água $(0,6 \mathrm{~cm})+\mathrm{PMMA}(0,4 \mathrm{~cm})+$ água $(0,7 \mathrm{~cm}$ ) irradiada por um feixe de raios $\mathrm{X}$ de $80 \mathrm{kV}$ (filtração adicional de 2,2 $\mathrm{mm}$ de $\mathrm{Al}$ e $0,6 \mathrm{~mm}$ de $\mathrm{Cu}$

3.14 Sistema de subtração das componentes de background para extrair informação somente da amostra

4.1. Validação do algorítimo implementado. Comparação do perfil radial representado por $\Psi_{\boldsymbol{s}}\left(\mathrm{keV} \mathrm{mm}^{-2}\right)$ com valores obtidos por Poludniowsky et al. (2009), utilizando uma amostra de tecido adiposo com dimensões de $0,5 \times 0,5 \times 0,5 \mathrm{~cm}^{3}$.

4.2. Influência da abertura do colimador nas imagens e perfis radiais. a) Distribuição de $K_{c}^{a r}{ }_{\text {espalhado }} / N_{0}$ em função da raio ao longo de um eixo central do detector, de uma imagem $18 \times 18 \mathrm{~cm}^{2}$ para diferentes aberturas do colimador circular de $6 \mathrm{~mm}, 4 \mathrm{~mm}$ e $1 \mathrm{~mm}$ de diâmetro em uma amostra de dimensões de $2 \times 2 \times 2 \mathrm{~cm}^{3}$ composta por PMMA e em b) suas respectivas imagens planares.

4.3. Resolução espacial ao longo do raio do detector, variando a abertura do colimador ( $1 \mathrm{~mm}-*$, $4 \mathrm{~mm}-\star$ e $6 \mathrm{~mm}-\diamond$ ), para um feixe de $40 \mathrm{keV}$, espessura de $2 \mathrm{~cm}$ e distância da amostra ao detector de $32 \mathrm{~cm}$.

4.4. Influência da distância do centro da amostra ao detector. a) Distribuição de $K_{c}^{a r}{ }_{\text {espalhado }} / N_{0}$ em função do raio ao longo de um eixo central do detector, de uma imagem $18 \times 18 \mathrm{~cm}^{2}$, em distâncias de 11 , 32 e $50 \mathrm{~cm}$ do centro da amostra de PMMA $\left(2 \times 2 \times 2 \mathrm{~cm}^{3}\right)$ ao plano do detector. b) As imagens planares referentes aos perfis radiais em a).

4.5. Influência da distância do centro da amostra ao detector nas imagens. a) Variações nos perfis radiais intrínsecos de $2 \times 2 \times 2 \mathrm{~cm}^{3}$ de PMMA, conforme o aumento da distância do centro da amostra ao detector, utilizando um feixe de $40 \mathrm{keV}$. b) Ilustração das diferenças encontradas no plano da imagem e os deslocamentos causados nos picos de maior intensidade e FWHM, para um mesmo intervalo $\Delta \theta$ de espalhamento em distâncias do centro da amostra ao detector de $11 \mathrm{~cm}, 32 \mathrm{~cm}$ e $50 \mathrm{~cm}$. 62

4.6. a) Resolução espacial ao longo do raio do detector, variando a distância da amostra ao detector $(11 \mathrm{~cm}-\diamond, 32 \mathrm{~cm}-\star$ e $50 \mathrm{~cm}-\star$ ), para um feixe de $40 \mathrm{keV}$ e abertura de $1 \mathrm{~mm}$, e b) o comportamento da resolução espacial relativa conforme a variação da distância entre o centro da amostra ao eixo central do detector.

4.7. Influência da espessura das amostras compostas por PMMA, irradiadas por um feixe monoenergético de a) $20 \mathrm{keV} \mathrm{e} \mathrm{b)} 80 \mathrm{keV}$. A abertura do colimador foi de $1 \mathrm{~mm}$ e as amostras estão distanciadas a $32 \mathrm{~cm}$ do detector 
4.8 Variações nos perfis radiais intrínsecos de material PMMA, conforme variação na energia de $20 \mathrm{keV}$ e $80 \mathrm{keV}$. Os perfis radiais intrínsecos normalizados são idênticos para todas as espessuras

4.9. a) Resolução espacial ao longo de todo raio do detector, variando a espessura da amostra $(2 \mathrm{~cm}-$ $\mathbf{X}, 4 \mathrm{~cm}-*, 8 \mathrm{~cm}-\star$ e $10 \mathrm{~cm}-\diamond)$ e b) a resolução espacial relativa em função da espessura, utilizando uma distância da amostra ao detector de $32 \mathrm{~cm}$.

4.10. Distribuição de $K_{c}^{a r}$ espalhado $/ N_{0}$ em função da posição ao longo de um eixo central do detector, de uma imagem $18 \times 18 \mathrm{~cm}^{2}$, em feixes monoenergéticos de 30, 40 e $50 \mathrm{keV}$, para a) água e b) PMMA. A abertura do colimador foi de $1 \mathrm{~mm}$ e as amostras, ambas de $2 \times 2 \times 2 \mathrm{~cm}^{3}$, estão distanciadas a $32 \mathrm{~cm}$ do detector.

4.11. Comportamento dos perfis radiais de acordo com o aumento na energia do feixe incidente...... 68

4.12. Influência de espectros retangulares no perfil radial da imagem. Em a) a fluência do número de fótons em energia normalizada em função da energia do espectro, para diferentes larguras espectrais. Em b) a distribuição de $K_{c}^{a r}$ espalhado $/ N_{0}$ em função da posição ao longo de um eixo central do detector, de uma imagem 18x18 $\mathrm{cm}^{2}$ e material da amostra de PMMA, para os espectros retangulares mostrados em a) comparado a um monoenergético de $40 \mathrm{keV}$.

4.13. Resolução espacial ao longo do raio do detector, variando a largura do espectro de raios $X$ $(8,5 \mathrm{keV}-\star, 8,82 \mathrm{keV}-\star, 16,2 \mathrm{keV}-\diamond$ e $16,6 \mathrm{keV}-\square)$, para uma amostra espessura de $2 \mathrm{~cm}$ distanciada à $32 \mathrm{~cm}$ do detector.

4.14. Influência de espectros triangulares no perfil radial da imagem. Em a) a fluência do número de fótons em energia normalizada pelo máximo em função da energia do espectro, para diferentes larguras espectrais. Em b) a distribuição de $K_{c}^{a r}{ }_{\text {espalhado }} / N_{0}$ em função da posição ao longo de um eixo central do detector, de uma imagem $18 \times 18 \mathrm{~cm}^{2}$ e material da amostra de PMMA, para os espectros triangulares mostrados em a).

4.15. A distribuição de $K_{S} / N_{0}$ em função da posição ao longo de um eixo central do detector, de uma imagem $18 \times 18 \mathrm{~cm}^{2}$ e material da amostra de PMMA, para os espectros retangular e triangular de mesma largura espectral $(5,5 \mathrm{keV})$ e energia média $(36,4 \mathrm{keV})$.

4.16. Perfis radiais de imagens por espalhamento de raios $\mathrm{X}$ da água, utilizando um espectro de $50 \mathrm{kV}$.

4.17. Perfis radiais de imagens por espalhamento de raios $X$, variando as espessuras das amostras de PMMA em $1 \mathrm{~cm}, 2 \mathrm{~cm}$ e $4 \mathrm{~cm}$, utilizando um espectro de $80 \mathrm{kV}(2,5 \mathrm{~mm}$ de $\mathrm{Al})$.

4.18. Imagens por espalhamento de raios $X$ para amostras de $2 \mathrm{~cm}$ de PMMA, nylon e água e seus respectivos perfis radiais, utilizando um espectro de energia de $50 \mathrm{kV}(2,2 \mathrm{~mm}$ de $\mathrm{Al}+0,6 \mathrm{~mm}$ de $\mathrm{Cu})$. 
4.19. Imagens por espalhamento de raios $X$ para amostras de $2 \mathrm{~cm}$ de PMMA, nylon e água e seus respectivos perfis radiais, utilizando um espectro de energia de $80 \mathrm{kV}(2,2 \mathrm{~mm}$ de $\mathrm{Al}+0,6 \mathrm{~mm}$ de $\mathrm{Cu})$.

4.20. Imagens por espalhamento de raios $X$ para amostras de $2 \mathrm{~cm}$ de PMMA, nylon e água e seus respectivos perfis radiais, utilizando um espectro de energia de $80 \mathrm{kV}(2,5 \mathrm{~mm}$ de $\mathrm{Al})$. 77

4.21. Perfis radiais de imagens por espalhamento de raios $X$, utilizando amostras homogênea e heterogênea de PMMA e PMMA+água com espessura de $2 \mathrm{~cm}$, em análise do contraste e CNR, para um espectro de energia de a) $50 \mathrm{kV}(2,2 \mathrm{~mm}$ de Al e 0,6 $\mathrm{mm}$ de $\mathrm{Cu}$ ), b) $80 \mathrm{kV}(2,2 \mathrm{~mm}$ de $\mathrm{Al} \mathrm{e} \mathrm{0,6} \mathrm{mm}$ de $\mathrm{Cu}$ ) e c) $80 \mathrm{kV}(2,5 \mathrm{~mm}$ de $\mathrm{Al})$.

4.22. Perfis radiais de imagens por espalhamento de raios $X$, utilizando amostras homogênea e heterogênea de PMMA e PMMA+água com espessura de $4 \mathrm{~cm}$, em análise do contraste e CNR, para um espectro de energia de a) $50 \mathrm{kV}(2,2 \mathrm{~mm}$ de $\mathrm{Al} \mathrm{e} 0,6 \mathrm{~mm}$ de $\mathrm{Cu}$ ), b) $80 \mathrm{kV}(2,2 \mathrm{~mm}$ de $\mathrm{Al} \mathrm{e} \mathrm{0,6} \mathrm{mm}$ de $\mathrm{Cu}$ ) e c) $80 \mathrm{kV}(2,5 \mathrm{~mm}$ de Al $)$. 81

4.23. Sistematização para a obtenção de um pixel da imagem formada pela componente espalhada dos raios X (NISAR, 2004)... 82 


\section{Sumário}

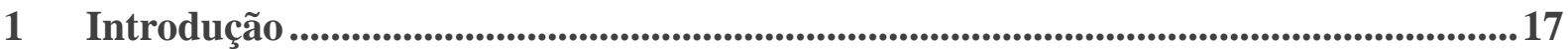

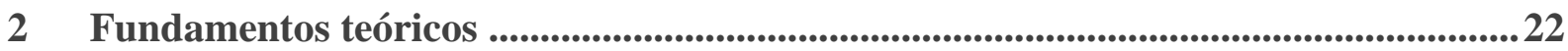

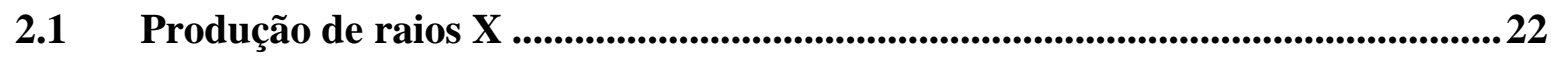

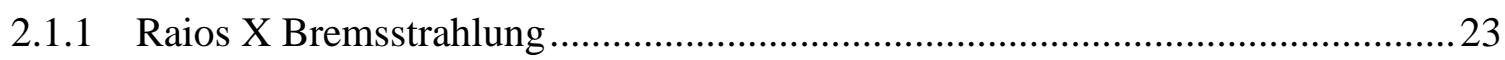

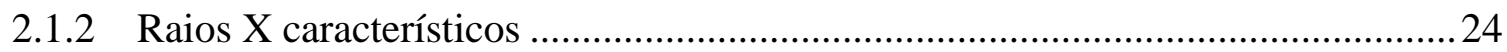

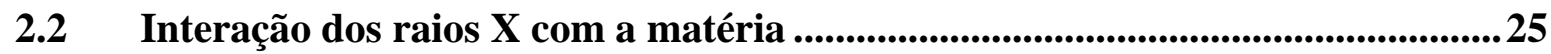

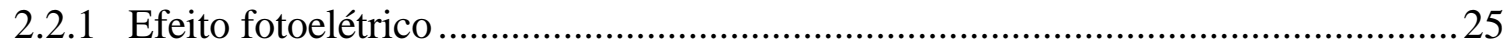

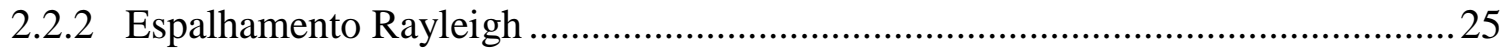

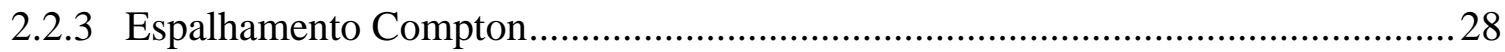

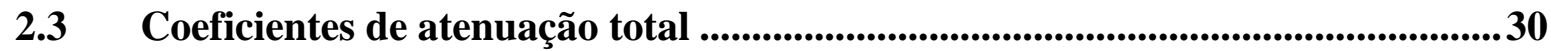

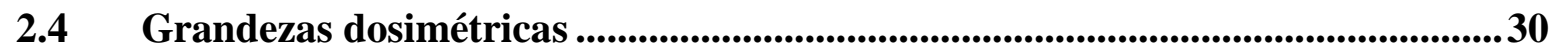

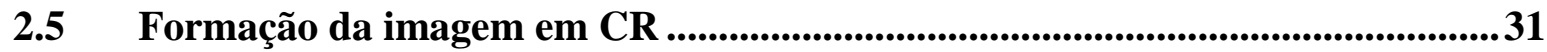

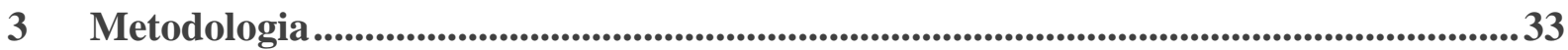

3.1 Cálculos analíticos para a obtenção da imagem devido a componente espalhada

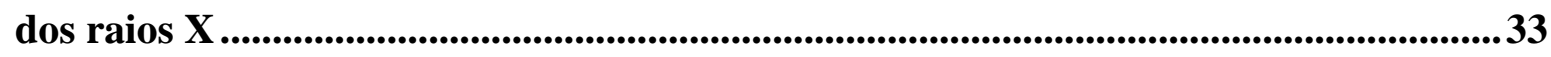

3.1.1 Fonte extensa e divergência dos raios ............................................................ 34

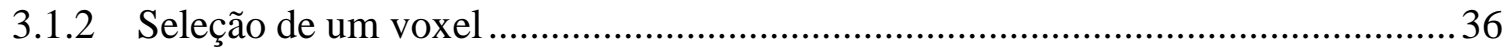

3.1.3 Fótons espalhados sob um elemento de volume (voxel) …................................ 38

3.1.4 Algorítmo para aquisição das imagens por espalhamento de raios X .................. 41

3.1.5 Influência na modelagem do fator de forma nas imagens e nos perfis radiais por espalhamento de raios $\mathrm{X}$.

3.1.6 Borramento espacial gerado nos perfis radiais da imagem relacionado aos parâmetros geométricos e físicos do sistema.

3.2 Metodologia experimental para a aquisição das imagens por espalhamento de raios $X$. 


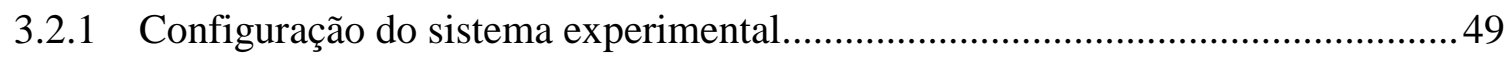

3.2.2 Espectros de raios $\mathrm{X}$ e amostras utilizadas para aquisição das imagens ..............50

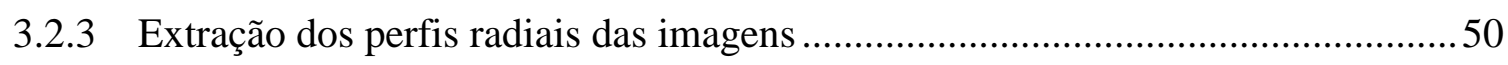

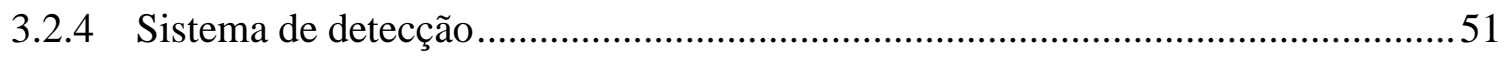

3.2.5 Correções das componentes de background do sistema......................................53

3.2.6 Distribuição radial do contraste (C) e razão contraste-ruído (CNR) .....................54

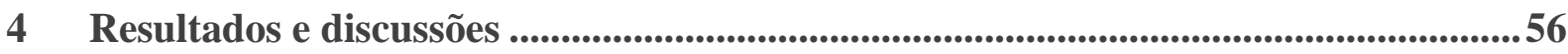

4.1 Estudo dos parâmetros geométricos e físicos em imagens formadas pela componente espalhada dos raios $\mathrm{X}$ por meio de cálculos analíticos ............................5

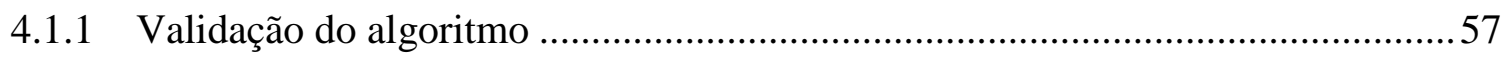

4.1.2 Influência da abertura do colimador $(\phi)$ nos perfis radiais das imagens ................58

4.1.3 Influência da distância da amostra ao detector nos perfis radiais das imagens ..... 61

4.1.4 Influência da espessura das amostras nos perfis radiais da imagem .....................64

4.1.5 Análise da influência do espectro incidente nos perfis radiais da imagem ...........67

\subsection{Estudo de imagens formadas pela componente espalhada dos raios $\mathrm{X}$}

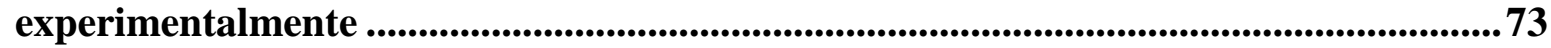

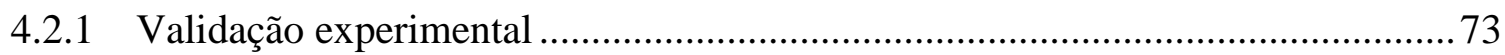

4.2.2 Influência da espessura nos perfis radiais da imagem ......................................... 74

4.2.3 Imagens formadas e extração dos perfis radiais de amostras homogêneas ...........75

4.2.4 Distribuição radial do contraste e CNR em amostras heterogêneas ...................... 77

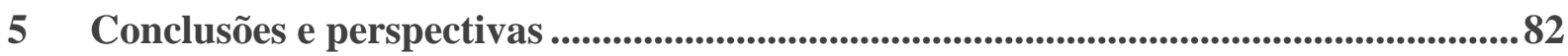

5.1 Conclusões da influência dos parâmetros geométricos e físicos.........................82

5.2 Conclusões no contraste e CNR das imagens experimentais...............................83

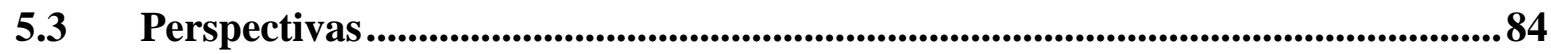

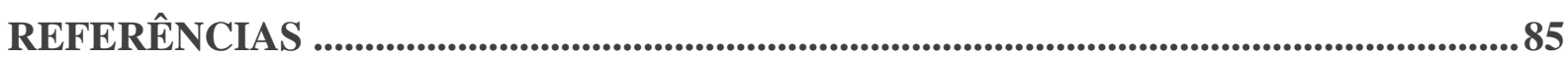




\section{Introdução}

Em radiodiagnóstico, imagens de raios $X$ convencionais são baseadas na projeção de um objeto $3 D$ em um plano $2 D$ (imagem), ou seja, cada pixel da imagem carrega informação sobre o coeficiente de atenuação linear $(\mu)$ do material de interesse ao longo de uma linha (da fonte ao pixel do detector). Neste sistema, após a interação dos fótons com o meio, idealmente, a imagem coletaria apenas os fótons primários, ou seja, somente aqueles transmitidos pelo material e que não sofreram espalhamento. Na prática, entretanto, um grande número de fótons espalhados também são detectados, e são considerados uma componente deletéria nas imagens. O método mais comum para evitar a perda de informação e a diminuição na qualidade da imagem devido a componente espalhada dos raios $\mathrm{X}$, é colocar uma grade anti-espalhamento em frente ao receptor de imagem (MOTZ e DANOS, 1978; ZHAN, ZIMMERMAN, et al., 2019). Uma abordagem completamente diferente das técnicas de imagens convencionais por projeção é utilizar a componente espalhada ao invés da componente primária, baseando-se no fato de que fótons espalhados carregam informação a respeito da estrutura espacial eletrônica dos materiais, e que estas informações podem ser utéis para diferenciar tecidos (SPELLER, 1999; JOHNS, LECLAIR e WISMAYER, 2002).

Johns e Yaffe (1983), reportaram a predominância do espalhamento elástico sob o inelástico sobre um receptor de imagem, por meio de um experimento utilizando uma amostra de $2 \mathrm{~cm}$ de água, irradiada por um feixe de raios $\mathrm{X}$ de $80 \mathrm{kV}$. Na faixa de energia de radiodiagnóstico $(20-150 \mathrm{keV})$, eles observaram que apesar dos trabalhos anteriores mostrarem em sua maioria a baixa probabilidade de interação do espalhamento elástico, comparado aos demais efeitos, e considerá-lo indistinguível em relação à radiação primária (razões pelas quais, até aquele momento, tem tido pouco destaque na literatura), o espalhamento elástico pode ser distinguído devido a natureza dos picos característicos de seu material (destacados nos estudos anteriores de Narten e Levy (1972) utilizando a água) e contribuir consideravelmente na intensidade espalhada que atinge o receptor de imagem. Conclusões similares foram obtidas por meio de cálculos analíticos apresentados por Morin e Berroir (1983), considerando uma amostra de água de 21,4 cm, irradiada por um feixe monoenergético na faixa de $20-80 \mathrm{keV}$, destacando a contribuição do espalhamento elástico de primeira ordem.

Harding et al. (1987), aplicou as propriedades do espalhamento em imagens de tomografia computadorizada (computed tomography, CT) utilizando um objeto simulador 
composto por diferentes materiais, irradiado por feixes colimados de raios X (120 kVp), detectando a componente espalhada à baixos ângulos $\left(1,3^{\circ}\right.$ à $\left.6,1^{\circ}\right)$, indicando a potencialidade da técnica em diferenciar tecidos biológicos e adquirir diferentes contrastes. No entanto, apontam a necessidade de um melhoramento na resolução de momento transferido $(\Delta \chi)$, o qual é determinado pelo conjunto de borramentos angular e espectral, significantemente prejudicado pelas componentes do sistema. Diversos trabalhos aperfeiçoaram a técnica desenvolvendo um desenho para a construção de um tomógrafo específico para detectar a componente espalhada (HARDING, NEWTON e KOSANETZKY, 1990; HARDING e MARTENS, 1993; HARDING, 2004), entretanto, pouco aplicável na área médica.

Seguindo a premissa da considerável contribuição dos fótons espalhados no detector e que sua distribuição difere de acordo com o material de interesse (KOSANETZKY, KNOERR, et al., 1987; POLETTI, GONÇALVES, et al., 2002), diversos autores apontaram a possibilidade de se utilizar a componente espalhada dos raios X para diferenciar tecidos e serem utilizados em aplicações médicas como uma nova ferramenta diagnóstica.

Westmore et al. (1996), apresentaram o método de imagem por espalhamento de raios $\mathrm{X}$, utilizando um intensificador de imagem utilizado em fluoroscopia, para amostras de tecido com espessuras de $\sim 3 \mathrm{~cm}$, irradiadas por um feixe de raios $X$ aplicado em radiodiagnóstico (70 $\mathrm{kVp}$ ), e propuseram um método para reconstruir as seções de choque de espalhamento dos materiais. Os resultados mostraram que o sistema pode ser interpretado como a medida da seção de choque utilizando um feixe monoenergético e que quando utilizado um espectro de energia de raios X este sistema é borrado em decorrência da superposição da seção de choque em cada energia. Posteriormente, outros trabalhos aplicaram o estudo para diferentes materiais biológicos de interesse, utilizando um feixe filtrado por gadolíneo a fim de diminuir a largura espectral, o qual resulta em menor influência na resolução espacial da imagem (BATCHELAR e CUNNINGHAM, 2002; BATCHELAR, CHUN, et al., 2002; DAVIDSON, BATCHELAR, et al., 2005), no entanto, diminuem significantemente (90\%) a intensidade do feixe incidente. Beath et al. (2009) realizaram um estudo do borramento espacial da imagem, utilizando filtros balanceados para gerar um feixe pseudomonoenergético, e apresentam uma relação aproximada que avalia os fatores que mais contribuem para distorções na imagem, dificultando a identificação de alguns materiais, concluindo que a utilização de um espectro de raios $\mathrm{X}$ altera significantemente os padrões de espalhamento devido ao aumento das incertezas no ângulo de espalhamento, causado pela largura do espectro de raios $\mathrm{X}$. 
Diversos estudos foram feitos para se analisar a viabilidade da técnica de imagens por espalhamento de raios X em contrastar objetos de composições similares. Leclair e Johns (1999) desenvolveram métodos semi analíticos para análise de imagens por espalhamento de raios $\mathrm{X}$ em aplicações médicas, formulando um modelo que consiste em um material de fundo com mesmas dimensões do alvo, ambos situados no interior de um fantoma de água, os resultados apresentaram máxima razão contraste ruído (contrast noise ratio, CNR) entre as substâncias branca e cinzenta cerebral sob um fantoma de $15 \mathrm{~cm}$ de água e excedem às imagens primárias, em todas as energias de $10-200 \mathrm{keV}$ nas angulações de $2^{\circ}-12^{\circ}$, para espessuras $\leq 4 \mathrm{~cm}$. Posteriormente, ainda utilizando o método semi analítico e a modelagem anterior, apresentaram uma faixa ótima de momento transferido $(\chi)$ de $0,5 \mathrm{~nm}^{-1}$ à $0,7 \mathrm{~nm}^{-1}$, a qual maximiza a $C N R$ entre materiais equivalentes ao tecido (PMMA e nylon) (LECLAIR e JOHNS, 2002). No entanto, utilizam para os cálculos uma modelagem bidimensional simplificada, com fontes pontuais e feixes paralelos, o que podem gerar resultados destoantes à prática.

Uma modelagem mais completa para predizer a informação da componente espalhada foi desenvolvida utilizando o método determinístico seguindo um modelo tridimensional (DUVAUCHELLE, FREUD, et al., 2000; FREUD, DUVAUCHELLE, et al., 2004; FREUD, DUVAUCHELLE, et al., 2006). Este método utiliza, basicamente, a técnica de traçado de raios, originados de uma fonte extensa interpretada como um conjunto de fontes pontuais, que emitem radiação isotrópicamente. No entanto, os resultados destes trabalhos foram apresentados somente em número de fótons, o qual representa a informação obtida em um determinado tipo de detector (detectores contadores), e utilizam raios paralelos e campos extensos sobre a amostra, os quais não são utilizados na modelagem de imagens por projeção utilizando a componente espalhada dos raios $\mathrm{X}$.

Outros estudos mostraram resultados promissores no que diz respeito às imagens por espalhamento de raios $\mathrm{X}$, apresentando maiores contrastes e $C N R$ comparadas às imagens primárias. Taibi et al. (2000), realizaram um estudo por simulação Monte Carlo para analisar o contraste entre tecidos tumoral e saúdavel em uma mama de dimensões reais, utilizando as componentes primária e espalhada dos raios $\mathrm{X}$, em feixes monoenergéticos de 20, 25 e $35 \mathrm{keV}$. Os resultados mostraram um contraste entre os materiais superior utilizando a componente espalhada à baixos ângulos $\left(2^{\circ}-10^{\circ}\right)$ quando comparado a componente primária. Análogamente, por simulação Monte Carlo, Cunha et al. (2011) elaborou um modelo composto por uma mistura de tecidos adiposo e glandular como material de fundo, com o objetivo de analisar o contraste de cinco objetos esféricos de composições distintas, mostrando a vantagem 
das imagens por espalhamento de raios $\mathrm{X}$ em contrastar objetos comparados às imagens utilizando a componente primária, para espectros clínicos aplicados em mamografia. Diversos outros estudos por simulação Monte Carlo, mostraram a eficácia na detectabilidade de pequenos materiais equivalentes ao tecido (ZHENG, VASSILJEV, et al., 2015) e tumores malignos sob mamas com alta densidade de tecido fibroglandular (MARTICKE, MONTEMONT, et al., 2017), dificilmente visualizados nas imagens convencionais.

Os trabalhos propostos pela literatura vem apontando grandes avanços na técnica de formação de imagens por espalhamento de raios $X$, e mostraram que os padrões de espalhamento de um determinado material são significantemente influenciados pelas componentes do sistema. No entanto, a maioria destes estudos foram feitos por meio da análise do borramento angular nos perfis de espalhamento ou seção de choque. Neste trabalho, a influência de cada componente do sistema foram analisadas diretamente nos perfis radiais extraídos das imagens por projeção, utilizando a componente espalhada, após o desenvolvimento, implementação e validação de um algorítmo para a realização dos cálculos analíticos do espalhamento de primeira ordem, seguindo um modelo tridimensional completo (fonte extensa, raios divergentes, colimadores e objetos tridimensionais) extendido para grandezas radiométrica e dosimétrica, e são avaliados pelo borramento espacial da imagem adquirida, auxiliando na construção do arranjo experimental. O objetivo geral deste trabalho se designa ao estudo experimental para avaliar a potencialidade das imagens utilizando a componente espalhada dos raios $\mathrm{X}$ em aplicações médicas, ou seja, analisar se a técnica estudada é útil em contrastar objetos de materiais e composições similares, sob a aplicação de espectros de energia e detectores clínicos.

Este trabalho está organizado da seguinte maneira:

O capítulo 2 apresenta os fundamentos teóricos necessários para o entendimento da formação de imagens por espalhamento de raios $\mathrm{X}$, desde a geração dos raios $\mathrm{X}$ no tubo, interação da radiação com a matéria, grandezas dosimétricas e sistema de detecção utilizado.

O capítulo 3 apresenta a metodologia aplicada neste trabalho, e descreve os cálculos analíticos e a implementação de um algoritmo para geração de imagens por espalhamento de raios $\mathrm{X}$, de modo à auxiliar no estudo dos parâmetros do sistema para a formação da imagem e construção do arranjo experimental; e descreve os métodos experimentais para obtenção da imagem de amostras homogêneas e heterogêneas equivalentes ao tecido.

O capítulo 4 apresenta os resultados das imagens e perfis radiais obtidos por meio dos cálculos analíticos seguidos pela análise e discussão do borramento espacial gerado nos perfis 
radiais da imagem e as incertezas $(\Delta r)$ no raio $r$ do detector em decorrência de cada parâmetro do sistema; e os resultados das imagens e perfis radiais pelos métodos experimentais utilizando espectros de energia e detectores clínicos para a análise e discussão do contraste e $C N R$ dos materiais estudados utilizando a componente espalhada dos raios X comparados à componente primária.

O capítulo 5 refere-se às conclusões obtidas e perspectivas futuras deste trabalho. 


\section{Fundamentos teóricos}

Neste capítulo serão descritos os fundamentos teóricos e os conceitos básicos necessários para a realização deste trabalho. As seções apresentam os fundamentos teóricos desde a produção de raios $\mathrm{X}$; os processos de interações dos raios X com o material, na faixa de energia utilizada em radiodiagnóstico $(20-150 \mathrm{keV})$; coeficientes de atenuação total; grandezas dosimétricas e o sistema de detecção em radiografia computadorizada.

\subsection{Produção de raios $X$}

Em um tubo de raios X (Fig. 2.1), elétrons são liberados por um filamento (cátodo) em decorrência do efeito termiônico, estes elétrons são acelerados quando aplicada uma diferença de potencial (tensão) no tubo, caminhando em direção ao ânodo (alvo). No impacto com o alvo, a energia cinética dos elétrons é convertida em outras formas de energia, como por exemplo

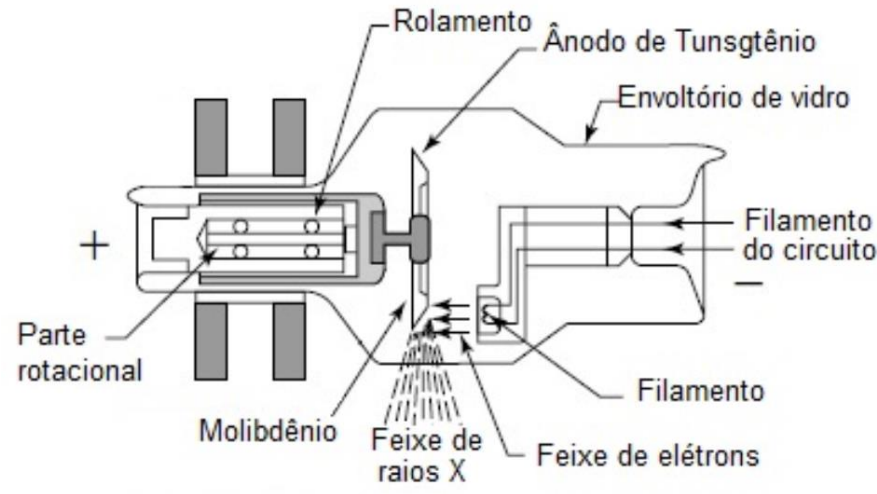

Fig. 2.1. Sistema simplificado de um tubo de raios $X$ (HENDEE, RITENOUR e HOFFMANN, 2002).

raios $\mathrm{X}$ e calor (forma de energia predominante) (HENDEE, RITENOUR e HOFFMANN, 2002). O espectro de raios $X$ produzido possui duas componentes distintas: raios $X$ Bremsstrahlung e raios $X$ característicos (Fig. 2.2) (Podgorsak, 2010). Filtros adicionais possuem um papel importante na forma dos espectros de raios $\mathrm{X}$, e podem ser utilizados convenientemente para reduzir o número de fótons de baixa energia, absorvendo fótons de energia que não são úteis para a formação da imagem (BUSHBERG, SEIBERT, et al., 2001). 


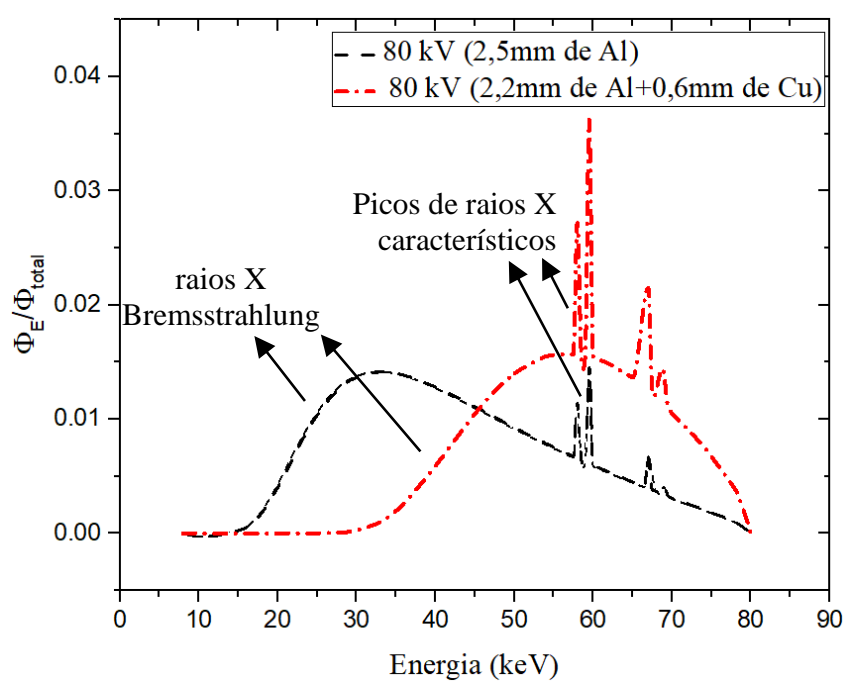

Fig. 2.2. Exemplo de espectros de raios $X$ com diferentes filtrações, proveniente de um alvo de $\mathrm{W}$ e tensão aplicada de $80 \mathrm{kV}$ (adquiridos pelo software SpekCalc (POLUDNIOWSKI, LANDRY, et al., 2009b)).

\subsubsection{Raios X Bremsstrahlung}

A parte contínua do espectro é denominado raios X Bremsstrahlung e são gerados quando os elétrons acelerados em direção ao alvo se encontram próximos ao núcleo atômico do

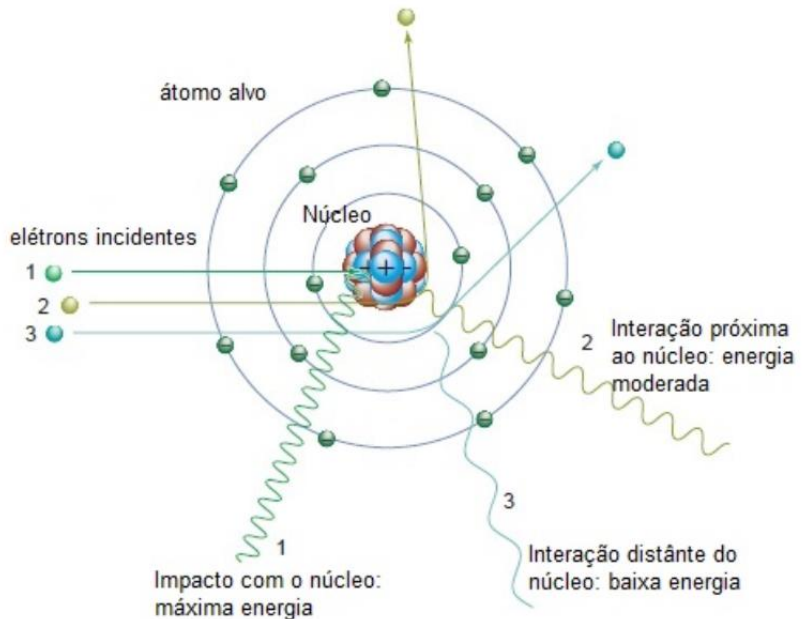

Fig. 2.3. Ilustração dos processos de interação dos elétrons com o núcleo atômico do alvo. A energia dos raios X produzido depende da distância de interação entre o elétron e o núcleo do alvo (OKUNO, et al.,1986).

material do ânodo, sendo desacelerados por forças Coulombianas (Fig. 2.3), mudando assim suas direções, e em consequência, ocasionando em uma perda de energia cinética, a qual é emitida na forma de raios X. Este tipo de radiação é responsável pela maior parte da emissão de raios $\mathrm{X}$, e sua energia depende da distância entre os elétrons incidentes e o núcleo alvo, 
quanto mais próximos ao núcleo maiores energias são produzidas, as quais compõem o espectro de raios X (OKUNO et al., 1986).

\subsubsection{Raios X característicos}

Os picos discretos do espectro são denominados raios $\mathrm{X}$ característicos (Fig. 2.2). Os elétrons ligados ao átomo do material alvo possuem uma energia de ligação que é característica do elemento e são distribuídos em camadas eletrônicas ou níveis de energia. Um elétron do cátodo pode colidir com um elétron atômico do material alvo (Fig. 2.4), com energia cinética suficiente para arrancá-lo, resultando em uma vacância que pode ser preenchida por um elétron de uma camada mais externa, este processo de transição de uma camada à outra, resulta na emissão de raios $\mathrm{X}$ característicos do material, resultando em uma energia dada pela diferença

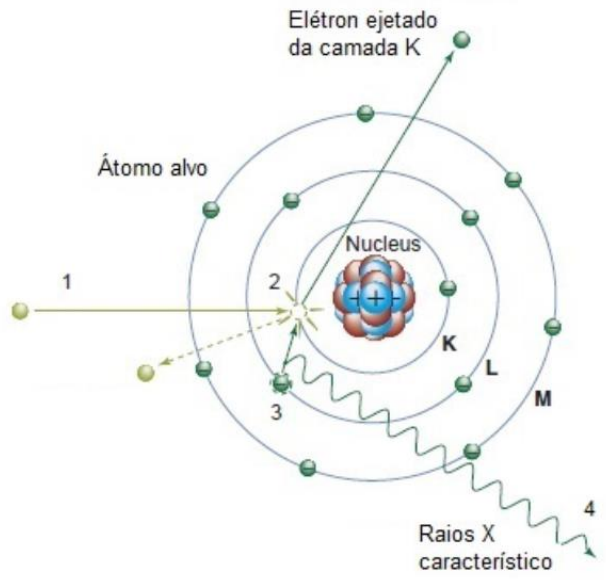

Fig. 2.4. Aproximação esquemática do modelo de Bohr para a produção de radiação característica em um átomo do alvo. O elétron (1) colide com um elétron ligado da camada $\mathrm{K}$, ejetando-o (2). Um elétron da camada $L$ preenche a vacância deixada na camada $K$ (3), e a diferença de energia dessas camadas resulta na emissão de radiação característica (4). Sequência númerica para ocorrer a emissão de radiação característica 1, 2, 3 e 4 (OKUNO, et al., 1986).

entre as duas camadas envolvidas no processo. Neste processo, após o elétron ser arrancado do átomo, também pode ocorrer a liberação de um elétron Auger, nomenclatura dada ao elétron que recebeu a energia liberada nesta transição eletrônica (OKUNO, et al.,1986). 


\subsection{Interação dos raios $X$ com a matéria}

$\mathrm{Na}$ faixa de energia utilizada em radiodiagnóstico os efeitos predominantes da interação dos raios X incidentes com o material são o efeito fotoelétrico, espalhamento Rayleigh e espalhamento Compton, os quais são apresentados nesta seção.

\subsubsection{Efeito fotoelétrico}

O efeito fotoelétrico (Fig 2.5) ocorre quando um fóton, de energia $h v$ maior ou igual a energia de ligação do elétron $\left(E_{b}\right)$, interage com um elétron fortemente ligado ao átomo (normalmente da camada K). Nessa interação, o fóton é completamente absorvido e o elétron é ejetado com energia cinética, $E_{\text {cinét. }}=h v-E_{b}$. Após a interação, a vacância deixada pelo
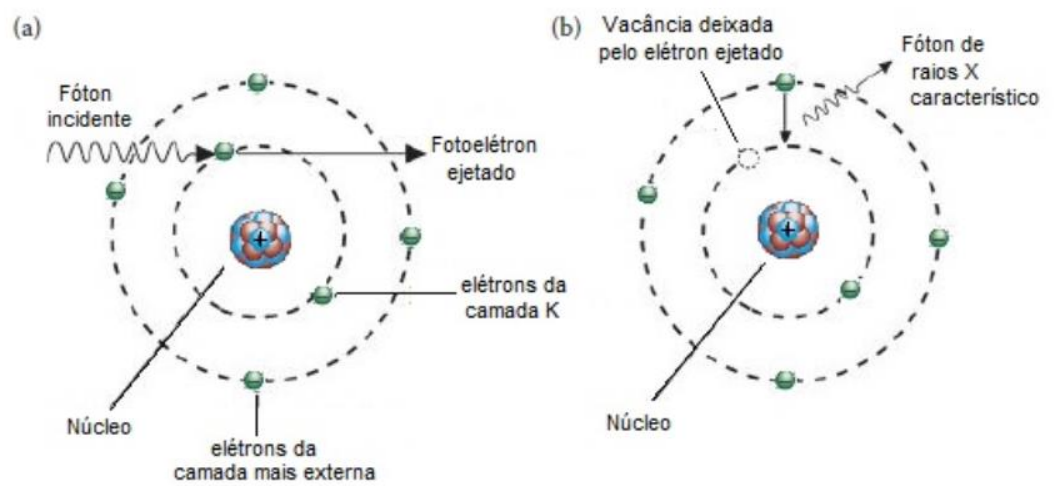

Fig. 2.5. Representação esquemática do efeito fotoelétrico (OKUNO, et al., 1986).

elétron será completado por outro elétron vindo de uma camada superior, a energia de transição de uma camada à outra será emitida na forma de raios $\mathrm{X}$ característicos ou na emissão de um elétron Auger (PODGORSAK, 2010). Para fótons com energia menor que $100 \mathrm{keV}$, a seção de choque fotoelétrica, $\tau$, é dada por

$$
\tau \propto \frac{Z^{4}}{h v^{3}}
$$

onde $Z$ é o número atômico do material (ATTIX, 1986).

\subsubsection{Espalhamento Rayleigh}

O espalhamento Thomson, ou espalhamento clássico, pode ser entendido através do modelo ondulatório da luz. Uma onda eletromagnética, com comprimento de onda $\lambda$ e energia $h v$, incide sobre um elétron livre ou fracamente ligado (isto é, $h v>E_{b}$ ) em repouso no espaço, o mesmo começa a oscilar com uma certa aceleração devido a força que o campo elétrico exerce sobre ele, fazendo com que irradie energia na forma de onda eletromagnética em uma direção 
diferente da incidente (JOHNS e CUNNINGHAM, 1983). Neste processo, não há transferência de energia para o elétron e a frequência da onda espalhada é a mesma da onda incidente. A probabilidade da onda eletromagnética ser espalhada sob um ângulo de espalhamento $\theta$ por unidade de ângulo sólido, para um elétron livre, é dada por

$$
\left(\frac{d \sigma}{d \Omega}\right)_{T h}=\frac{r_{0}^{2}}{2}\left(1+\cos ^{2}(\theta)\right)
$$

onde $r_{0}=2.81794 \times 10^{-15} \mathrm{~m}$ é o raio clássico do elétron livre.

A seção de choque total de espalhamento Thomson pode ser obtida pela integral sob o ângulo sólido $(\Omega)$, sabendo que $d \Omega=2 \pi \operatorname{sen} \theta d \theta$,

$$
\sigma_{T h}=\int\left(\frac{d \sigma}{d \Omega}\right)_{T h} d \Omega=\frac{r_{0}^{2}}{2} \int_{0}^{\pi}\left(1+\cos ^{2} \theta\right) 2 \pi \operatorname{sen} \theta d \theta=\frac{8 \pi}{3} r_{0}^{2} .
$$

No espalhamento Rayleigh (Fig. 2.6), os elétrons encontram-se ligados ao átomo e são vistos como uma nuvem eletrônica com densidade de carga, $\varrho(\vec{r})$. Desta forma, a seção de choque

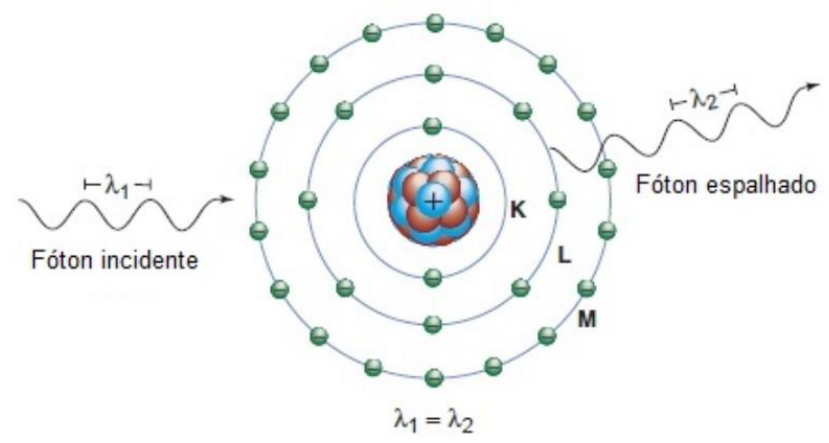

Fig. 2.6. Representação esquemática do espalhamento Rayleigh, o qual há uma troca de momento, porém a energia se conserva na interação do fóton com um elétron ligado (OKUNO, et al., 1986).

diferencial de espalhamento Rayleigh por ângulo sólido pode ser determinada contabilizando o espalhamento por cada diferencial de carga, $-e \varrho(\vec{r}) d^{3} \vec{r}$, na posição $\vec{r}$ da distribuição eletrônica, ponderando essas contribuições por um fator de fase $\left(e^{i \vec{q} \cdot \vec{r}}\right)$, de modo que (ALSNIELSEN e MCMORROW, 2011)

$$
\left(\frac{d \sigma}{d \Omega}\right)_{\text {Rayleigh }}=\left(\frac{d \sigma}{d \Omega}\right)_{T h}\left[\int \varrho(\vec{r}) e^{i \vec{q} \cdot \vec{r}} d^{3} \vec{r}\right]^{2}=\left(\frac{d \sigma}{d \Omega}\right)_{T h} F^{2}(\chi, Z),
$$

onde $F(\chi, Z)$ é o fator de forma atômico, $\vec{q} \cdot \vec{r}$ é a diferença de fase entre a onda incidente e espalhada, e $\chi$ é o momento transferido dado por

$$
\chi=\frac{E}{h c} \operatorname{sen}\left(\frac{\theta}{2}\right)
$$


e a seção de choque Rayleigh atômica pode ser obtida pela integral em todo o ângulo de espalhamento $\theta$ (PODGORSAK, 2010)

$$
\sigma_{\text {Rayleigh }}=\pi r_{0}^{2} \int_{0}^{\pi}\left(1+\cos ^{2} \theta\right) F^{2}(x, Z) \operatorname{sen} \theta d \theta .
$$

Para um dado material o fator de forma possui níveis de complexidade, dependendo do modelo de interferência entre os elétrons. Neste caso, após a interação do meio com a radiação eletromagnética incidente, podem ocorrer interferências $(i)$ entre elétrons pertencentes ao mesmo átomo, e então, o fator de forma $F_{M A I}(\chi, Z)$ é definido pelo modelo atômico independente; $(i i)$ e interferências entre elétrons de átomos diferentes pertencentes à diferentes moléculas, e neste caso, o fator de forma molecular é dado por $F_{m o l}(\chi, Z)$ (JOHNS e YAFFE, 1983; POLETTI, GONÇALVES e MAZZARO, 2001) A primeira, a qual leva em conta o modelo atômico independente, em uma mistura pode ser adquirida pela soma do fator de forma de cada elemento $i$, e sua respectiva abundância atômica $w_{i}$, de modo que $F_{M A I}{ }^{2}(\chi, Z)=$ $\sum_{i} n_{i} f(\chi, Z)_{i}{ }^{2}$ (Fig. 2.7, curva I), o qual $f(\chi, Z)_{i}$ é o fator de forma elementar (HUBBELL e ØVERBØ, 1979; HUBBELL, VEIGELE, et al., 1975). O segundo, o qual leva em conta interações entre elétrons pertencentes à diferentes moléculas, considera uma função de interferência $I(\chi, Z)$ multiplicativa em $F_{M A I}(\chi, Z)$, resultando em $F_{m o l}(\chi, Z)$, de modo a

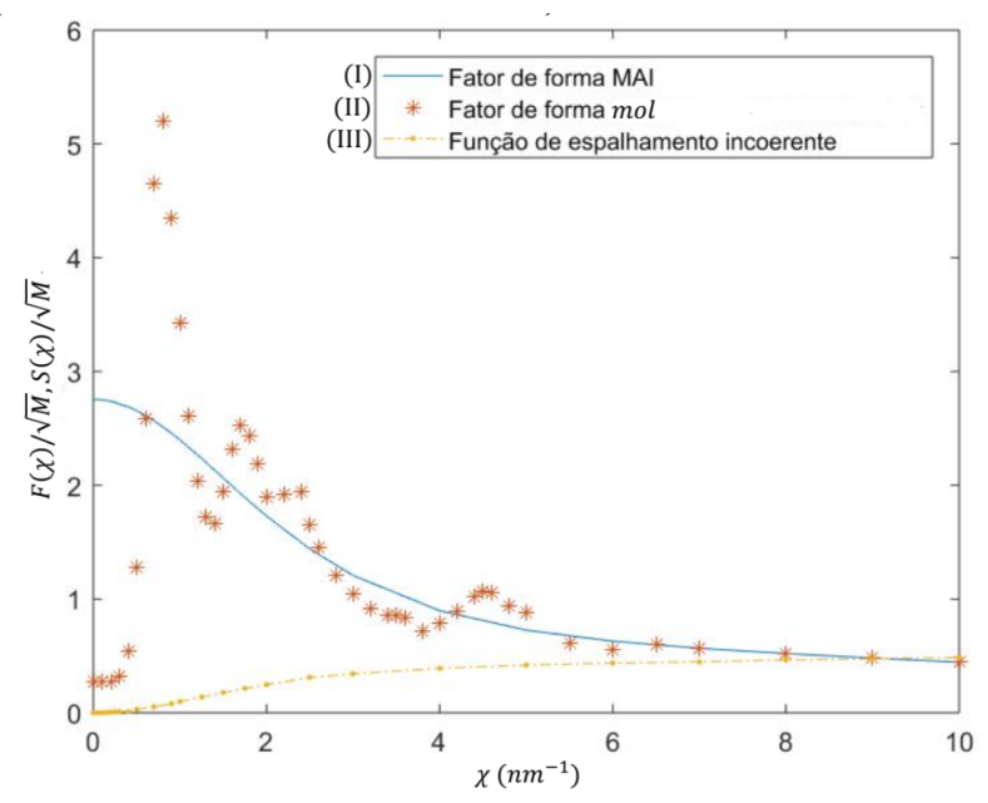

Fig. 2.7. Curvas do fator de forma do espalhamento elástico e a função de espalhamento incoerente em função do momento transferido $\chi$ para o PMMA. As curvas são representadas por (I) $F_{M A I}(\chi)$ (HUBBELL, VEIGELE, et al., 1975); (II) $F_{m o l}(\chi)$ a função de interferência multiplicativa foi retirada dos dados de Tartari et al. (2002) e (III) $S(\chi)$ (HUBBELL, VEIGELE, et al., 1975). Ambas as curvas foram normalizadas pela raiz da massa molecular $\sqrt{M}$ do composto. 
considerar as estruturas moleculares e sua organização espacial no material (Fig. 2.7, curva II) (TARTARI, TAIBI, et al., 2002).

\subsubsection{Espalhamento Compton}

Um outro efeito pode ocorrer por meio da interação da radiação eletromagnética com um elétron livre ou fracamente ligado em um átomo do meio $\left(h v \gg E_{b}\right)$. Em 1923, Arthur Compton por meio de seus experimentos observou que apesar dos raios $\mathrm{X}$ incidirem com comprimento de onda $\lambda$ sobre um alvo, os raios $\mathrm{X}$ espalhados resultaram em máximos de intensidade em dois comprimentos de onda; um deles com mesmo comprimento de onda da radiação eletromagnética incidente $\lambda$ e outro $\operatorname{com} \lambda^{\prime}$ maior. A presença deste $\lambda^{\prime}$ observado não pode ser compreendida se os raios $\mathrm{X}$ incidentes forem encarados somente como uma onda eletromagnética clássica, e então dispôs da consideração da radiação quantizada, possuindo um conjunto de fótons cada qual com energia incidente $E=h v$ que colidem com os elétrons do meio (EISBERG e RESNICK, 1994). Após a interação, em consequência da conservação de momento e energia, o fóton incidente com energia $E$ é espalhado sob um ângulo $\theta$, e o elétron é ejetado em um ângulo $\phi^{\prime}$, com energia cinética $E_{\text {cinét. }}=E-E^{\prime}$, e a energia do fóton espalhado em função da energia incidente é dada por

$$
E^{\prime}=\frac{E}{1+\frac{E}{m_{0} c^{2}}(1-\cos (\theta))} .
$$

onde $m_{0} c^{2}=0,511 \mathrm{MeV}$ a energia de repouso do elétron.

Mais tarde, em 1928 Oscar Klein e Yoshio Nishina derivaram uma expressão para a seção de choque diferencial de espalhamento por ângulo sólido para um elétron livre, adicionando uma expressão à seção de choque diferencial de espalhamento Thomson, a função Klein-Nishina, dada por

$$
F_{K N}=\frac{1}{[1+\varepsilon(1-\cos (\theta))]^{2}}\left[1+\frac{\varepsilon^{2}(1-\cos (\theta))^{2}}{[1+\varepsilon(1-\cos (\theta))]\left[1+\cos ^{2}(\theta)\right]}\right],
$$

a qual depende da energia do fóton incidente $E$ e do ângulo de espalhamento $\theta$, sendo $\varepsilon=$ $E / m_{0} c^{2}$. Portanto, a seção de choque diferencial de espalhamento Compton por ângulo sólido relacionada ao efeito Compton é dada pela junção de (2.8) e (2.9),

$$
\left(\frac{d \sigma}{d \Omega}\right)_{\text {Compton }}^{K N}=\left(\frac{d \sigma}{d \Omega}\right)_{T h} F_{K N}
$$


Para energias baixas, onde $E \ll m_{0} c^{2}$, ou ângulos de espalhamento pequenos em $\theta \rightarrow 0$, a seção de choque diferencial de espalhamento por ângulo sólido em (2.9) se aproxima de (2.2).

A seção de choque atômica do espalhamento inelástico determinada por Klein-Nishina $\left(\sigma_{\text {Compton }}\right)$ é linearmente proporcional à seção de choque eletrônica $\sigma_{\text {Compton }}^{K N}$ (determinada pela integral da equação (2.9) em todo o ângulo sólido), e resulta em

$$
\sigma_{\text {Compton }}=Z \sigma_{\text {Compton }}^{K N}
$$

onde $Z$ é o número atômico do material. No entanto, quando comparada a medida da seção de

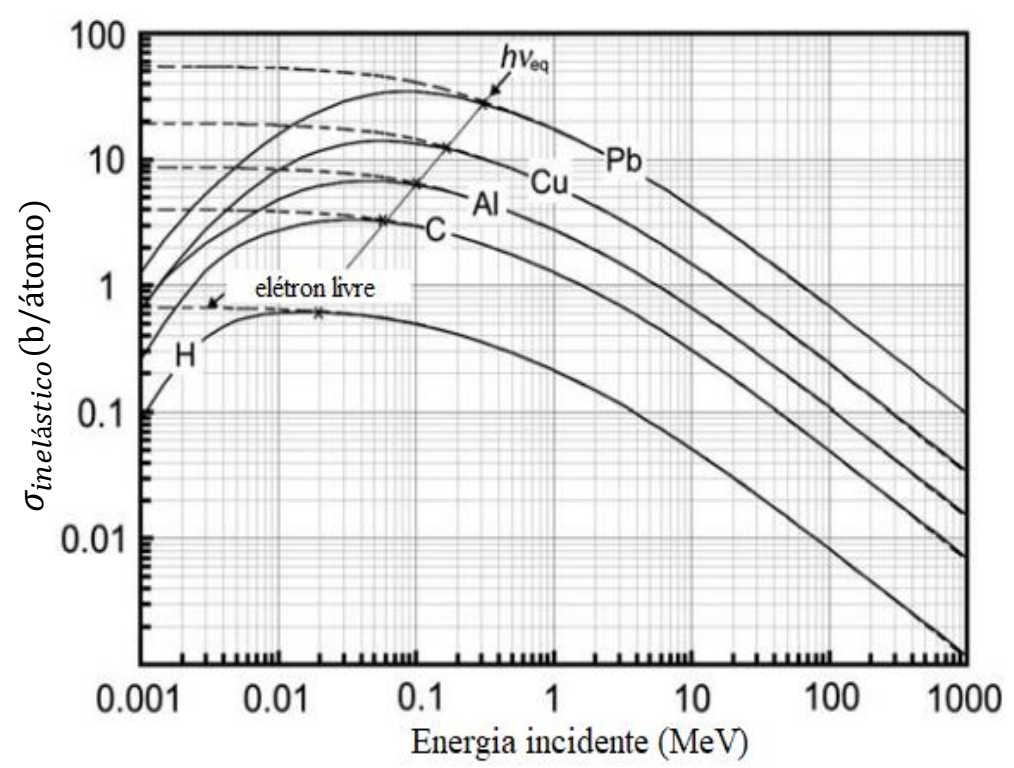

Fig. 2.8. Comparação da seção de choque atômica medida com a calculada por Klein-Nishina em função da energia do fóton incidente em diferentes materiais. A energia $h v_{e q}$ corresponde à energia a qual a seção de choque atômica de Klein-Nishina e a medida são equivalentes (PODGORSAK, 2010).

choque atômica com a calculada por Klein-Nishina, a equação (2.10) apresenta uma discrepância quando o material é irradiado por fótons de baixas energias, e a medida da seção de choque atômica é significantemente menor (Fig. 2.8) (PODGORSAK, 2010). Evidentemente, para fótons incidentes de energias mais baixas a associação de elétron livre se torna insatisfeita e a energia de ligação do elétron afeta a seção de choque atômica. Para corrigir este efeito de ligação do elétron em energias mais baixas, o método mais notável foi desenvolvido por John Hubbell (PODGORSAK, 2010), adicionando uma função que leva em conta os elétrons orbitais do átomo, denominada função de espalhamento incoerente $S(\chi, Z)$ (Fig. 2.7, curva III) (HUBBELL, VEIGELE, et al., 1975)Neste caso, a seção de choque diferencial atômica do espalhamento inelástico levando em conta a ligação do elétron é dada por 


$$
\left(\frac{d \sigma}{d \Omega}\right)_{\text {Compton }}=\left(\frac{d \sigma}{d \Omega}\right)_{\text {Compton }}^{K N} S(\chi, Z) .
$$

Portanto, a seção de choque Compton é dada pela integral em ângulo sólido de (2.11)

$$
\sigma_{\text {Compton }}=\pi r_{0}^{2} \int_{0}^{\pi}\left(1+\cos ^{2} \theta\right) \times F_{K N} \times S(\chi, Z) \operatorname{sen} \theta d \theta
$$

\subsection{Coeficientes de atenuação total}

A seção de choque total representa a probabilidade de interação, dada pela contribuição individual das seções de choque de cada processo de interação dos fótons com a matéria. Na faixa de energia utilizada em radiodiagnóstico, como os efeitos predominantes são o efeito fotoelétrico, espalhamento Rayleigh e Compton, partindo de (2.1), (2.6) e (2.12) a seção de choque total pode ser escrita por

$$
\sigma=\tau+\sigma_{\text {Rayleigh }}+\sigma_{\text {Compton }}
$$

O coeficiente de atenuação linear é a probabilidade de interação por unidade de caminho e se relaciona com a seção de choque (2.13) através do número de átomos por volume $n_{v}$

$$
\mu=n_{v} \sigma=N_{a} \frac{\rho}{A}
$$

onde $N_{a}=6,022 \times 10^{-23}$ é o número de Avogrado, $\rho$ é a densidade e $A$ é a massa atômica.

O coeficiente de atenuação linear muda de acordo com estado físico da matéria, pois depende do número de átomos presentes em uma camada de material. É conveniente, então, dividir essa grandeza pela densidade para eliminar essa dependência, definindo assim o coeficiente de atenuação mássico, $\mu / \rho$.

Dada a composição de um material, o coeficiente de atenuação mássico do mesmo, $(\mu / \rho)_{\text {comp }}$, pode ser determinado através da regra das misturas

$$
\left(\frac{\mu}{\rho}\right)_{c o m p}=\sum_{i} w_{i}\left(\frac{\mu}{\rho}\right)_{i}
$$

onde $(\mu / \rho)_{i}$ é o coeficiente de atenuação linear mássico e $w_{i}$ a fração peso do i-ésimo elemento presente no material, dado por $w_{i}=a_{i} A_{i} / \sum_{i} a_{i} A_{i}$, sendo $a_{i}$ e $A_{i}$ a abundância e o peso atômico do i-ésimo elemento (ATTIX, 1986).

\subsection{Grandezas dosimétricas}

Para se descrever a interação da radiação com a matéria, torna-se necessário definir grandezas dosimétricas que podem ser obtidas em um local de interesse. Estas grandezas não 
estocásticas são as medidas dos processos pelos quais a energia de uma partícula é convertida ou depositada na matéria. Neste trabalho, a grandeza dosimétrica utilizada foi o kerma (Kinetic Energy Releasy in Medium), o qual descreve o primeiro passo em dissipação de energia pela radiação ionizante, e é definida em termos da energia transferida $\left(E_{t r}\right)$ de partículas não carregadas para partículas carregadas por unidade de massa em um ponto de interesse, incluindo a energia de perdas radioativas e excluindo a energia transferida de uma partícula para outra (ATTIX, 1986). De modo geral o kerma $K$ é definido por

$$
K=\frac{d E_{t r}}{d m}
$$

onde $d E_{t r}$ é o valor esperado da energia transferida em um volume infinitesimal de massa $d m$. Se um ponto é irradiado por um feixe polienergético, a equação (2.16) é dada por

$$
K=\int_{E_{\min }}^{E_{\max }} E \frac{d \phi}{d E}\left(\frac{\mu_{t r}}{\rho}\right)_{E, Z} d E
$$

onde $\left(\mu_{t r} / \rho\right)_{E, Z}$ é o coeficiente de transferência de energia e $d \phi / d E$ é a distribuição diferencial da fluência de fótons de energia $E$ em um ponto (ATTIX, 1986).

\subsection{Formação da imagem em CR}

A formação de uma imagem digital de raios X pode ser conceitualmente dividida em três estágios separados. O primeiro estágio é a interação do raio X com um meio de detecção adequado para gerar uma resposta mensurável. O segundo estágio é o armazenamento dessa resposta com um dispositivo registrador. O terceiro estágio é a medida dessa resposta armazenada. A maioria das instalações de sistemas de radiografia digital se baseia em dois tipos genéricos de detectores: placas de imagem baseadas em armazenamento de fósforo (radiografia computadorizada ou computer radiography, $C R$ ) e detectores de tela plana (radiografia direta, DR). Existem dois tipos de detectores de tela plana, o tipo de conversão direta, que emprega selênio como material conversor de raios X, e o tipo indireto, que usa uma tela cintiladora (NEITZEL, 2005).

A radiografia computadorizada baseia-se no uso de fósforos fotoestimuláveis. Esses fósforos na forma de pó são depositados em um substrato para formar uma placa de imagem (Fig. 2.9). Os mecanismos de absorção de raios $X$ são idênticos aos das telas convencionais de fósforo usadas com filme. Entretanto, o sinal óptico útil em $C R$ não provem da luz emitida como resposta imediata à radiação incidente, mas da emissão subsequente, quando a imagem latente, que consiste de cargas armadilhadas, é opticamente estimulada e liberada de armadilhas 
metaestáveis. Isso inicia um processo chamado luminescência fotoestimulada (PSL), resultando na emissão de luz de comprimento de onda pequeno (azul) em quantidade proporcional a irradiação de raios $\mathrm{X}$ original. Em $C R$, a placa de imagem inserida num cassete é exposta a raios X e lida através de varredura com laser para liberar PSL. A luz azul de PSL é coletada com uma

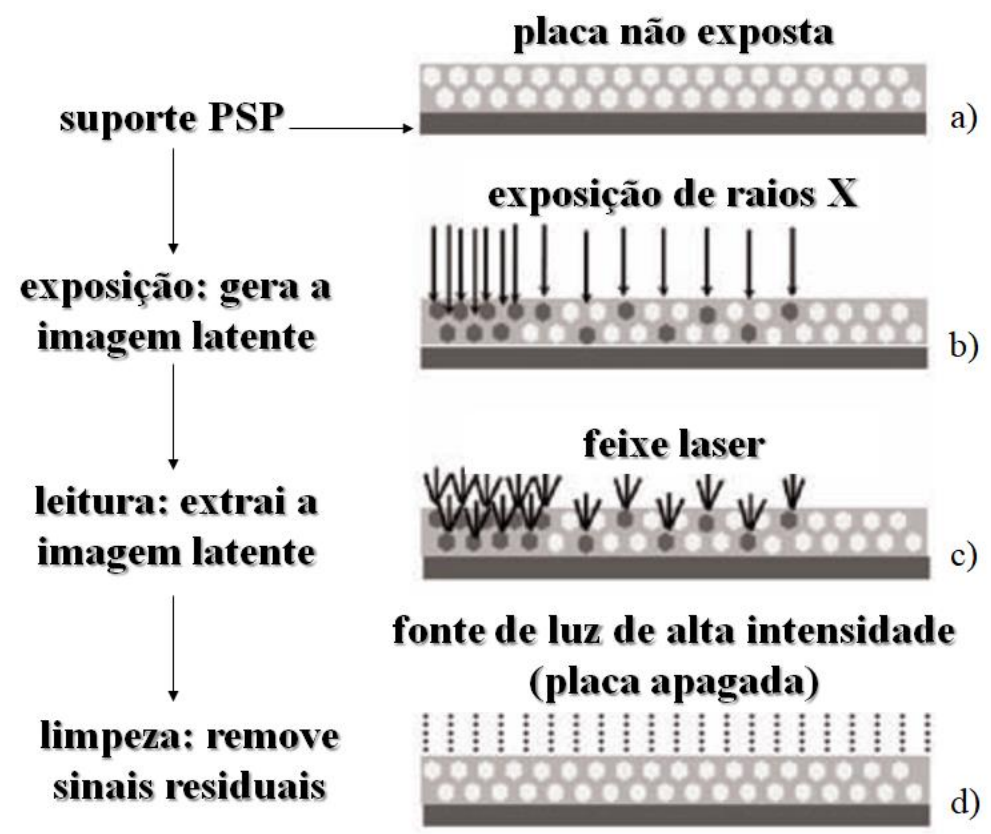

Fig. 2.9. Ciclo de um sistema de radiografia computadorizada. a) Utilizando uma placa de fósforo fotoestimulável (Photoestimulable phosphor, PSP). b) A exposição por raios X gera a imagem latente, onde os elétrons são armadilhados em um estado metaestável. c) A imagem é lida através da varredura de um feixe laser para liberar PSL, o qual é coletada por um guia de luz e detectada por um tubo fotomultiplicador, posteriormente, d) residuos de elétrons armadilhados são removidos com uma fonte de luz de alta intensidade, e a placa pode ser reutilizada.

guia de luz e detectada por um tubo fotomultiplicador (PMT) (ROWLANDS, 2002). O sinal do PMT é digitalizado para formar uma imagem (FUJITA, UEDA, et al., 1989).

Sistemas CR baseados em placas de imagem de armazenamento de fósforo são similares a sistemas tela filme no manuseio de cassetes, mas oferecem todas as vantagens de processamento de imagens e manipulação digital de dados (NEITZEL, 2005). 


\section{Metodologia}

Neste capítulo serão descritos os métodos aplicados neste trabalho. As seções 3.1 e 3.2 descrevem a metodologia utilizada para os cálculos analíticos e a realização do experimento, necessária para o estudo dos perfis radiais formados pela radiação espalhada no plano do detector devido à interação dos raios $\mathrm{X}$ com materiais equivalentes ao tecido.

\subsection{Cálculos analíticos para a obtenção da imagem devido a componente espalhada dos raios $\mathrm{X}$}

$\mathrm{O}$ estudo e desenvolvimento de imagens geradas pela interação dos raios X com a matéria demandam uma extensa série de testes e medidas experimentais, sua aplicação e otimização geralmente designa uma tarefa complexa e exige um vasto intervalo de tempo. Além disso, é necessário um conhecimento prévio dos principais parâmetros físicos e geométricos que influenciam a imagem. Portanto, é preciso desenvolver ferramentas virtuais para auxiliar a construção experimental, facilitando a montagem e estudo, de maneira a considerar todos estes parâmetros. Deste modo, foi implementado um algoritmo em MATLAB® para a realização dos cálculos analíticos que preveem a imagem, baseados no método determinístico seguindo um modelo tridimensional. Este método utiliza, basicamente, a técnica de traçado de raios, originados de uma fonte extensa que emite radiação isotrópicamente (DUVAUCHELLE, FREUD, et al., 2000; FREUD, DUVAUCHELLE, et al., 2004; FREUD, DUVAUCHELLE, et al., 2006; LI, KIM, et al., 2007; LI, ZHAO, et al., 2008; INANC, 2002; INANC, 2007). Os raios são delimitados por um colimador localizado à distância $D_{0}$ da fonte e atingem o plano da superfície de uma amostra de espessura $T$ localizado à distância $D_{1}$ do colimador (Fig. 3.1). Após ocorrer a interação com um voxel da amostra, os raios atingem um pixel do detector em um determinado ângulo $\theta$ ' com a normal $\hat{n}$ do plano. Individualmente, ao analisar um raio que espalha a um ângulo $\theta$ em relação a sua direção de incidência, um espectro de energia $\bar{E}$ deve ser considerado para o cálculo do momento transferido $\chi$, resultando em uma faixa de $\chi$ em cada pixel que compõe o detector plano. 
As subseções seguintes descrevem com mais detalhes cada componente do processo de formação da imagem por espalhamento de raios X implementado no algoritmo, seguido de seu fluxograma.

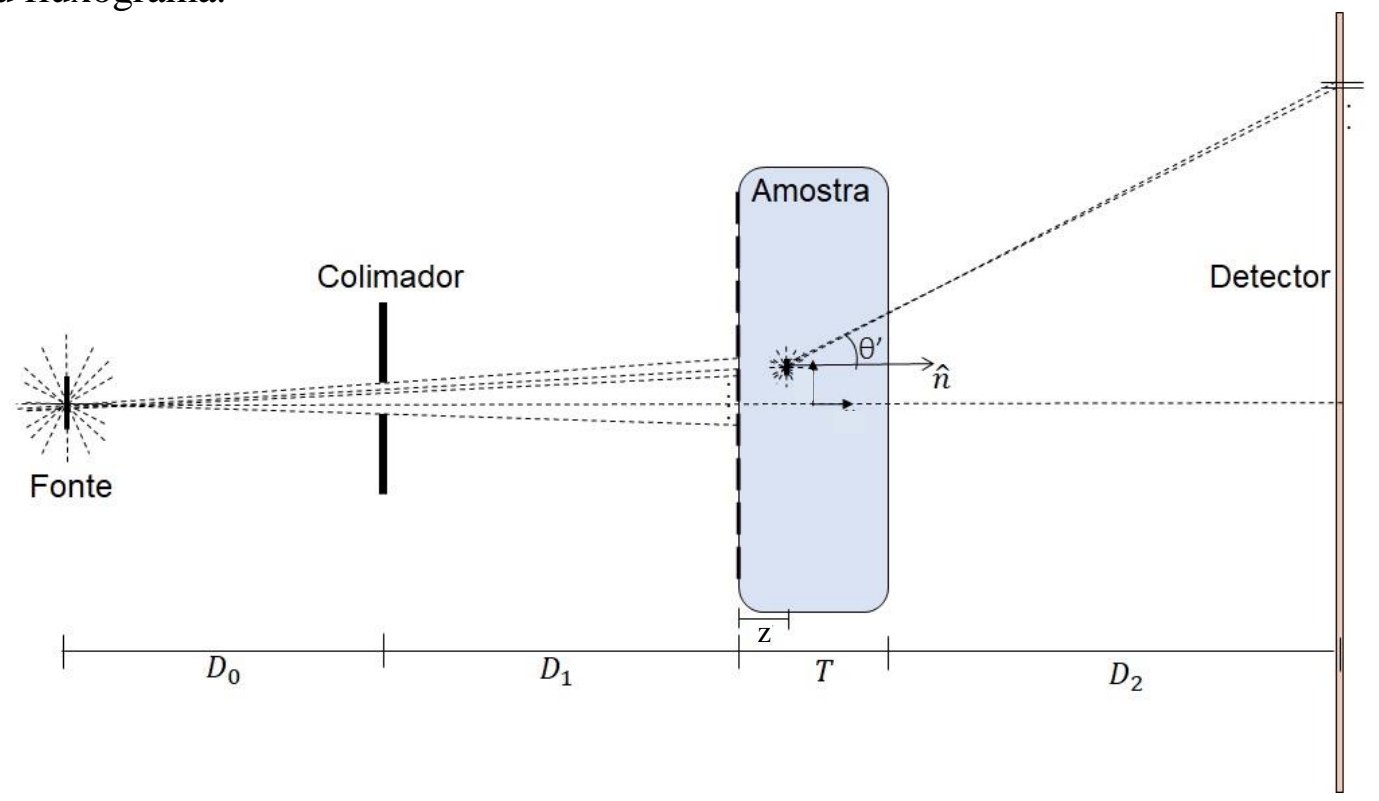

Fig. 3.1. Representação simplificada do modelo adotado no algoritmo. Uma infinidade de raios é gerada por uma fonte extensa de tamanho $Y$ à uma distância $D_{0}$ de um colimador de abertura $\phi$. Os raios delimitados pelo colimador interagem com uma amostra composta por material equivalente ao tecido de espessura $T$. Ao espalharem a um ângulo $\theta$ em relação à radiação incidente, atingem um pixel de um detector plano localizado à $D_{2}+T / 2$ do centro da amostra (origem do sistema de coordenadas).

\subsubsection{Fonte extensa e divergência dos raios}

Uma fonte de raios $\mathrm{X}$ pode ser classificada como uma fonte pontual quando suas dimensões físicas forem, aproximadamente, muito menores do que a distância o qual a intensidade de radiação emitida é medida. No entanto, na prática as dimensões da fonte são 
caracterizadas pela área da distribuição de elétrons no alvo do tubo de raios $\mathrm{X}$, desse modo, a fonte é identificada como uma fonte extensa (BUSHBERG, SEIBERT, et al., 2001).

Uma fonte linear de tamanho $\mathrm{Y}$ foi dividida em n elementos no eixo y do sistema de

a)

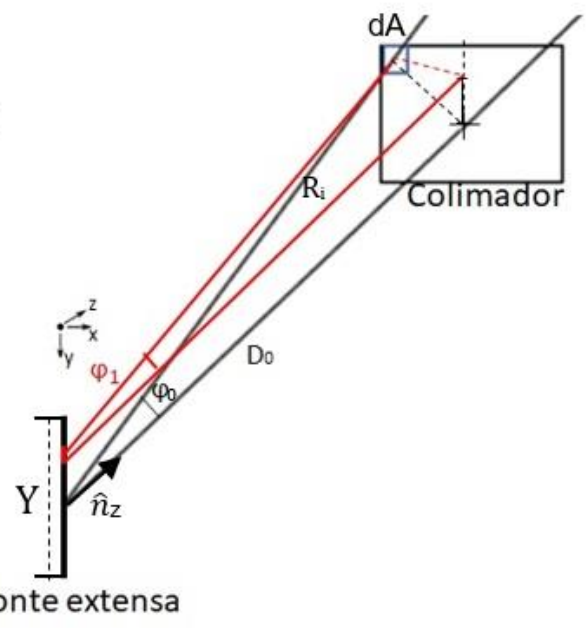

b)

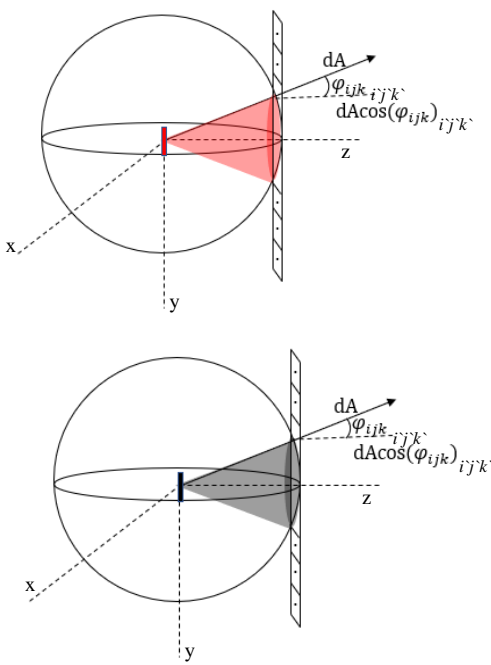

Fig. 3.2. Representação da fonte extensa como um conjunto de fontes pontuais. Em a) a fonte de tamanho Y é dividida em $\mathrm{n}$ elementos, o qual em b) é representado por $\mathrm{n}$ fontes pontuais onde um número $\mathrm{n}_{\mathrm{i}}$ de raios são traçados ao atingir os elementos de área dA do colimador, levando em conta a divergência dos raios.

coordenadas, cada elemento individualmente se comporta como uma fonte pontual que emite radiação isotrópicamente (Fig. 3.2a). Os raios provenientes de uma determinada fonte pontual, faz um ângulo $\left(\varphi_{i j k}\right)_{i^{\prime} j^{\prime} k^{\prime}}$ em relação a $\hat{n}_{z}$, caracterizando a divergência dos raios, posteriormente, atinge um elemento de área $\mathrm{dA}$ no colimador. A fluência $\Phi_{0}\left(D_{0},\left(\varphi_{i j k}\right)_{i^{\prime} j^{\prime} k^{\prime}}\right)$ que sai da fonte e chega ao colimador pode ser definida por

$$
\Phi_{0}\left(D_{0},\left(\varphi_{i j k}\right)_{i j^{\prime} k^{\prime}}\right)=\frac{d N_{0}}{d A}=\frac{d N_{0}}{d \Omega_{c}} \frac{d \Omega_{c}}{d A},
$$

o qual usualmente é expresso em $\mathrm{m}^{-2}$ ou $\mathrm{cm}^{-2}$ (ATTIX, 1986). $d N_{0}$ é o diferencial do número de fótons que saem da fonte e chegam ao colimador; $d \Omega_{c}$ o diferencial de ângulo sólido compreendido por um determinado elemento da fonte com ângulo projetado sob o plano do colimador (Fig. 3.2b). Os dois termos multiplicativos da equação podem ser escritos como 


$$
\frac{d N_{0}}{d \Omega_{c}}=\frac{N_{0}}{4 \pi} e^{-\left(\frac{\mu_{a r}(E) D_{0}}{\cos \left(\varphi_{i j k}\right)_{i^{\prime} j^{\prime} k^{\prime}}}\right)} \text { e } \frac{d \Omega_{c}}{d A}=\frac{\cos \left(\varphi_{i j \mathrm{k}}\right)_{\mathrm{i}^{\prime} \mathrm{j}^{\prime} \mathrm{k}^{\prime}}}{R_{i}^{2}}=\frac{\cos ^{3}\left(\varphi_{i j k}\right)_{i^{\prime} j^{\prime} k^{\prime}}}{D_{0}^{2}}
$$

de forma que $\Phi_{0}\left(D_{0},\left(\varphi_{i j k}\right)_{i^{\prime} j^{\prime} k^{\prime}}\right)$ resulta em

$$
\Phi_{0}\left(D_{0}, \varphi_{i j k}\right)=\frac{N_{0} \cos ^{3}\left(\varphi_{i j k}\right)_{i j^{\prime} k^{\prime}}}{4 \pi D_{0}^{2}} e^{-\left(\frac{\mu a r}{\cos (E) D_{0}}\right)}
$$

onde $\mu_{a r}(E)$ é o coeficiente de atenuação linear do ar.

Após o colimador, os raios percorrem uma distância $R_{i}^{\prime}$ até a superfície da amostra localizada à uma distância $D_{1}$ do colimador (Fig. 3.3). Em consequência, a fluência $\Phi_{0}$ deve ser escrita agora em função de $D_{0}+D_{1}$, análoga aos princípios da equação (3.1)

$\Phi_{0}\left(D_{0}+D_{1},\left(\varphi_{i j k}\right)_{i j^{\prime} k^{\prime}}\right)=\frac{d N_{0}}{d A}=\frac{d N_{0}}{d \Omega_{a}} \frac{d \Omega_{a}}{d A}=\frac{N_{0} \cos ^{3}\left(\varphi_{i j k}\right)_{i^{\prime} j^{\prime} k^{\prime}}}{4 \pi\left(D_{0}+D_{1}\right)^{2}} e^{-\left(\frac{\mu_{a r}(E)\left(D_{0}+D_{1}\right)}{\cos \left(\varphi_{i j k}\right)_{i j^{\prime} k^{\prime}}}\right)}$

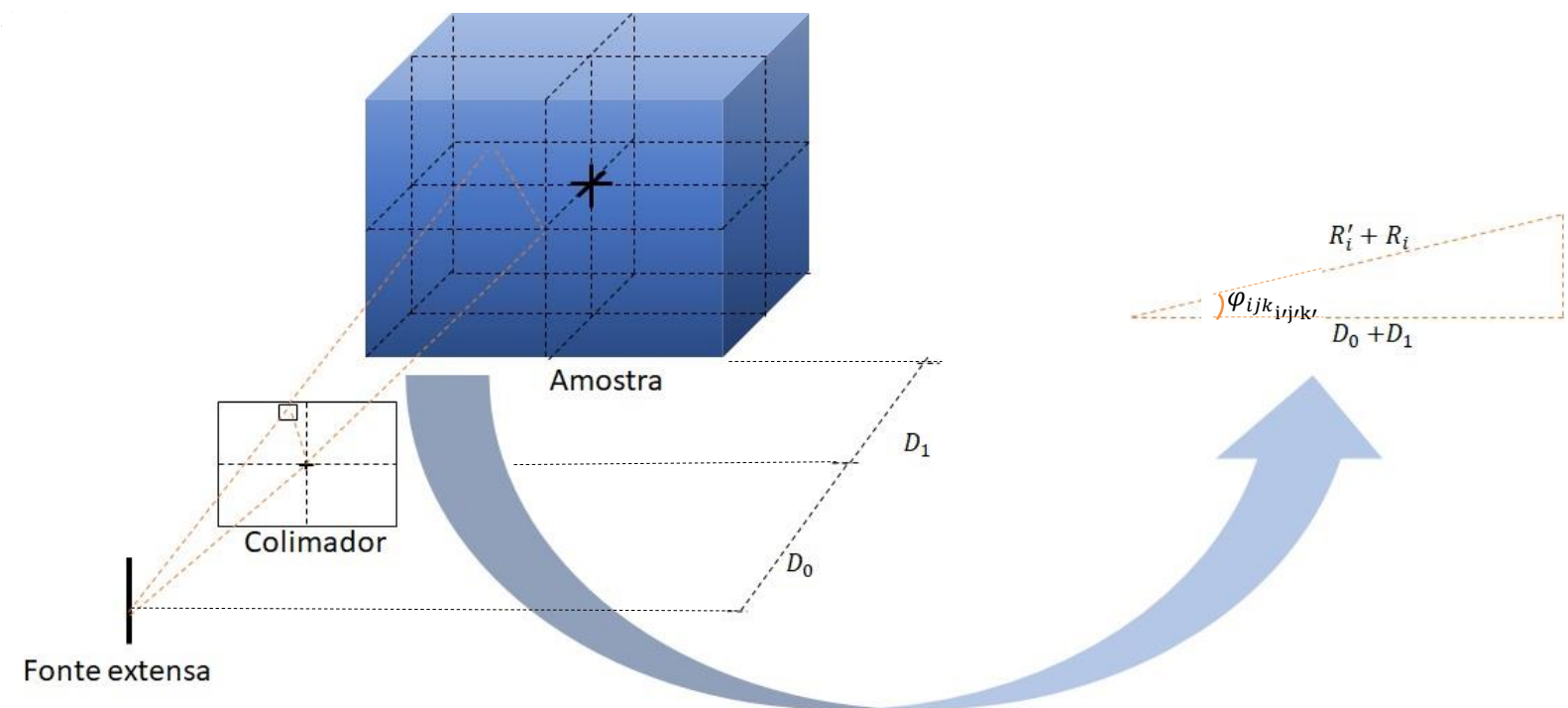

Fig. 3.3. Representação do caminho percorrido por um fóton até a superfície da amostra.

Antes de prosseguir com o estudo do caminho percorrido pelo fóton é necessário definir o voxel que contém o material de estudo, o qual este fóton interage.

\subsubsection{Seleção de um voxel}

Uma amostra de dimensões $M x N x T \mathrm{~cm}$, composta por um material em estudo, foi dividida em $m_{x}, m_{y}$ e $m_{z}$ elementos em x, y e $\mathrm{z}$, de modo que a origem do sistema de coordenadas se encontra no centro da amostra (Fig. 3.4a), os voxels por sua vez, são pequenos paralelepípedos que assumem dimensões $\left(\frac{M}{m_{x}}\right) \times\left(\frac{N}{m_{y}}\right) \times\left(\frac{T}{m_{z}}\right) \mathrm{cm}$. No entanto, ao defini-los 
nem todos eles serão interceptados pelos raios provenientes da fonte, somente alguns sofrerão interação com os fótons. Neste caso, foram definidos os voxels ativos por meio da intercecção dos raios com planos xy contidos no centro do voxel (Fig. 3.4b), para isso então é necessário, primeiramente, definir os planos xy.

Dado que $\mathrm{A}, \mathrm{B}$ e $\mathrm{C}$ são pontos pertencentes ao plano $a x+b y+c z+d=0$, e os vetores não paralelos $\overrightarrow{A B}$ e $\overrightarrow{B C}$ são vetores diretores do plano. A normal $\vec{n}$ ao plano e ortogonal aos vetores $\overrightarrow{A B}$ e $\overrightarrow{B C}$ é definido pelo produto vetorial $\overrightarrow{A B} \times \overrightarrow{B C}$

$$
\begin{gathered}
=\left|\begin{array}{ccc}
\hat{\imath} & \hat{\jmath} & \hat{k} \\
\left(x_{B}-x_{A}\right) & \left(y_{B}-y_{A}\right) & \left(z_{B}-z_{A}\right) \\
\left(x_{C}-x_{B}\right) & \left(y_{C}-y_{B}\right) & \left(z_{C}-z_{B}\right)
\end{array}\right| \\
=\left[\left(y_{B}-y_{A}\right)\left(z_{C}-z_{B}\right)-\left(y_{C}-y_{B}\right)\left(z_{B}-z_{A}\right)\right] \hat{\imath}+\left[\left(x_{C}-x_{B}\right)\left(z_{B}-z_{A}\right)-\left(x_{B}-x_{A}\right)\left(z_{C}-z_{B}\right)\right] \hat{\jmath}+ \\
{\left[\left(x_{B}-x_{A}\right)\left(y_{C}-y_{B}\right)-\left(x_{C}-x_{B}\right)\left(y_{B}-y_{A}\right)\right] \hat{k}}
\end{gathered}
$$

de modo que,

$$
\begin{aligned}
& a=\left[\left(y_{B}-y_{A}\right)\left(z_{C}-z_{B}\right)-\left(y_{C}-y_{B}\right)\left(z_{B}-z_{A}\right)\right] \\
& b=\left[\left(x_{C}-x_{B}\right)\left(z_{B}-z_{A}\right)-\left(x_{B}-x_{A}\right)\left(z_{C}-z_{B}\right)\right], \\
& c=\left[\left(x_{B}-x_{A}\right)\left(y_{C}-y_{B}\right)-\left(x_{C}-x_{B}\right)\left(y_{B}-y_{A}\right)\right]
\end{aligned}
$$

o valor $d$ pode ser encontrado pela substituição de qualquer ponto pertencente ao plano (WINTERLE, 2000).

Análogo aos cálculos mostrados por Freud et al. (2006), um fóton proveniente de um ponto $D\left(x_{D}, y_{D}, z_{D}\right)$ determinado pelo elemento da fonte, caminha em direção ao plano do colimador e o intercepta em um ponto $E\left(x_{E}, y_{E}, z_{E}\right)$. A reta que descreve o caminho percorrido pelo fóton na direção $\overrightarrow{D E}$ possui equação vetorial,

$$
(x, y, z)=\left(x_{D}, y_{D}, z_{D}\right)+\lambda\left(x_{E}-x_{D}, y_{E}-y_{D}, z_{E}-z_{D}\right)
$$

Se um ponto da reta é comum ao plano, as suas coordenadas verificam a equação do plano, tal que,

$$
\begin{gathered}
a\left(x_{D}+\lambda\left(x_{E}-x_{D}\right)\right)+b\left(y_{D}+\lambda\left(y_{E}-y_{D}\right)\right)+c\left(z_{D}+\lambda\left(z_{E}-z_{D}\right)\right)+d=0 \\
\therefore \lambda=-\frac{a x_{D}+b y_{D}+c z_{D}+d}{a\left(x_{E}-x_{D}\right)+b\left(y_{E}-y_{D}\right)+c\left(z_{E}-z_{D}\right)},
\end{gathered}
$$

em que, $a, b$ e $c$ são encontrados pelas equações (3.2). Substituindo a equação (3.4) na equação (3.3), encontra-se o ponto $(x, y, z)$ interceptado pela reta ao plano presente em um voxel, estes serão definidos como os voxels ativos. 


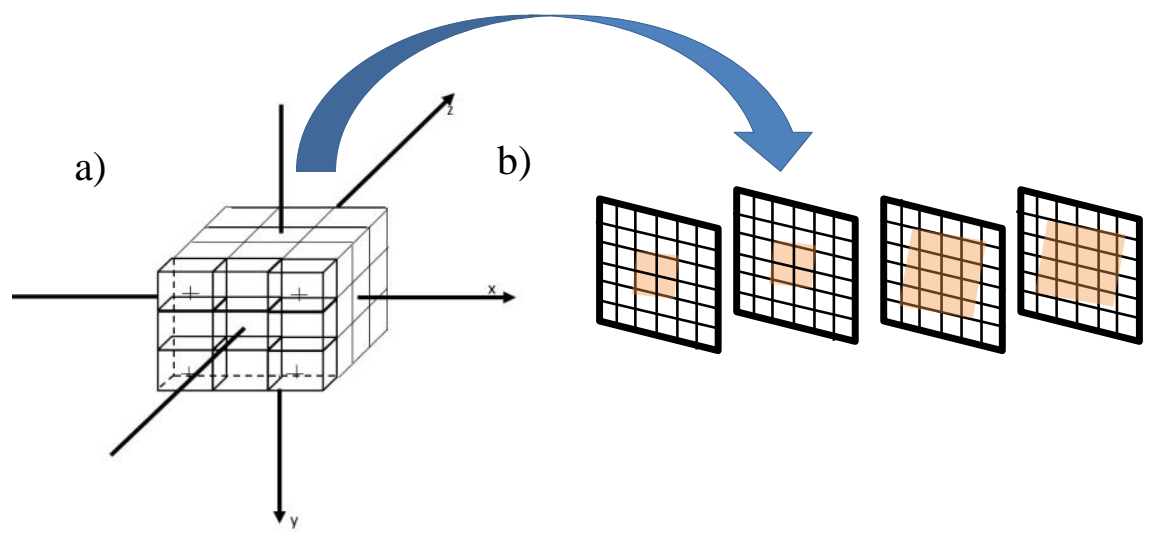

Fig. 3.4. Sistema de seleção dos voxels ativos. a) Uma amostra contendo um material de estudo é composta por voxels de dimensões $\left(\frac{M}{m_{x}}\right) \times\left(\frac{N}{m_{y}}\right) \times\left(\frac{T}{m_{z}}\right) \mathrm{cm}$, o qual são definidos como ativos aqueles que, b) contendo um plano xy em seu centro, é interceptado por um raio.

\subsubsection{Fótons espalhados sob um elemento de volume (voxel)}

Antes de uma complexa visão macroscópica da amostra, é necessário entender primeiramente, o espalhamento dos fótons por um simples elemento de volume (voxel) localizado na entrada, onde incide o feixe de raios X (FREUD, DUVAUCHELLE, et al., 2004). Ao incidir sob a amostra, o número de fótons primários sofre um decréscimo ao percorrer de $z$ à $z+\delta z$, em direção à $\left(\varphi_{i j k}\right)_{i^{\prime} j^{\prime} k^{\prime}}$, e ângulo sólido $\Delta \Omega$ (YAO e LESZCZYNSKI, 2009). Desta forma, a variação $\Delta N$ do número de fótons $\operatorname{com} \delta z \rightarrow 0$, pode ser escrita por

$$
\begin{gathered}
\Delta N\left(D_{0}+D_{1}+z,\left(\varphi_{i j k}\right)_{i^{\prime} j^{\prime} k^{\prime}}\right) \\
=\left[\Phi_{0}\left(D_{0}+D_{1}+z,\left(\varphi_{i j k}\right)_{i^{\prime} j^{\prime} k^{\prime}}\right)\left(D_{0}+D_{1}+z\right)^{2}\right. \\
\left.-\Phi_{0}\left(D_{0}+D_{1}+z+\delta z,\left(\varphi_{i j k}\right)_{i^{\prime} j^{\prime} k^{\prime}}\right)\left(D_{0}+D_{1}+z+\delta z\right)^{2}\right] \frac{\Delta \Omega}{\cos ^{2}\left(\varphi_{i j k}\right)_{i^{\prime} j^{\prime} k^{\prime}}} \\
=-\left[\frac{\partial \Phi_{0}\left(D_{0}+D_{1}+z,\left(\varphi_{i j k}\right)_{i^{\prime} j^{\prime} k^{\prime}}\right)}{\partial z}\left(D_{0}+D_{1}+z\right)^{2} \delta z+2 \Phi_{0}\left(D_{0}+D_{1}+z,\left(\varphi_{i j k}\right)_{i^{\prime} j^{\prime} k^{\prime}}\right)\left(D_{0}+D_{1}+\right.\right. \\
z) \delta z] \frac{\Delta \Omega}{\cos ^{2}\left(\varphi_{i j k}\right)_{i^{\prime} k^{\prime}}},
\end{gathered}
$$

sendo que, a fluência $\Phi_{0}\left(D_{0}+D_{1}+z,\left(\varphi_{i j k}\right)_{i j^{\prime} k^{\prime}}\right)$ após percorrer uma distância $z$, perpendicular ao plano xy é dada por

$$
\Phi_{0}\left(D_{0}+D_{1}+Z,\left(\varphi_{i j k}\right)_{i^{\prime} j^{\prime} k^{\prime}}\right)=\frac{N_{0} \cos ^{3}\left(\varphi_{i j k}\right)_{i j^{\prime} k^{\prime}}}{4 \pi\left(D_{0}+D_{1}+z\right)^{2}} e^{-\left(\frac{\mu \operatorname{ar}(E)\left(D_{0}+D_{1}\right)}{\cos \left(\varphi_{i j k}\right)_{i j^{\prime} k^{\prime}}}\right)} e^{-\left(\frac{\mu_{i}(E) z}{\cos \left(\varphi_{i j k}\right)_{i j^{\prime} k^{\prime}}^{\prime}}\right)},
$$


neste caso, $\mu_{i}(E)$ é o coeficiente de atenuação do material da amostra. Após solução de $\partial \Phi_{0}\left(D_{0}+D_{1}+z,\left(\varphi_{i j k}\right)_{i^{\prime} j^{\prime} k^{\prime}}\right) / \partial z$, a equação (3.5) resulta em

$$
\begin{aligned}
& \Delta N\left(D_{0}+D_{1}+z,\left(\varphi_{i j k}\right)_{i j^{\prime} k^{\prime}}\right)= \\
& \mu_{i} \frac{N_{0}}{4 \pi} e^{-\mu_{i} z / \cos \left(\varphi_{i j k}\right)^{\prime \prime j^{\prime} k^{\prime}}} e^{-\mu_{\operatorname{ar}}\left(D_{0}+D_{1}\right) / \cos \left(\varphi_{i j k}\right)_{i^{\prime} j^{\prime} k^{\prime}}} \delta z \Delta \Omega,
\end{aligned}
$$

A fração de $\Delta N\left(z, \varphi_{i j k}\right)$ do número de fótons primários que sofrem espalhamento é dada por

$$
\frac{\Delta N_{s}}{\Delta N}=\frac{\mu_{s}}{\mu_{i}}
$$

sendo $\mu_{s}=n_{v} d \sigma_{s} / d \Omega^{\prime}$, o qual $d \sigma_{s} / d \Omega^{\prime}=d \sigma_{\text {Rayleigh }}\left(\theta, E_{0}\right) / d \Omega^{\prime}+d \sigma_{\text {Compton }}\left(\theta, E^{\prime}\right) / d \Omega^{\prime}$ e $n_{v}$ é o número de átomos por volume do centro espalhador e pode ser expresso por

$$
n_{v}=\frac{N_{a} \rho}{\sum_{i} a_{i} M_{i}}
$$

onde $N_{a}$ é a constante de Avogadro $\left(6,022 \times 10^{23} \mathrm{~mol}^{-1}\right), \rho$ a densidade do material da amostra, $M_{i}$ e $a_{i}$ a massa molar e a abundância do i-ésimo elemento do material (FREUD, DUVAUCHELLE, et al., 2004; POLETTI, GONÇALVES e MAZZARO, 2001). O número de fótons $\Delta N_{S}$ são defletidos em um ângulo $\theta_{i " j " k} k^{\prime \prime}$ com relação à direção de incidência, e $\theta^{\prime}{ }_{i " j} j^{\prime \prime} k^{\prime \prime}$ em relação à normal ao plano xy $\left(\hat{n}_{\mathrm{xy}}\right)$ do voxel. Em seguida, caminham em direção à $\theta^{\prime}{ }^{\prime \prime} j^{\prime \prime} k^{\prime \prime} \mathrm{e}$ ângulo sólido $d \Omega^{\prime}$ sob o plano de um detector, posicionado à uma distância $\left(D_{2}+T-z\right)$ (Fig. 3.5). O detector de dimensões $D_{x} \times D_{y} \mathrm{~cm}$ é dividido em $N_{D_{x}}$ e $N_{D_{y}}$ elementos no plano $x y$,

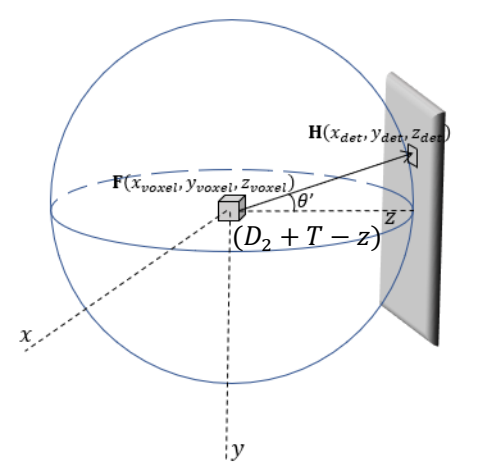

Fig. 3.5. Caminho percorrido pelo fóton após interagir com o material do voxel e atingir um pixel do detector à distância $\left(D_{2}+T-z\right)$ do centro espalhador.

sendo o tamanho dos pixels do detector plano definido por $\left(D_{x} / N_{D_{x}}\right) \times\left(D_{y} / N_{D_{y}}\right) \mathrm{cm}$. O fóton que é espalhado, proveniente da interação com o material do voxel, se origina em um ponto $\mathrm{F}$ de coordenadas $\left(x_{\text {voxel }}, y_{\text {voxel }}, z_{\text {voxel }}\right)$ no centro do voxel ativo e caminha em direção ao centro 
de cada pixel do detector em um ponto $\mathrm{H}$ de coordenadas $\left(x_{\text {det }}, y_{\text {det }}, z_{\text {det }}\right)$, cujo produto vetorial de $\overrightarrow{F H}$ com a normal $\hat{n}_{\mathrm{xy}}$ do plano xy resulta em $\cos \left(\theta^{\prime}{ }^{\prime \prime} j^{\prime \prime} k^{\prime \prime}\right)$.

A fluência espalhada $\left(\Phi_{S}\right)$ por um elemento de volume, em seguida, atinge um elemento de área $d A_{x y}$ do detector (definido por um pixel), em um ângulo sólido $d \Omega^{\prime}$. Substituindo a equação (3.6) em (3.7), partindo da equação (3.1)

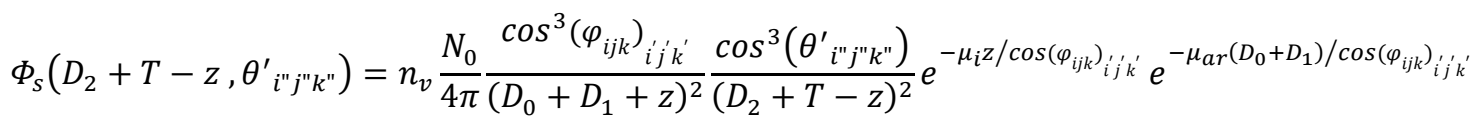

$$
\begin{aligned}
& e^{-\mu_{a r} D_{2} / \cos \left(\theta^{\prime} i^{\prime \prime} j^{\prime \prime} k\right.} e^{-\mu_{i}(T-z) / \cos \left(\theta^{\prime} i^{\prime \prime} j^{\prime \prime} k^{\prime \prime}\right.} \frac{d \sigma_{S}}{d \Omega^{\prime}} \delta z,
\end{aligned}
$$

A equação (3.8) remete à informação de um voxel pertencente ao eixo z, localizado na entrada da amostra onde incide o feixe de raios X, no entanto, voxels adjacentes e seguidos a este poderão ser ativados em diferentes coordenadas $\mathrm{x}, \mathrm{y}$ e $\mathrm{z}$, devido à direção e divergência do raio. Então, as componentes na verdade deverão englobar as contribuições de toda a amostra nas coordenadas x, y e z. Neste caso, para cada elemento da fonte, $\Phi_{s}$ que atinge o detector, é dado por

$$
\begin{aligned}
& \Phi_{S}=\sum_{i^{\prime \prime}}^{m_{x}} \sum_{j^{\prime \prime}}^{m_{y}} \sum_{k^{\prime \prime}}^{m_{z}} n_{v} \frac{N_{0}}{4 \pi} \frac{\cos ^{3}\left(\varphi_{i j k}\right)_{i{ }^{\prime} k^{\prime}}}{\left(D_{0}+D_{1}+z_{k^{\prime \prime}}\right)^{2}} \frac{\cos ^{3}\left(\theta^{\prime}{ }^{\prime \prime}{ }^{\prime \prime} k^{\prime \prime}\right)}{\left(D_{2}+T-z_{k^{\prime \prime}}\right)^{2}} e^{-\mu_{i} z_{i^{\prime \prime}} j^{\prime \prime} k^{\prime \prime} / \cos \left(\varphi_{i j k}\right)_{i^{\prime} j^{\prime} k^{\prime}}} \\
& e^{-\mu_{a r}\left(D_{0}+D_{1}\right) / \cos \left(\varphi_{i j k}\right)_{i j^{\prime} k^{\prime}}^{\prime}} e^{-\mu_{a r} D_{2} / \cos \left(\theta^{\prime} i^{\prime \prime} j^{\prime \prime} k^{\prime \prime}\right)} e^{-\mu_{i}\left(T-z_{k^{\prime \prime}}\right) / \cos \left(\theta^{\prime} i^{\prime \prime} j^{\prime \prime} k^{\prime \prime}\right)} \frac{d \sigma_{S}\left(E, \theta^{\prime} i^{\prime \prime} j^{\prime \prime} k^{\prime \prime}\right)}{d \Omega^{\prime}} \delta z_{k^{\prime \prime}},
\end{aligned}
$$

tal que, cada elemento da fonte que passa pela área do colimador resulta em $\Phi_{s}^{d}=$ $\sum_{i^{\prime}}^{c o l_{x}} \sum_{j^{\prime}}^{c o l_{j}} \sum_{k^{\prime}}^{c o l_{z}}\left(\Phi_{s}\right)_{i^{\prime} j^{\prime} k^{\prime}}$, em que $\operatorname{col}_{x}$, $\operatorname{col}_{y}$ e $\operatorname{col}_{z}$ são o número de divisões do colimador em $\mathrm{x}, \mathrm{y}$ e $\mathrm{z}$, respectivamente. Para todos os elementos da fonte, a fluência espalhada total que atinge o detetor é dada por $\Phi_{S}^{D}=\sum_{j}^{n}\left(\Phi_{S}^{d}\right)_{j}$, para simplicidade dos cálculos o colimador foi aproximado para uma superfície em $x y$.

A fluência em energia espalhada detectada é dada por $\Psi^{\prime}{ }_{s}=E \Phi_{s}^{D}$, sendo $E=E_{0}$, para o espalhamento elástico e $E=E^{\prime}$ (equação (2.7), seção 2.2), para o espalhamento inelástico, em feixes monoenergéticos. Em um espectro de energia polienergético, a energia $E$ será multiplicada a um peso $\left(p(E)=\Phi_{E} / \Phi_{\text {total }}\right.$, sendo $\Phi_{E}$ a fluência em energia), a informação contendo todo espectro será dada por $\bar{E}=\sum_{i}^{n^{\prime}} E_{i} p(E)_{i}$, sendo i $=1,2, \ldots$, n' energias, neste caso, $\Psi_{s}=\sum_{i}^{n^{\prime}} \sum_{j}^{n}\left(\Phi_{s}^{d}\right)_{j} E_{i} p(E)_{i}$. A distribuição de kerma colisional no ar de espalhamento sob o detector plano é definida pela energia transferida pelos fótons espalhados em um volume $V$ de massa $m$ do detector, devido a interações coulombianas com elétrons do meio, e pode ser escrito 
por $\left(K_{c}^{a r}\right)_{\text {espalhado }}=\Psi^{\prime}{ }_{S}\left(\frac{\mu_{a b}}{\rho}\right)_{a r}$, para um feixe monoenergético, e $\left(K_{c}^{a r}\right)_{\text {espalhado }}=$ $\sum_{i}^{n^{\prime}} \sum_{j}^{n}\left(\Phi_{S}^{d}\right)_{j} E_{i} p(E)_{i}\left(\left(\frac{\mu_{a b}}{\rho}\right)_{a r}\right)$, para um espectro polienergético.

\subsubsection{Algorítmo para aquisição das imagens por espalhamento de raios $\mathbf{X}$}

Sumariamente, os assuntos levantados nas subseções anteriores são mostrados sob o ponto de vista dos cálculos analíticos que estimam a distribuição dos fótons espalhados de primeira ordem em um detector plano. $\mathrm{O}$ sinal adquirido em cada pixel do detector, o qual depende das diversas componentes mencionadas, é representado por um ponto da matriz da imagem, e a junção de todos estes elementos retrata a imagem formada utilizando a componente espalhada dos raios X. À nível de simplicidade, foi implementado um algoritmo em MATLAB® com a finalidade de desenvolver os cálculos analíticos para a obtenção da imagem, uma representação simplificada foi feita por meio de um diagrama, apresentado na Fig. 3.6.

Alguns parâmetros devem ser informados previamente e comporão a base de dados de entrada, incluindo os fatores físicos e geométricos. Neste trabalho, foi utilizado para os cálculos um tamanho de fonte de $1 \mathrm{~mm}$, o qual origina raios direcionados à um colimador circular. Uma amostra de dimensões $\mathrm{x}, \mathrm{y}$ e z, com centro localizado à uma distância $D_{0}+D_{1}+T / 2=34 \mathrm{~cm}$ da fonte, é constituída por voxels de mesmo tamanho $\left(8 \mathrm{~mm}^{3}\right)$, compostos por um material de densidade $\rho$ e coeficiente de atenuação $\mu_{i}$. Os dados de $\mu_{i}(E), \mu_{a r}(E)$ e $\rho$ incorporados nos cálculos são disponibilizados pelo National Institute of Standards and Technology (NIST), utilizando a base de dados XCOM (BERGER, HUBBELL, et al., 2005). Os materiais estudados foram o tecido adiposo, de composição e proporção atômica retiradas de ICRU Report 44 (ICRU 1989), contendo $\mathrm{C}, \mathrm{N}, \mathrm{H}_{\text {e O}}{ }^{1}$; e materiais equivalentes ao tecido, dentre eles o PMMA $\left(\left(\mathrm{C}_{5} \mathrm{H}_{8} \mathrm{O}_{2}\right)_{n}\right)$, nylon $\left(\left(\mathrm{C}_{12} \mathrm{H}_{22} \mathrm{O}_{3} \mathrm{~N}_{2}\right)_{n}\right)$ e água $\left(\mathrm{H}_{2} \mathrm{O}\right)$.

${ }^{1}$ Seguindo ICRU Report 44, a composição elementar em porcentagem por massa do tecido adiposo é $\mathrm{C}(59,8), \mathrm{H}(11,4), \mathrm{N}(0,7)$, e $\mathrm{O}(27,8)$, outros elementos como $\mathrm{Na}, \mathrm{S}$ e $\mathrm{Cl}$ possuem apenas 0,1 em porcentagem por massa. 


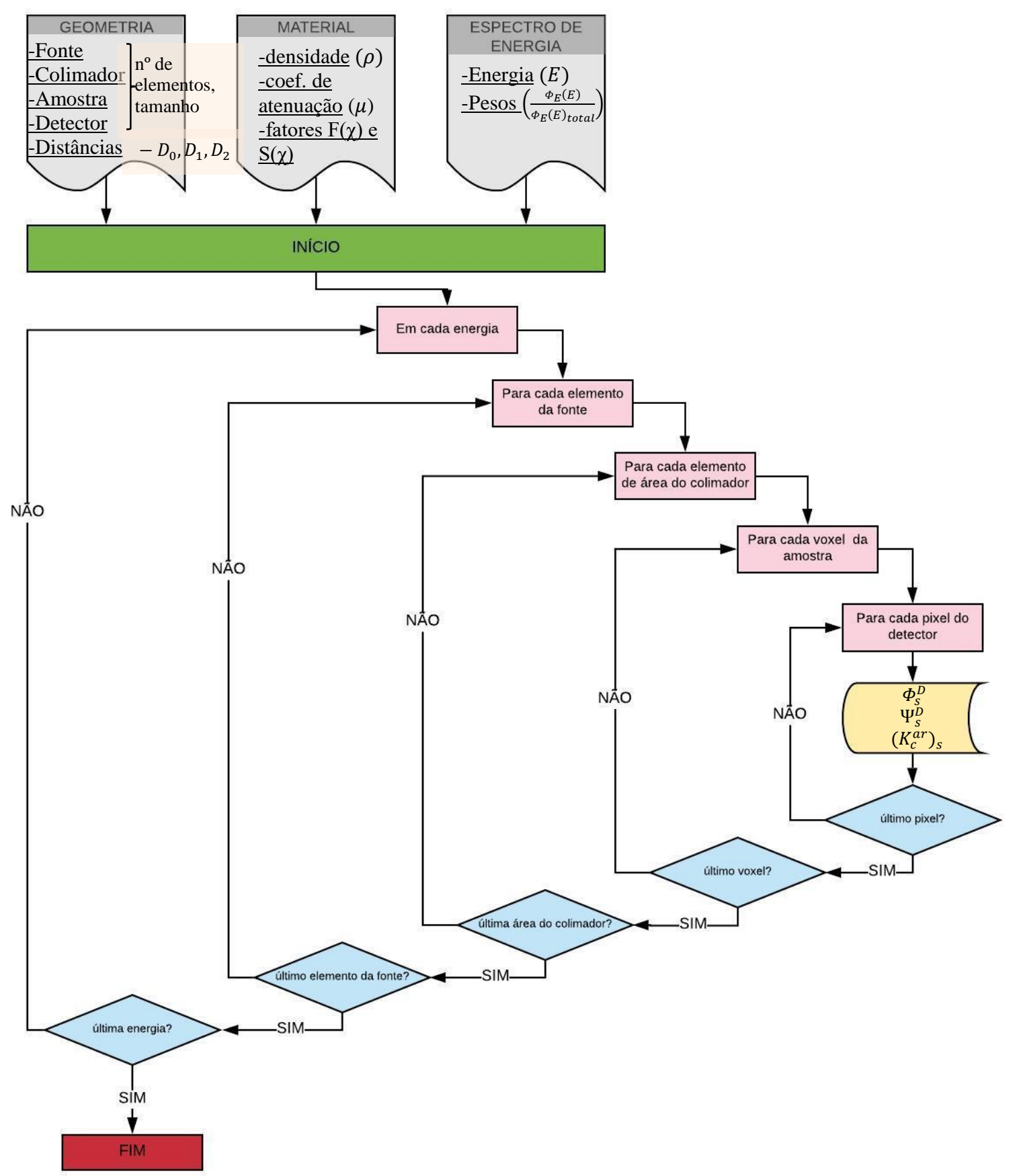

Fig. 3.6. Diagrama simplificado do algoritmo implementado em MATLAB®.

Os feixes incidentes de raios $\mathrm{X}$ foram simulados pelo software SpekCalc (POLUDNIOWSKI, 2007; POLUDNIOWSKI, LANDRY, et al., 2009b), as energias e os seus respectivos pesos são englobados em nosso algorítmo.

A validação do algoritmo foi feita por comparação com valores encontrados na literatura, propostos por Poludniowsky et. al 2009, utilizando um espectro de $100 \mathrm{kV}$, e uma amostra de $0,5 \times 0,5 \times 0,5 \mathrm{~cm}^{3}$ de tecido adiposo. As bases de dados foram as mesmas utilizadas 
pelo trabalho da literatura. Neste caso, os valores de fator de forma para o tecido adiposo foram retirados dos resultados experimentais propostos por Tartari et. al 2002.

Posteriormente, o algoritmo desenvolvido, implementado e validado foi utilizado para o estudo da influência das componentes do sistema (abertura do colimador, distância amostradetector, espessura da amostra, energia e espectro de raios $\mathrm{X}$ incidente) por meio da análise do borramento espacial nos perfis radiais extraídos das imagens por projeção, utilizando a componente espalhada dos raios $\mathrm{X}$.

\subsubsection{Influência na modelagem do fator de forma nas imagens e nos perfis radiais por espalhamento de raios $X$}

A figura 3.7 mostra o efeito da modelagem do fator de forma na imagem por espalhamento, em amostras de 0,5 cm de PMMA (Fig. 3.7a, b e c) e tecido adiposo (Fig. 3.7d, e e f), utilizando um feixe monoenergético de $80 \mathrm{keV}$ e distância da amostra ao detector de $28 \mathrm{~cm}$. Os cálculos da seção de choque diferencial de espalhamento por ângulo sólido incluem os fatores de forma $F_{M A I}(\chi, Z)$ e a função de espalhamento incoerente $S(\chi, Z)$, retirados dos dados tabelados por Hubbel e Øverbø (1979) e Hubbel et al. (1975), respectivamente, e os fatores de forma molecular $F_{m o l}(\chi, Z)$ retirados de Poletti et al. (2002).

Análogo aos resultados encontrados por Leliveld et al. (1996) e Poludniowsky et al. (2009), as curvas da figura 3.7a e 3.7d apresentam claras diferenças em suas estruturas utilizando $F_{m o l}$, comparado aos perfis utilizando $F_{M A I}$. As figuras ressaltam, por meio da utilização de $F_{\text {mol }}$ que as formas dos perfis são característicos do espalhador e variam de material para material.

O PMMA apresenta picos bem definidos nas posições $0,8 \mathrm{~cm} ; 1,7 \mathrm{~cm} \mathrm{e} 4,2 \mathrm{~cm}$ e o tecido adiposo em 1,1 cm;2,2 cm e $4 \mathrm{~cm}$. No entanto, utilizando $F_{M A I}$ ambos os materiais possuem apenas um pico central, não apresentando picos característicos decorrentes do efeito de interferência entre os raios $\mathrm{X}$ espalhados por elétrons pertencentes à diferentes átomos de diferentes moléculas (JOHNS e YAFFE, 1983; POLETTI, GONÇALVES, et al., 2002; POLETTI, GONÇALVES e MAZZARO, 2001). 
a)

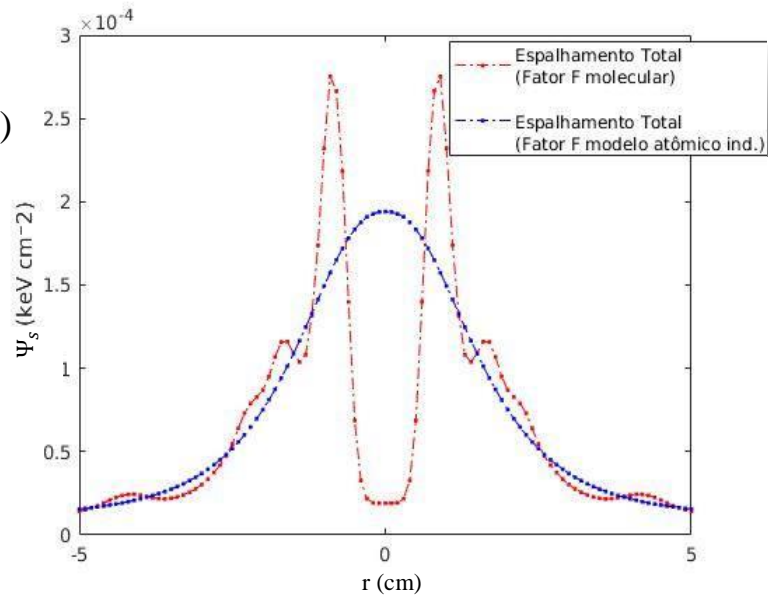

b)

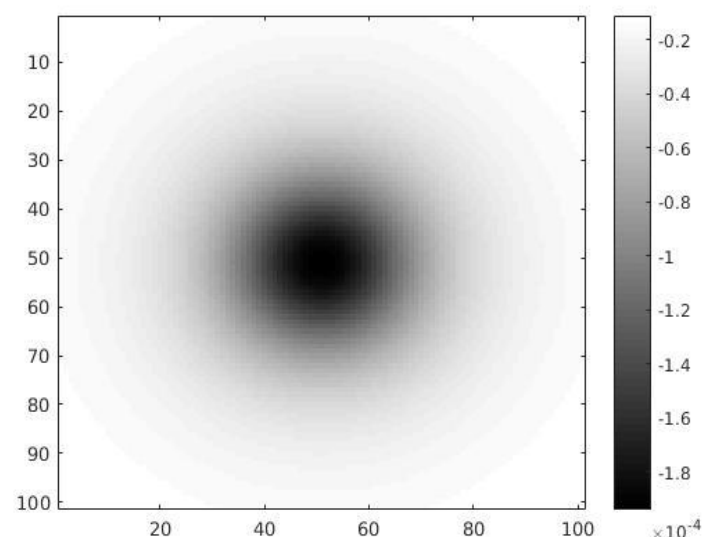

c)

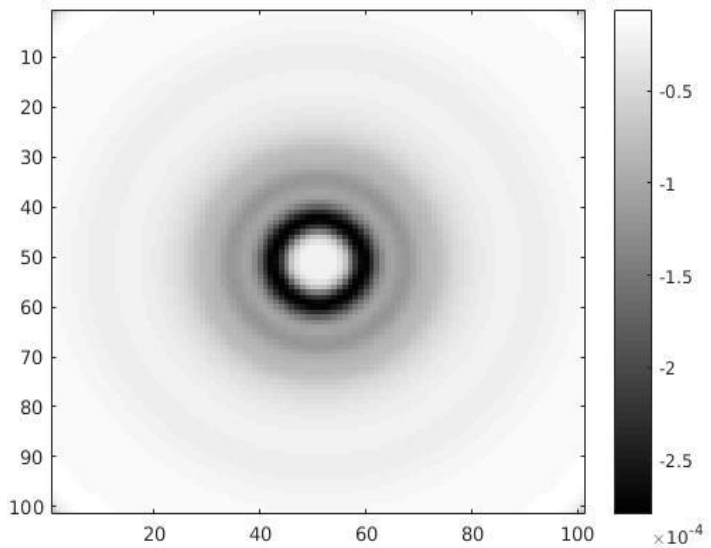

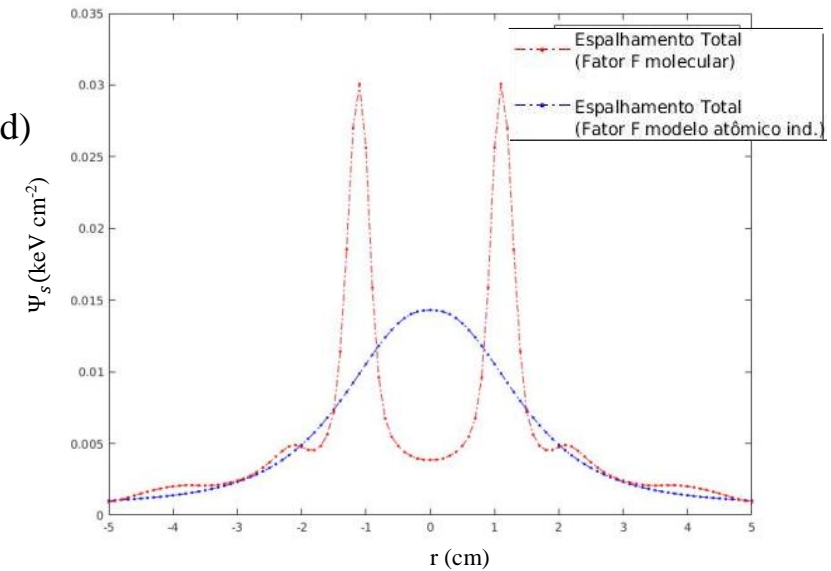

e)

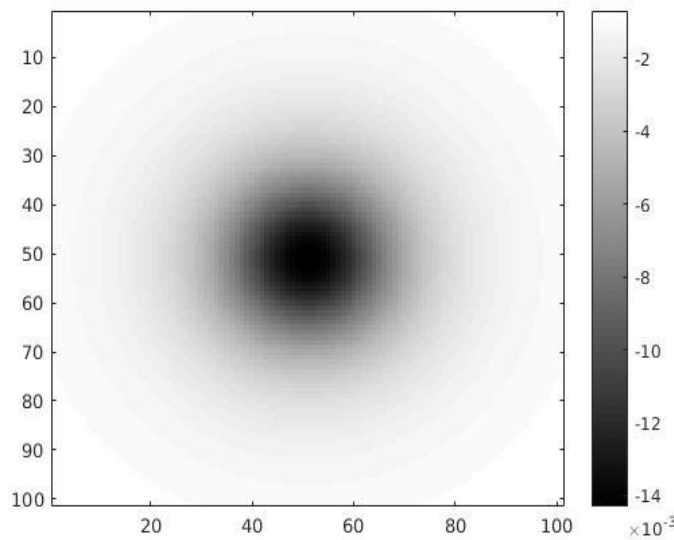

f)

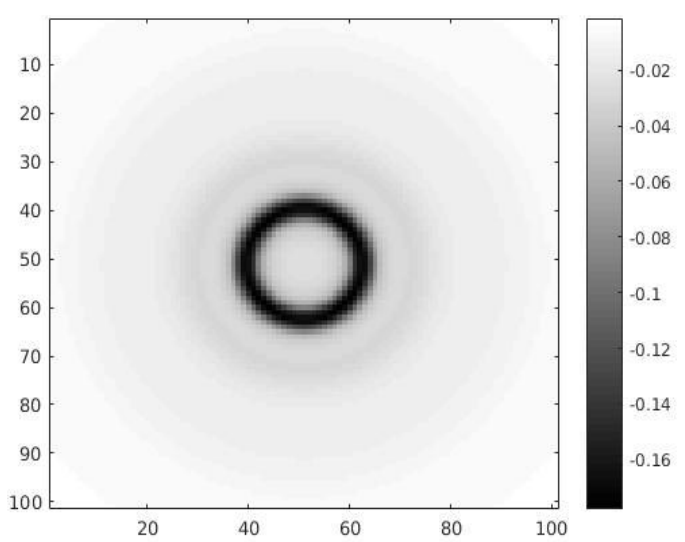

Fig. 3.7. Distribuição da $\Psi_{S}$ em função da posição ao longo de um eixo central do detector de uma imagem $10 \times 10 \mathrm{~cm}^{2}$ variando a modelagem do fator de forma, para um feixe monoenergético de $80 \mathrm{keV}$. Em a) a representação utilizando o fator de forma do modelo atômico independente e o fator de forma molecular para o PMMA, e suas respectivas imagens planares em b) e c). Analogamente, à direita, em d) para o tecido adiposo, e suas respectivas imagens planares em e) e f).

As figuras $3.7 \mathrm{c}$ e $3.7 \mathrm{f}$ representam as distribuições de $\Psi_{S}$ no plano do detector. As imagens obtidas utilizando $F_{m o l}$ apresentam anéis concêntricos em diferentes posições e intensidades, o qual descrevem os perfis radiais no plano azimutal. Por outro lado, as figuras $3.7 \mathrm{~b}$ e $3.7 \mathrm{e}$ utilizando $F_{M A I}$, para o PMMA e tecido adiposo, resultaram somente em um círculo central de maior intensidade. 
Embasado nos resultados e nas grandes diferenças encontradas nas duas modelagens, a utilização de $F_{M A I}$ não se mostrou fidedigna no que se refere à caracterização dos materiais. Portanto, os resultados apresentados serão incorporados somente $F_{m o l}$ nos cálculos do espalhamento coerente de primeira ordem.

\subsubsection{Borramento espacial gerado nos perfis radiais da imagem relacionado aos parâmetros geométricos e físicos do sistema}

$\mathrm{O}$ perfil radial ao longo de um eixo central da imagem por espalhamento de raios $\mathrm{X}$ pode sofrer alterações devido aos parâmetros geométricos e físicos do sistema. As deformações nas imagens e perfis radiais são geradas pelas variações destes parâmetros, originados pelo tamanho da fonte, abertura do colimador, dimensões da amostra, distância da amostra ao detector, tamanho do pixel e forma do espectro de energia dos raios $\mathrm{X}$, as quais geram um borramento espacial nos perfis radiais decorrentes das incertezas no ângulo de espalhamento (PANI, COOK, et al., 2009).

Seguindo o proposto por Beath et al. (2009), o ângulo de espalhamento $\theta$ pode ser associado ao raio do detector $r$, em uma amostra de espessura $T$ com centro localizado a uma distância de $D_{2}+T / 2$ do detector plano (Fig. 3.8), de modo que

$$
r=\left(D_{2}+T / 2\right) \operatorname{tg}(\theta) .
$$

Idealmente, um perfil radial reproduzirá picos e larguras intrínsecos do material de estudo se existir uma relação unívoca entre o raio $r$ do detector e o ângulo, ou seja, quando o tamanho da fonte $Y$ for infinitesimalmente pequena de maneira que a fonte se comporte como

a)

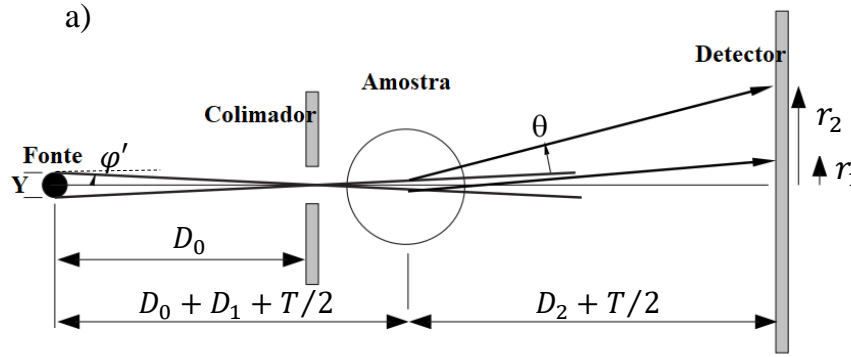

b)

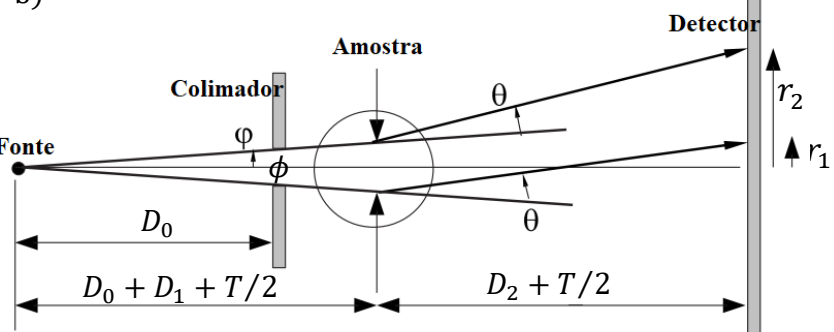

Fig. 3.8. Diagrama simplificado de um sistema para aquisição de imagens por espalhamento de raios $\mathrm{X}$, utilizando um detector plano, localizado a uma distância $D_{2}+T / 2$ do centro de uma amostra de espessura $T$, a qual é irradiada por um feixe de raios $\mathrm{X}$ originado de a) uma fonte de tamanho $Y, \mathrm{~b}$ ) o feixe que atinge a amostra possui tamanho definido pela abertura do colimador $\phi$ localizado a uma distância $D_{0}$ da fonte e $D_{1}$ da superfície da amostra (adaptado de BEATH e CUNNINGHAM, 2009). 
uma fonte pontual, colimado de forma a apresentar divergência nula, irradiando uma amostra de espessura infinitesimalmente pequena, o qual após interagir com o material da amostra os raios são espalhados em um ângulo $\theta$ atingindo pixels do detector, infinitesimalmente pequenos. Neste caso, a resultante da imagem comporá somente a informação do material, em

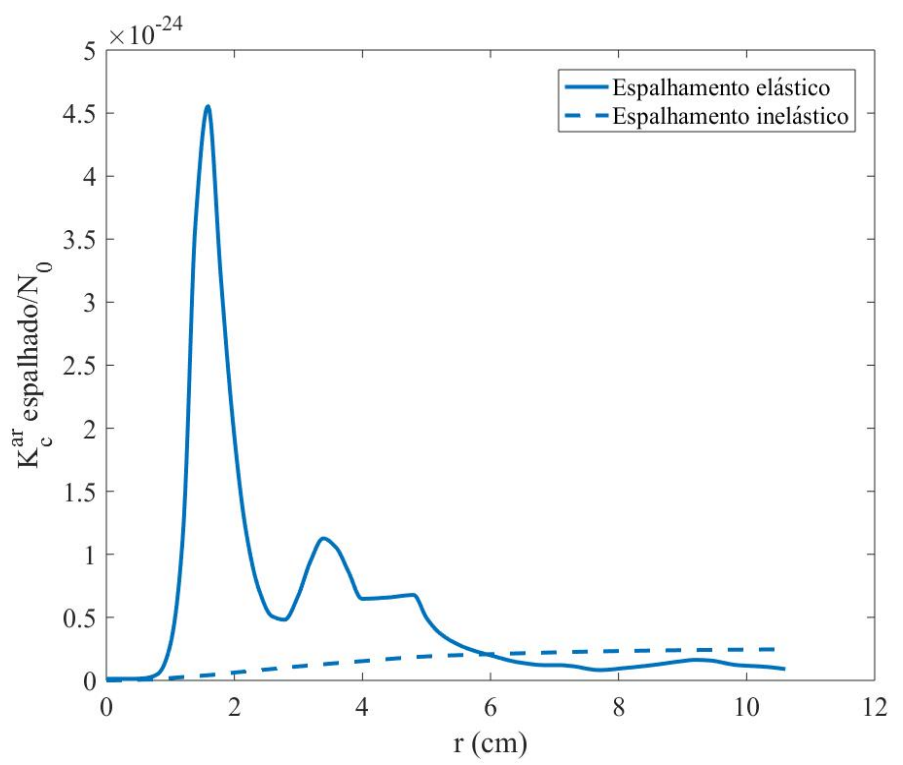

Fig. 3.9. Perfil radial intrínseco do PMMA, em kerma colisional no ar normalizado pelo número de fótons incidentes em função da posição ou raio de um eixo central do detector. A energia do feixe incidente é de $40 \mathrm{keV}$ e o centro da amostra se encontra à $32 \mathrm{~cm}$ do detector plano. A posição do pico principal se encontra em $1,59 \mathrm{~cm}$ e a FWHM resulta em $0,67 \mathrm{~cm}$.

ausência do borramento geométrico causado pelas componentes do sistema. A figura 3.9 ilustra o kerma colisional no ar normalizado pelo número de fótons incidentes $\left(N_{0}\right)$ em função da posição ou raio de um eixo central do detector, ilustrando o perfil radial intrínseco do PMMA, em um feixe de $40 \mathrm{keV}$ e distância de $32 \mathrm{~cm}$ do centro da amostra ao detector plano. $\mathrm{O}$ estudo da influência de cada parâmetro nos perfis radiais da imagem foi realizado por meio da análise da incerteza em $r(\Delta r)$ em função do raio do detector, para cada variável do sistema, e comparados ao perfil radial intrínseco do material.

\section{i. $\quad$ Incerteza em r relacionada ao tamanho da fonte $(Y)$}

Uma fonte de tamanho finito $Y$ introduz um borramento em $r$, de maneira que os raios originados de suas extremidades passam pelo centro do colimador localizado a uma distância $D_{0}$ da fonte e atingem uma amostra a uma distância $D_{1}$ do colimador (Fig. 3.8a). Em seguida, são espalhados formando um ângulo $\theta$ em relação ao raio incidente de divergência $\varphi^{\prime}$, atingindo o detector plano sob uma faixa de $r_{2}$ à $r_{1}$, de modo que 


$$
r_{2}=\left(D_{1}+T / 2\right) \operatorname{tg}\left(\varphi^{\prime}\right)+\left(D_{2}+T / 2\right) \operatorname{tg}\left(\theta+\varphi^{\prime}\right)
$$

e

$$
r_{1}=\left(D_{2}+T / 2\right) \operatorname{tg}\left(\theta+\varphi^{\prime}\right)-\left(D_{1}+T / 2\right) \operatorname{tg}\left(\varphi^{\prime}\right)
$$

onde $\operatorname{tg}\left(\varphi^{\prime}\right)=Y / 2 D_{0}$. Portanto a incerteza $\Delta r$ em relação ao tamanho da fonte é dado por

$$
\Delta r=\frac{Y\left(D_{1}+T / 2\right)}{D_{0}}
$$

Neste trabalho, foi padronizado o tamanho da fonte em $1 \mathrm{~mm}$.

\section{ii. Incerteza em r relacionada à abertura do colimador $\phi$}

A amostra é irradiada por raios com pequenas divergências atingindo uma área em sua superfície definida pela abertura $\phi$ do colimador, localizado a uma distância $D_{0}$ da fonte e $D_{1}$ da superfície da amostra. Os raios que saem de um elementro do eixo central da fonte com uma divergência $\varphi$ (Fig. 3.8a, aproximadamente uma fonte pontual sem variações em Y), atingem as extremidades do colimador, após a interação com o material da amostra, os fótons são espalhados a um ângulo $\theta$ em relação à radiação incidente, atingindo o detector em $r_{2}=$ $(\phi / 2)+\left(D_{1}+T / 2\right) \operatorname{tg}(\varphi)+\left(D_{2}+T / 2\right) \operatorname{tg}(\theta+\varphi)$ e $r_{1}=\left(D_{2}+T / 2\right) \operatorname{tg}(\theta+\varphi)-(\phi / 2)-\left(D_{1}+\right.$ $T / 2) \operatorname{tg}(\varphi)$. Então, a variação $\Delta r$ devido à abertura do colimador pode ser escrita como

$$
\Delta r=\phi+2\left(D_{1}+T / 2\right) \operatorname{tg}(\varphi)
$$

sendo a $\operatorname{tg}(\varphi)=\phi / 2 D_{0}$, então

$$
\Delta r=\frac{\phi\left(D_{1}+D_{0}+T / 2\right)}{D_{0}}
$$

iii. Incerteza em r relacionada à distância da amostra ao detector e espessura da amostra

Os fótons que incidem sobre a superfície da amostra são espalhados a um ângulo $\theta \mathrm{em}$ relação ao incidente à uma distância do detetctor que varia em relação à espessura da amostra $T$, em $D_{2}+T / 2$ e $D_{2}-T / 2$, de modo que a origem do eixo de coordenadas se encontra no centro da amostra. Os fótons que se espalham nas extremidades da amostra, atingem o detector em $r_{2}=\left(D_{2}+T / 2\right) \operatorname{tg}(\theta)$ e $r_{1}=\left(D_{2}-T / 2\right) \operatorname{tg}(\theta)$, de modo que a variação $\Delta r$ resulta em

$$
\Delta r=\operatorname{Ttg}(\theta)
$$

o qual $\operatorname{tg}(\theta)$ pode ser expresso por $r /\left(D_{2}+T / 2\right)$. 
iv. Incerteza em $r$ devido à largura do espectro de energia $(\Delta E)$

$\mathrm{O}$ espectro de raios $\mathrm{X}$ polienergético exerce influência sobre a imagem, de forma que um borramento em $r$ é observado devido às superposições de todas as energias pertencentes ao espectro, escalado por um fator peso, o qual leva em conta a forma do espectro de raios $\mathrm{X}$ em decorrência da fluência incidente em cada energia. Partindo da equação (3.10), podemos associar a variação em $r$ com a variação em momento transferido sofrida pelas diversas energias que compõe o espectro, sendo

$$
r=\left(D_{2}+T / 2\right) \operatorname{tg}\left(2 \operatorname{sen}^{-1}\left(\frac{\chi h c}{E}\right)\right),
$$

onde $\chi$ é o momento transferido e $h c=12,398 \mathrm{keV} \AA$. Para ângulos pequenos, o diferencial de $r$ com relação à $E$ em (3.13), estima a variação $\Delta r$, a qual resulta em

$$
\Delta r \approx \frac{\Delta E}{E} r \text {. }
$$

A largura espectral é definida por $\Delta E_{R M S}=\left(\overline{E^{2}}-\bar{E}^{2}\right)^{1 / 2}$ (LECLAIR e JOHNS, 1999; BEATH e CUNNINGHAM, 2009; WESTMORE e FENSTER, 1997), onde $E$ assume a energia média do espectro polienergético em $\Delta r$.

Cada um dos mecanismos descritos acima contribui para o borramento espacial no perfil radial intrínseco. Uma vez que o borramento está associado ao raio do detector, a extensão de cada mecanismo gera um borramento espacial no perfil radial intrínseco e podem ser representados como uma convolução integral em cada $r$, resultando em aproximadamente

$$
\Delta r^{2} \approx \Delta{r_{Y}}^{2}+\Delta{r_{\phi}}^{2}+\Delta{r_{\Delta E}}^{2}+\Delta{r_{D_{2}}}^{2}+\Delta{r_{T}}^{2}+\Delta r_{\text {pixel }}{ }^{2},
$$

embora a incerteza em $r(\Delta r)$ gerada pelo sistema seja aproximadamente a soma dos quadrados em cada parâmetro individual, alguns componentes dependem uns dos outros, por exemplo, uma variação em espessura $T$ também gera uma variação na distância da amostra ao detector $\left(D_{2}\right)$, ou seja, o impacto da mudança em um parâmetro também pode gerar mudanças nos demais, os quais na verdade não são independentes. 


\subsection{Metodologia experimental para a aquisição das imagens por espalhamento de raios $X$}

\subsubsection{Configuração do sistema experimental}

A configuração experimental (Fig. 3.10) foi construída para aquisição das imagens utilizando a componente espalhada dos raios X, no Laboratório de Física das Radiações e Dosimetria, do Departamento de Física da Faculdade de Filosofia, Ciências e Letras de Ribeirão Preto (FFCLRP, Universidade de São Paulo). O sistema experimental desenvolvido neste trabalho foi constituído por um tubo de raios X industrial ISOLVOLT Titan E (GE) com ânodo de tungstênio (W) angulado à $20^{\circ}$ e tamanho focal de $1 \mathrm{~mm}$, apresentando uma filtração intrínseca de $2 \mathrm{~mm}$ de $\mathrm{Al}$ e $0,8 \mathrm{~mm}$ de Be, podendo ser adicionadas diferentes filtrações na saída do feixe de raios $X$.

Uma série de colimadores de $1 \mathrm{~mm}$ de diâmetro e espessura de $15 \mathrm{~mm}$ de chumbo foram dispostos ao longo do caminho do feixe, distanciados à 6,2 cm (na saída do feixe), $12 \mathrm{~cm}$

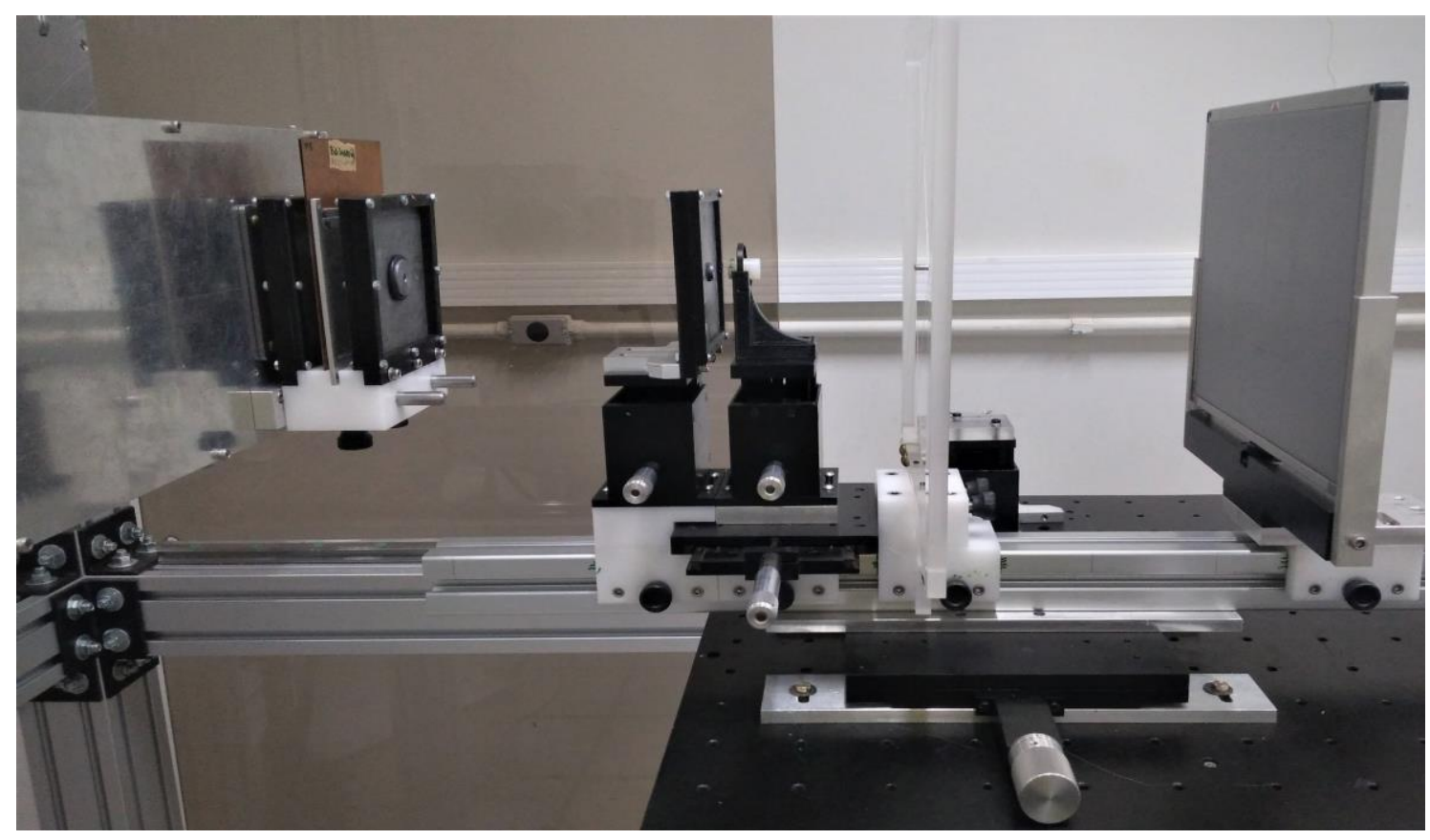

Fig. 3.10. Fotografia da configuração experimental utilizada para aquisição das imagens por espalhamento de raios $\mathrm{X}$.

e 24,2 $\mathrm{cm}$ do foco, envoltos por uma pequena placa de chumbo de $6 \mathrm{~mm}$ de espessura, para evitar que fótons espalhados pelo meio, antes de atingir a amostra, alterem as medidas nas imagens. 
Com a finalidade de obter somente a componente espalhada dos raios $\mathrm{X}$, um bloqueador da componente primária dos raios $\mathrm{X}$ transmitidos pela amostra, composto por $6 \mathrm{~mm}$ de espessura de $\mathrm{Sn}$ e 3,5 $\mathrm{mm}$ de diâmetro, foi localizado à $10 \mathrm{~cm}$ do centro da amostra. Seguido de um detector plano Vita Flex CR (Carestream Health, Onex Corporation, Toronto, Ontario, Canadá), de dimensões $20 \mathrm{~cm} \times 25$, com composição de $\mathrm{BaFBr} \mathrm{Eu}^{2+}$, lozalizado à $32 \mathrm{~cm}$ do centro da amostra.

\subsubsection{Espectros de raios $X$ e amostras utilizadas para aquisição das imagens}

Os espectros utilizados foram baseados nos trabalhos anteriores de Johns et al. (1983) e Leclair et al. (2002) de $80 \mathrm{kV}$ (filtração adicional de 2,5 mm de Al), em $2400 \mathrm{mAs}$. Outros dois espectros de $50 \mathrm{kV}$ e $80 \mathrm{kV}$ (2400 mAs e $3840 \mathrm{mAs}$, respectivamente) com maiores filtrações, de 2,2 $\mathrm{mm}$ de $\mathrm{Al}$ e 0,6 $\mathrm{mm}$ de $\mathrm{Cu}$, foram utilizados à fim de se avaliar as diferenças geradas nos perfis radiais, em relação às formas dos espectros de raios $\mathrm{X}$ utilizados.

Uma amostra homogênea ou heterogênea constituída por materiais equivalentes ao tecido de formato cilíndrico, com 1,45 cm de diâmetro, é localizada à $34,2 \mathrm{~cm}$ do foco. Os materiais homogêneos e heterogêneos utilizados foram: (i) PMMA (com espessuras de $1 \mathrm{~cm}$, $2 \mathrm{~cm}$ e $4 \mathrm{~cm}$ ), água e nylon (ambos com espessura de $2 \mathrm{~cm}$ ); e (ii) $5 \mathrm{~mm}$ de espessura de água envolto por PMMA (com espessura de 1,5 cm e 3,5 cm), totalizando amostras heterogêneas de $2 \mathrm{~cm}$ e $4 \mathrm{~cm}$ de espessura.

\subsubsection{Extração dos perfis radiais das imagens}

As imagens foram adquiridas por meio do detector plano CR. Por fim, as imagens geradas em formato DICOM são transportadas para o software Image J (image processing and analysis in Java, 2019), o qual são integradas em anéis concêntricos por meio do plugin radial profile disponibilizado pelo software (Fig. 3.11), extraindo os perfis radiais da imagem por espalhamento de raios $\mathrm{X}$, em valores de pixel. 


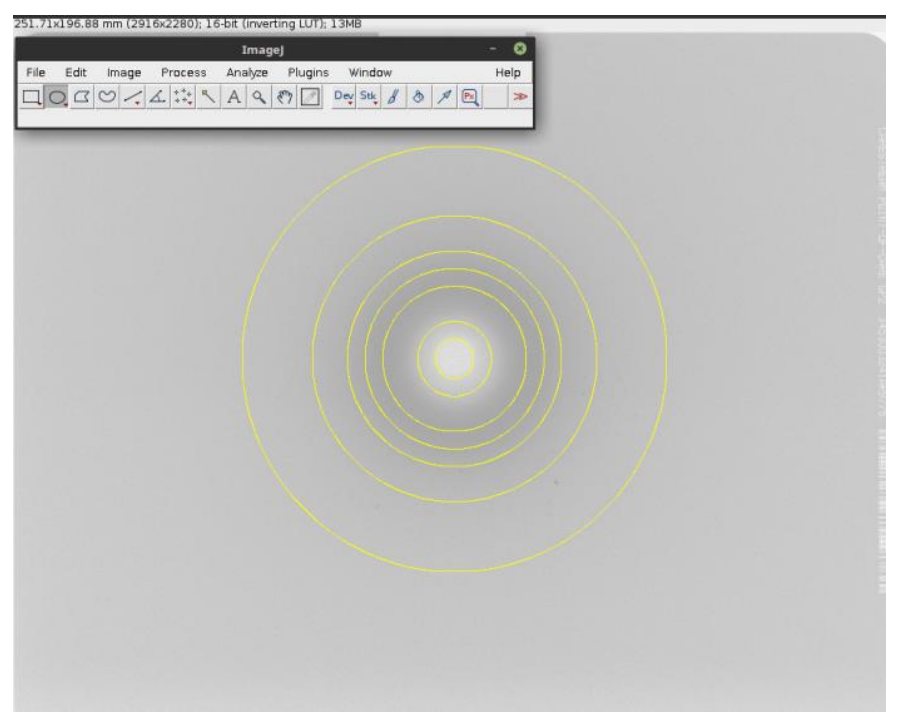

Fig. 3.11. Imagem de uma amostra de nylon $(2 \mathrm{~cm})$, irradiada por um espectro de $80 \mathrm{kV}$ (filtração adicional de $2,5 \mathrm{~mm}$ de $\mathrm{Al}$ ), em formato DICOM transportada para o software ImageJ, o qual é utilizado para a extração do perfil radial da imagem por meio do plugin radial profile.

\subsubsection{Sistema de detecção}

Alguns testes e medidas da performace do detector foi aplicado para caracterização do sistema de detecção, envolvendo análises da uniformidade, a qual avalia a performace e identifica variações ao longo do detector quando exposto aos raios $\mathrm{X}$; e a propriedade de transferência do sinal (STP, Signal Transfer Property), avaliando a resposta nas intensidades dos pixels de acordo com a variação em kerma no ar.

Os cassetes são primeiramente apagados antes de qualquer processo de análise, removendo sinais residuais de radiação de fundo ou outras fontes que possam alterar os valores de pixel. A uniformidade da imagem foi analisada após a irradiação de toda a área do detector localizado à $147 \mathrm{~cm}$ da fonte de raios $\mathrm{X}$, em 10,2 $\pm 0,2 \mu \mathrm{Gy}$. As medidas de kerma no ar foram adquiridas utilizando uma câmara de ionização TN34069 e um eletrômetro UNIDOS E T10010, ambos da PTW-Freiburg (Alemanha). Um único cassete foi exposto três vezes nas mesmas condições de medida. Para uma ROI (region of interest) em 80 \% da área da imagem os desvios padrões sob os valores de pixel (PV, pixel value) em todas as medidas foram $<20$, ou seja, dentro dos critérios de aceitação descritos em AAPM Report 93.

A figura 3.12 mostra a STP, a qual caracteriza o resultado de PV em resposta ao kerma no ar, em um ROI de 25 \% da área central da imagem. Após a exposição, cada imagem foi processada em um intervalo de 1 min. $\mathrm{O}$ mesmo procedimento foi repetido para os três espectros de raios $\mathrm{X}$ utilizados neste trabalho. 


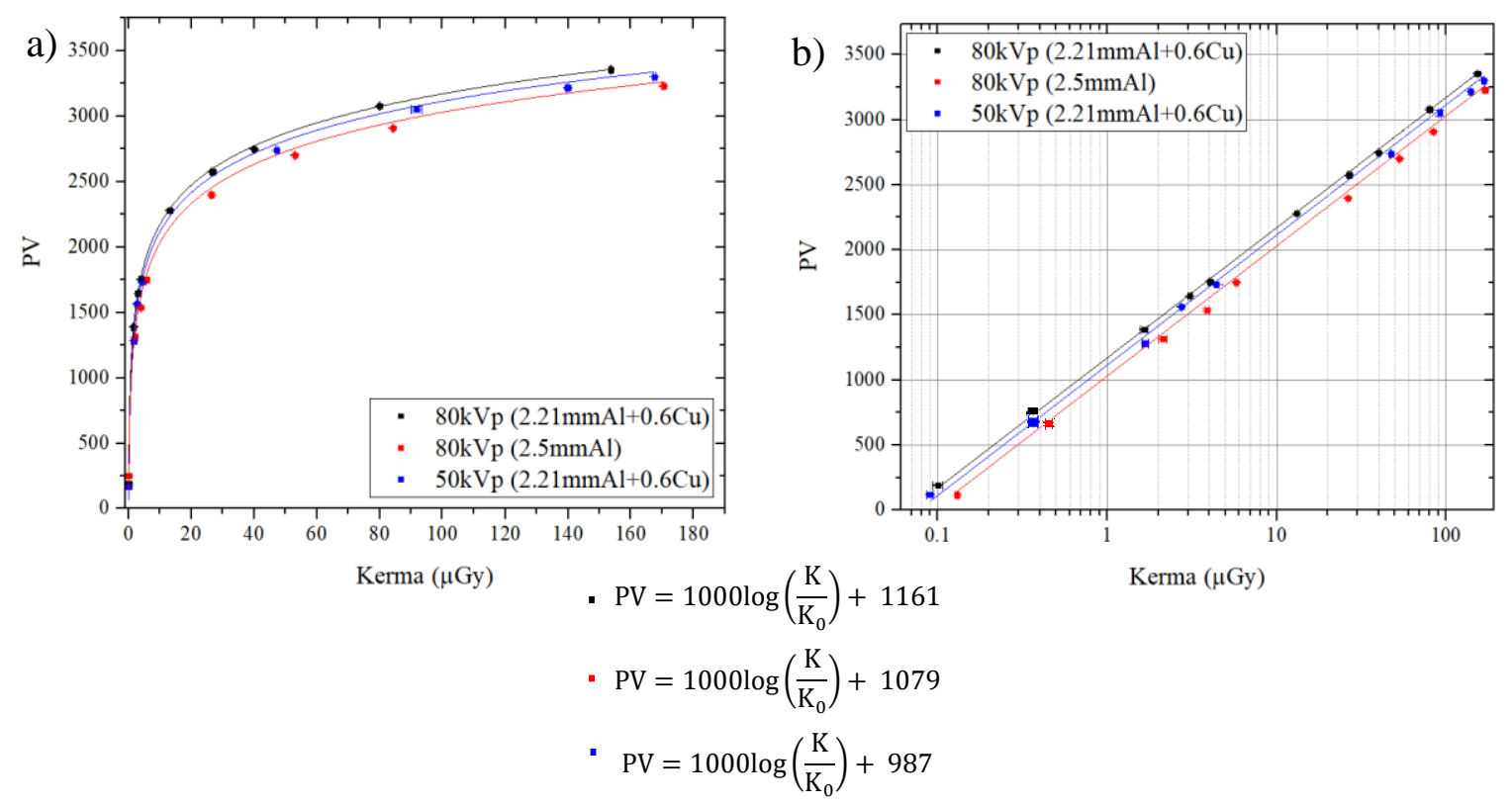

Fig. 3.12 Estudo da propriedade de transferência do sinal em diferentes qualidades do feixe.

Em a) as curvas ajustadas à uma função logarítimica e em b) inseridas em mono-log.

Similares aos resultados apresentados pela literatura (AAPM Report 116, 2009; MARSHALL, MACKENZIE e HONEY, 2011), as curvas de STP no sistema CR possuem uma resposta não linear com os valores de kerma, e neste trabalho, correspondem à uma função logarítimica (Fig. 3.12a). O coeficiente de correlação $\left(R^{2}\right)$ para os ajustes de todas as curvas foram de 0,999 , indicando que as distribuições dos pontos adquiridos experimentalmente são verossímeis às curvas ajustadas (Fig. 3.12b). As relações entre PV para o pós processamento das imagens em função do kerma no ar é dada por

$$
P V=1000 \log \left(\frac{K}{K_{0}}\right)+B,
$$

onde $K$ é o kerma no ar em $\mu G y / m A s, K_{0}$ uma constante de $1 \mu G y$ e B é o coeficiente que depende da qualidade do feixe incidente (AAPM Report 116, 2009).

Os perfis radiais da imagem foram linearizados por meio da curva STP em cada espectro de energia utilizado, e as imagens convertidas de PV para $K / K_{0}$ de pixel a pixel. A figura 3.13 exibe as diferenças nas formas dos perfis radiais de uma imagem expressa em PV e $K / K_{0}$ em função do raio do detector, mostrando o alargamento gerado em PV pela resposta logarítmica ao kerma no ar. 

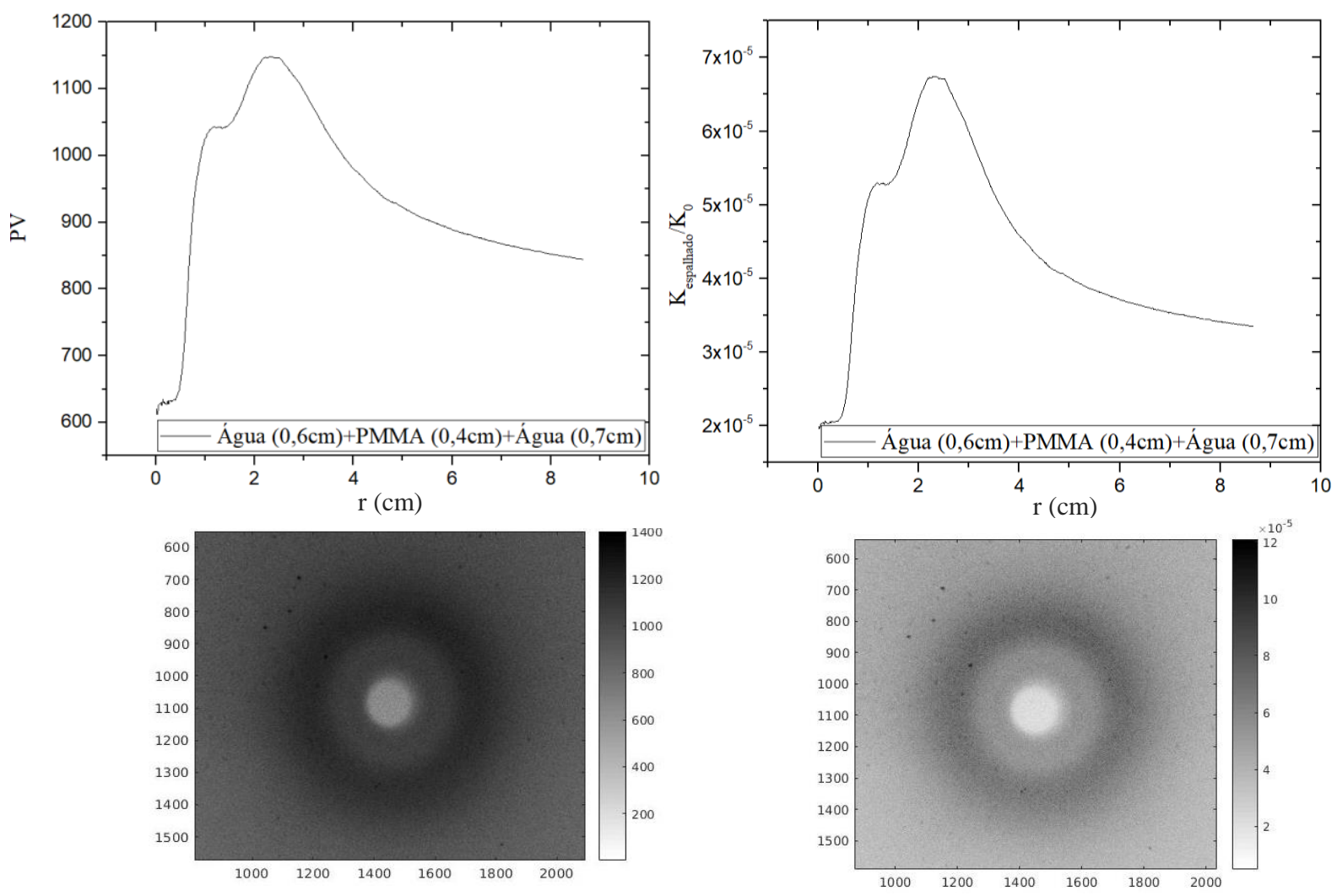

Fig. 3.13 Perfis radiais de imagens adquiridas experimentalmente pela componente espalhada dos raios $X$, expressos em PV e K/K , para uma amostra heterogênea de água $(0,6 \mathrm{~cm})+\mathrm{PMMA}$ $(0,4 \mathrm{~cm})+$ água $(0,7 \mathrm{~cm})$ irradiada por um feixe de raios $\mathrm{X}$ de $80 \mathrm{kV}$ (filtração adicional de 2,2 $\mathrm{mm}$ de $\mathrm{Al} \mathrm{e} 0,6 \mathrm{~mm}$ de $\mathrm{Cu}$ ).

\subsubsection{Correções das componentes de background do sistema}

A configuração experimental para a aquisição das imagens por espalhamento de raios $\mathrm{X}$ não é complexa, uma vez conhecida a influência dos parâmetros variáveis na imagem, por outro lado, para a análise da informação da amostra é necessário incluir as fontes de erro do sistema, levando em conta as componentes de fundo, ou background (POLETTI, GONÇALVES, et al., 2002). O background pode ser subtraído combinando uma série de medidas experimentais. Diante disto e embasado nos métodos descritos por Bradley et al. (1989) e Poletti et al. (2002), neste trabalho, foram realizadas quatro diferentes aquisições de imagem para a estimativa destas componentes (Fig. 3.14): (i) aquisição da imagem contendo informação da amostra, porta amostra e meio (ar e demais componentes do sistema) $\left(K_{A P M}\right)$; (ii) imagem contendo somente a informação anterior à amostra, adicionando no local da amostra uma espessura equivalente em chumbo $\left(K_{P b}\right)$; (iii) imagem contendo somente a informação do 
meio e do porta amostra $\left(K_{P M}\right)$; e (iv) imagem contendo somente a informação do meio $\left(K_{M}\right)$, retirando todas as outras componentes (amostra e porta amostra).

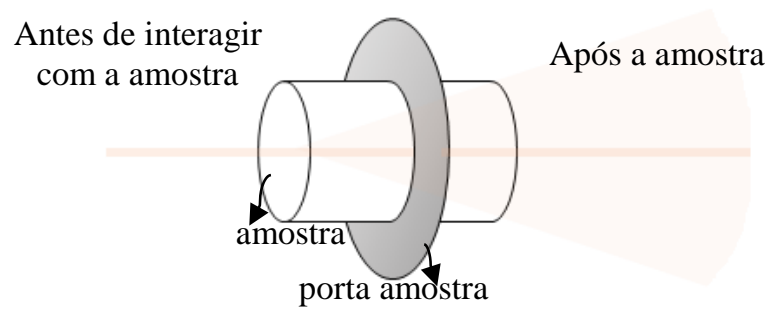

Fig. 3.14 Sistema de subtração das componentes de background para extrair informação somente da amostra.

Neste caso, a informação somente da componente espalhada pela amostra ( $\left.K_{\text {espalhado }}\right)$, deverá ser $K_{A P M}$ subtraído das demais informações contabilizadas no detector, resultando em

$$
K_{\text {espalhado }}=K_{A P M}-(\underbrace{\left(\frac{K_{P b} K_{M}}{K_{P M}}\right)}_{\begin{array}{c}
\text { Antes de interagir } \\
\text { com a amostra }
\end{array}}-\left[K_{P M}-K_{M}-\left(\frac{K_{P b} K_{M}}{K_{P M}}\right)-K_{P b}\right] T_{A}-\left[K_{M}-\left(\frac{K_{P b} K_{M}}{K_{P M}}\right)\right] T_{A} T_{P},
$$

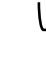

onde $T_{A}$ e $T_{P}$ são os fatores de transmissão da amostra e porta amostra, respectivamente. Ambos os espectros tiveram maiores contribuições do porta amostra comparados aos demais componentes do background. No entanto, os resultados variaram de acordo com o espectro de energia utilizado. A maior influência das correções no $K_{\text {espalhado }}$ foi observada no espectro de $80 \mathrm{kV}$ (filtração adicional de 2,2 $\mathrm{mm}$ de $\mathrm{Al} \mathrm{e} 0,6 \mathrm{~mm}$ de $\mathrm{Cu}$ ) para todas as amostras, em consequência de uma maior distribuição em energias mais altas do espectro comparadas aos demais espectros utilizados neste trabalho. No entanto, apresentam maior diferença relativa de 9,8 \% da medida de $K_{A P M}$ no pico principal do perfil radial da imagem utilizando a água, em decorrência de seu menor sinal de espalhamento comparado aos demais materiais (seção 4.2), de forma que a influência do porta amostra tenha um peso maior sobre a medida. Em resumo, as correções se mostraram importantes para extrair informação da componente de espalhamento da amostra, e o mesmo procedimento foi aplicado em todos perfis radiais da imagem.

\subsubsection{Distribuição radial do contraste (C) e razão contraste-ruído (CNR)}

Até o momento, o sistema experimental desenvolvido possibilitou o estudo de imagens por espalhamento de raios $\mathrm{X}$ contendo a informação de um material homogêneo ou heterogêneo. No entanto, o objetivo geral deste trabalho se designa ao estudo do potencial de 
imagens utilizando a componente espalhada dos raios $\mathrm{X}$ em aplicações médicas, ou seja, analisar se a técnica estudada é útil em contrastar objetos de materiais e composições similares, sob a aplicação de espectros de energia e detectores clínicos. Para tal finalidade, foram utilizadas amostras compostas por um material de fundo (PMMA), de $2 \mathrm{~cm}$ e $4 \mathrm{~cm}$, e outra com material heterogêneo, composta por $5 \mathrm{~mm}$ de espessura de água seguido por $1,5 \mathrm{~cm}$ e 3,5 $\mathrm{cm}$ do material de fundo, totalizando $2 \mathrm{~cm}$ e $4 \mathrm{~cm}$. A distribuição radial do contraste $(\mathrm{C})$ e $\mathrm{CNR}$ entre as duas amostras homogênea e heterogênea, de mesmas dimensões são dadas por

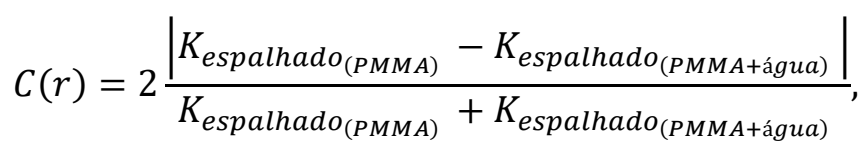

e

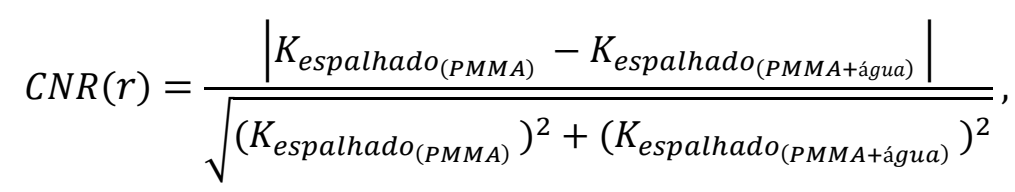

onde cada $K_{\text {espalhado }}$ é representado pela distribuição em todo o espectro para cada raio $r$ do detector. 


\section{Resultados e discussões}

Neste capítulo serão apresentados os resultados obtidos em âmbito de análise e estudo das influências dos parâmetros geométricos e físicos para a formação da imagem por espalhamento de raios X. A seção 4.1, apresenta a validação do método analítico desenvolvido neste trabalho e explora, por meio do algoritmo desenvolvido, a importância de cada parâmetro, mostrando as alterações nos perfis radiais da imagem analisando as variações nas posições dos picos principais e FWHM; e apresenta o borramento espacial gerado nos perfis radiais da imagem em decorrência das incertezas $(\Delta r)$ no raio do detector. A seção 4.2 apresenta os resultados e análises das imagens adquiridas experimentalmente para diferentes materiais equivalentes ao tecido, com o intuito de investigar o contraste e CNR das imagens utilizando a componente espalhada dos raios X e compará-las às imagens utilizando a componente primária, em amostras homogêneas e heterogêneas, para espectros de energia e detector clínicos. 


\subsection{Estudo dos parâmetros geométricos e físicos em imagens formadas pela componente espalhada dos raios $\mathbf{X}$ por meio de cálculos analíticos}

\subsubsection{Validação do algoritmo}

A figura 4.1 mostra a comparação entre os resultados obtidos neste trabalho por meio do algorítmo implementado com os valores obtidos por Poludniowsky et al. (2009) utilizando simulação Monte Carlo, o valor de $\Psi_{S}$ é a fluência em energia obtida em uma imagem por espalhamento em função do raio ao longo de um eixo central do detector, os dados referem-se à uma amostra de tecido adiposo com dimensões $0,5 \times 0,5 \times 0,5 \mathrm{~cm}^{3}$, considerando um feixe de $100 \mathrm{kV}$ retirado do software SpekCalc e distância da amostra ao detector de 53,6 cm.

O algorítmo foi adaptado para reproduzir as mesmas condições descritas no trabalho de referência, incluindo a base de dados experimentais apresentada por Tartari et al. (2002), no qual inclui a função de interferência no fator de forma, um importante parâmetro que modifica significantemente os resultados dos perfils radiais na imagem (seção 3.1.5).

Evidentemente, os resultados obtidos do algorítmo desenvolvido neste trabalho apresentaram uma boa concordância quando comparados ao proposto por Poludniowsky et al. (2009), de modo que foram observadas diferenças menores que 3\%. Estas comparações indicam que o algorítmo implementado para geração de imagens por espalhamento de primeira ordem

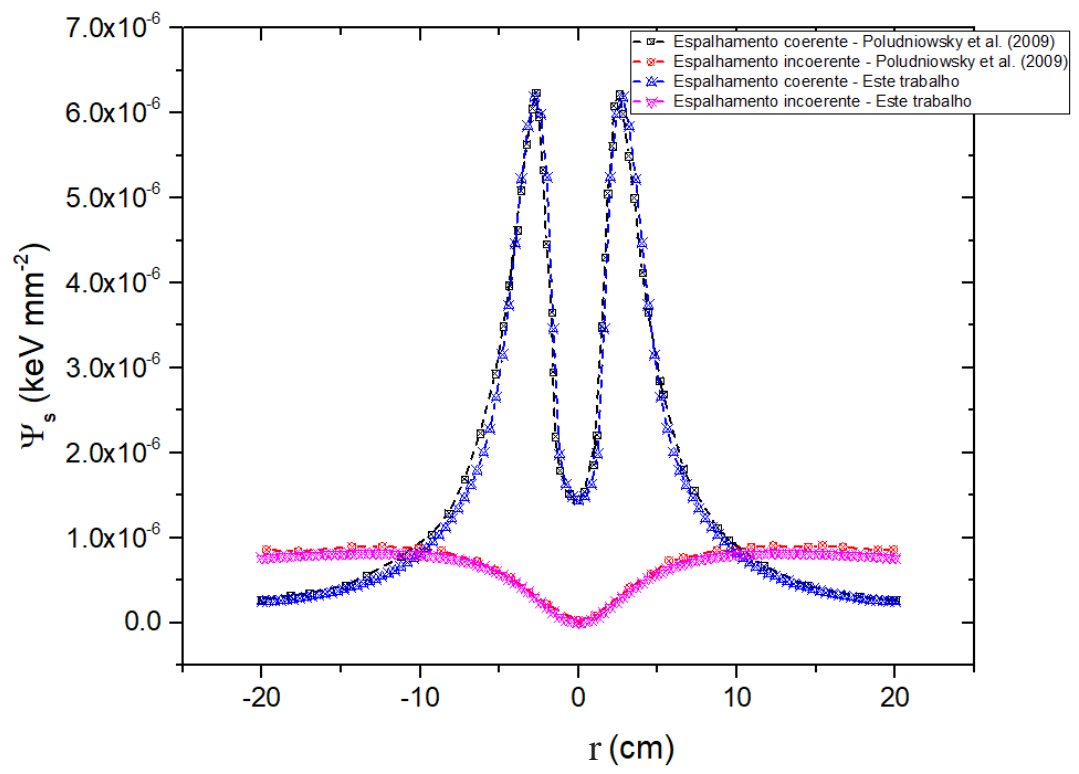

Fig. 4.1. Validação do algorítimo implementado. Comparação do perfil radial representado por $\Psi_{\boldsymbol{s}}\left(\mathrm{keV} \mathrm{mm}^{-2}\right)$ com valores obtidos por Poludniowsky et al. (2009), utilizando uma amostra de tecido adiposo com dimensões de $0,5 x 0,5 \times 0,5 \mathrm{~cm}^{3}$. 
possui resultados bastante similares aos propostos pela literatura em estudo, validando a sua utilização.

\subsubsection{Influência da abertura do colimador $(\phi)$ nos perfis radiais das imagens}

A figura em 4.2 apresenta as distribuições do kerma no ar espalhado sob o detector normalizado pelo número de fótons incidentes $\left(N_{0}\right)$ em função do raio ao longo de um eixo central em imagens de dimensões $10 \times 10 \mathrm{~cm}^{2}$. As imagens e os perfis radiais contêm informação de uma amostra de dimensões $2 \times 2 \times 2 \mathrm{~cm}^{3}$ de PMMA com centro localizado à $32 \mathrm{~cm}$ do detector, irradiada por um feixe de $40 \mathrm{keV}$, em diferentes aberturas do colimador de $6 \mathrm{~mm}, 4 \mathrm{~mm}$ e $1 \mathrm{~mm}$ de diâmetro.
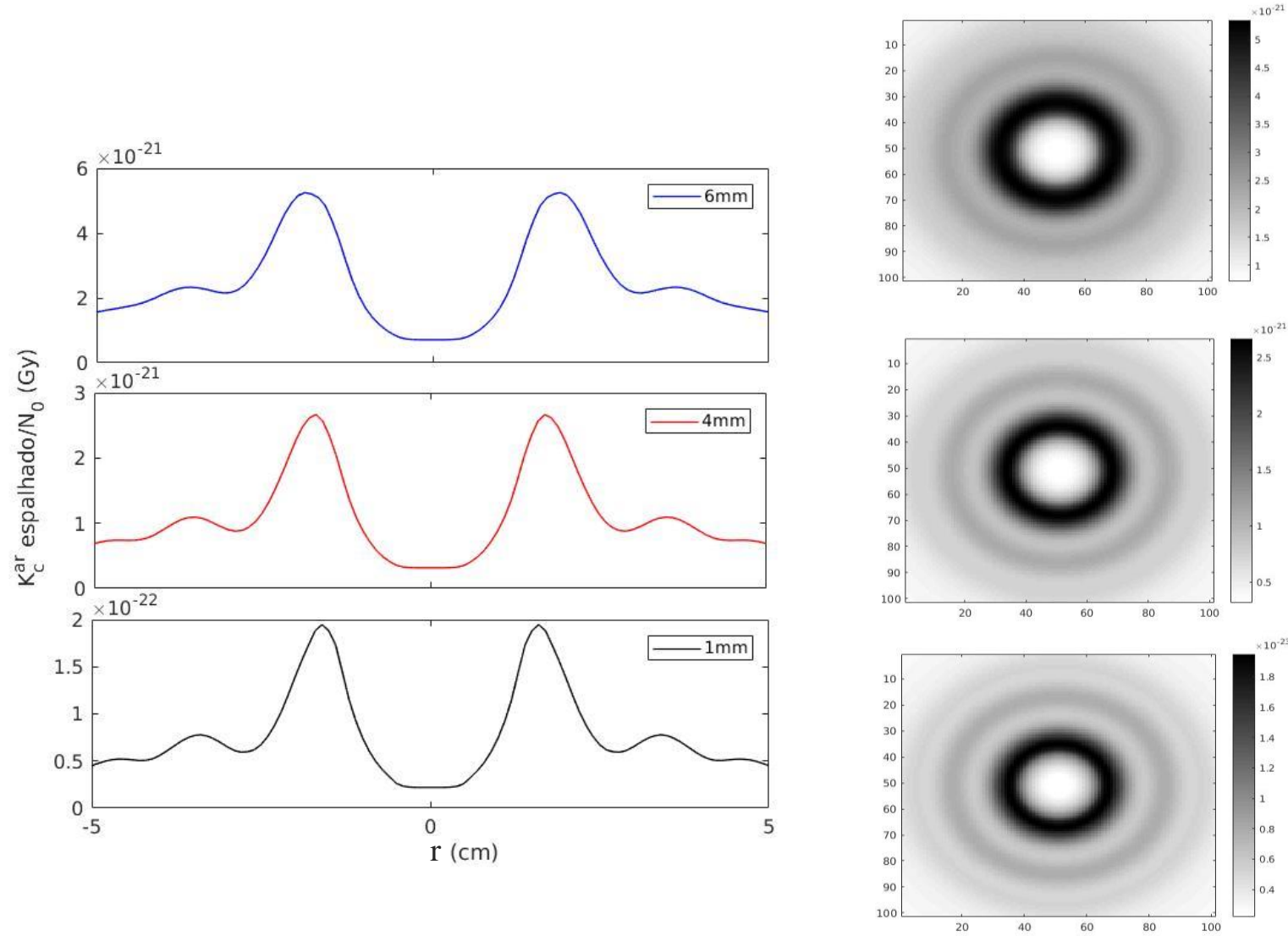

Fig. 4.2. Influência da abertura do colimador nas imagens e perfis radiais. a) Distribuição de $K_{c}^{a r}{ }_{\text {espalhado }} / N_{0}$ em função da raio ao longo de um eixo central do detector, de uma imagem $18 \times 18 \mathrm{~cm}^{2}$ para diferentes aberturas do colimador circular de $6 \mathrm{~mm}$, $4 \mathrm{~mm}$ e $1 \mathrm{~mm}$ de diâmetro em uma amostra de dimensões de $2 \times 2 \times 2 \mathrm{~cm}^{3}$ composta por PMMA e em b) suas respectivas imagens planares. 
Comparados ao perfil radial intrínseco (seção 3.1.6; Fig. 3.9), os picos principais foram deslocados na direção contrária ao eixo central conforme o aumento da abertura do colimador, em $2 \%, 7 \%$ e $19 \%$ para o colimador de $1 \mathrm{~mm}, 4 \mathrm{~mm}$ e $6 \mathrm{~mm}$, respectivamente; as FWHM aumentaram em $62,7 \%$ para a abertura de $1 \mathrm{~mm}$, enquanto que para $6 \mathrm{~mm}$ estas diferenças geradas na FWHM, aumentam em 95,2 \% relativa à $1 \mathrm{~mm}$. Estas diferenças nas posições dos picos principais e FWHM são causadas por um aumento no volume irradiado de acordo com o aumento da abertura do colimador, consequentemente, em um elemento de área do detector são vistos diversos ângulos provenientes de diferentes locais da amostra, os quais definem o intervalo de ângulos o qual correspondem aos valores da seção de choque diferencial de espalhamento por ângulo sólido, de modo que a resultante em um pixel do detector será o somatório de todas estas contribuições em diferentes ângulos de espalhamento. Estas deformações nas imagens e nos perfis radiais causadas por estes comportamentos, denominase borramento angular (WESTEMORE, FENSTER e CUNNINGHAM, 1996).

A figura 4.3 apresentam as incertezas $\Delta r$ ao longo do raio do detector em decorrência do borramento angular, variando a abertura do colimador $\phi$, os quais são resultados da soma

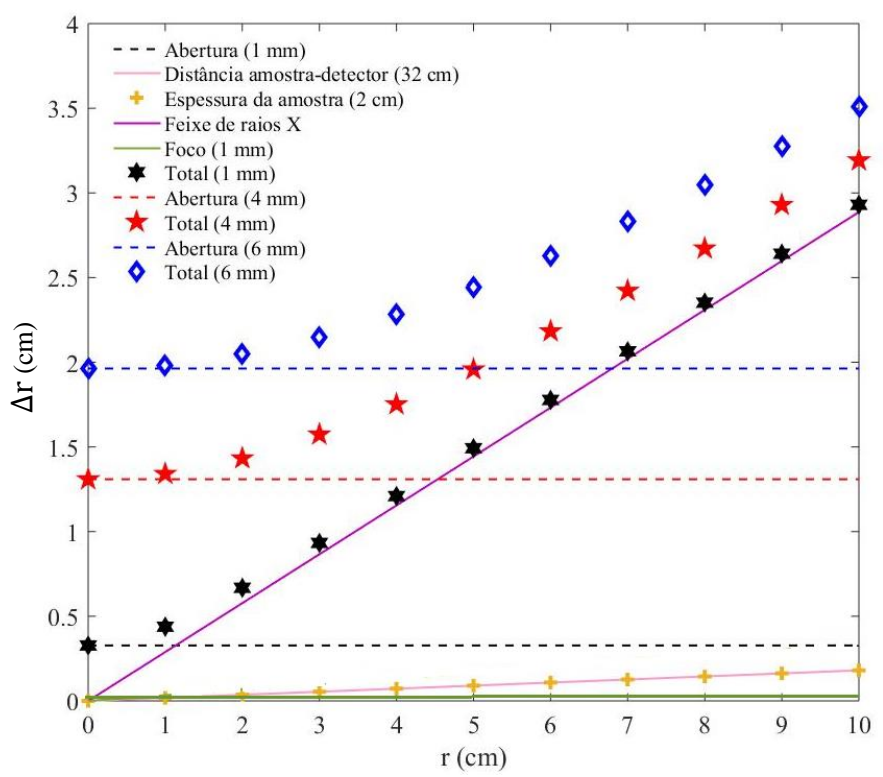

Fig. 4.3. Resolução espacial ao longo do raio do detector, variando a abertura do colimador $(1 \mathrm{~mm}-\star, 4 \mathrm{~mm}-\star$ e $6 \mathrm{~mm}-\diamond)$, para um feixe de $40 \mathrm{keV}$, espessura de $2 \mathrm{~cm}$ e distância da amostra ao detector de $32 \mathrm{~cm}$.

dos quadrados de todos os $\Delta r$ (equação (3.15)) dos demais parâmetros fixos do sistema, sendo que a curva $*$ apresenta os resultados da soma dos quadrados das componentes do sistema utilizando uma abertura de $1 \mathrm{~mm}$; $\star$ utilizando uma abertura de $4 \mathrm{~mm}$ e $\diamond$ utilizando uma 
abertura de $6 \mathrm{~mm}$. Estas curvas foram utilizadas para estimar as variações máximas nas posições dos picos principais e FWHM quando a abertura do colimador é alterada, encontrando as incertezas máximas correspondentes $(\Delta r / 2)$ geradas nas posições $(r)$ do pico principal e FWHM do perfil radial intrínseco, as quais seriam diferentes quando considerada, por exemplo, uma distribuição retangular, como proposto por Beath et al. (2009). Em relação à posição do pico principal do perfil radial intrínseco, $\phi$ gerou uma variação máxima em $r$ de 17,9\% em $1 \mathrm{~mm}$, 43,8 \% em $4 \mathrm{~mm}$ e 63,5 \% em $6 \mathrm{~mm}$, gerando um aumento de até 2,5 vezes em $6 \mathrm{~mm}$ comparado à $1 \mathrm{~mm}$. A FWHM pode sofrer variações em até 248 \% em $6 \mathrm{~mm}$ quando comparada à abertura de $1 \mathrm{~mm}$. Devido às aproximações consideradas na equação (3.15), por levar em conta somente uma variação máxima (nos cálculos da seção (3.1.6)), os resultados para a análise do borramento espacial gerado nos perfis radiais da imagem pelas incertezas $(\Delta r)$ no raio do detector são superestimados e resultam em valores maiores comparados aos obtidos pelo algoritmo, o qual leva em conta uma distribuição em cada pixel do detector dependente de todos os parâmetros geométricos e físicos do sistema.

Apesar dos resultados mostrarem valores de $K_{c}^{\text {ar }}$ espalhado $/ N_{0}$ maiores nos perfis radiais da imagem por espalhamento para maiores $\phi$ testados, evidentemente há uma perda na resolução espacial dos perfis radiais da imagem. Deste modo, todos os resultados seguintes das imagens e dos perfis radiais formados pela componente espalhada dos raios $\mathrm{X}$ foram adquiridos utilizando uma abertura de $1 \mathrm{~mm}$. 


\subsubsection{Influência da distância da amostra ao detector nos perfis radiais das imagens}

A figura em 4.4 apresenta as distribuições do kerma no ar espalhado sob o detector normalizado pelo número de fótons incidentes $\left(N_{0}\right)$ em função do raio ao longo de um eixo central em imagens de dimensões $10 \times 10 \mathrm{~cm}^{2}$. As imagens e os perfis radiais contêm informação
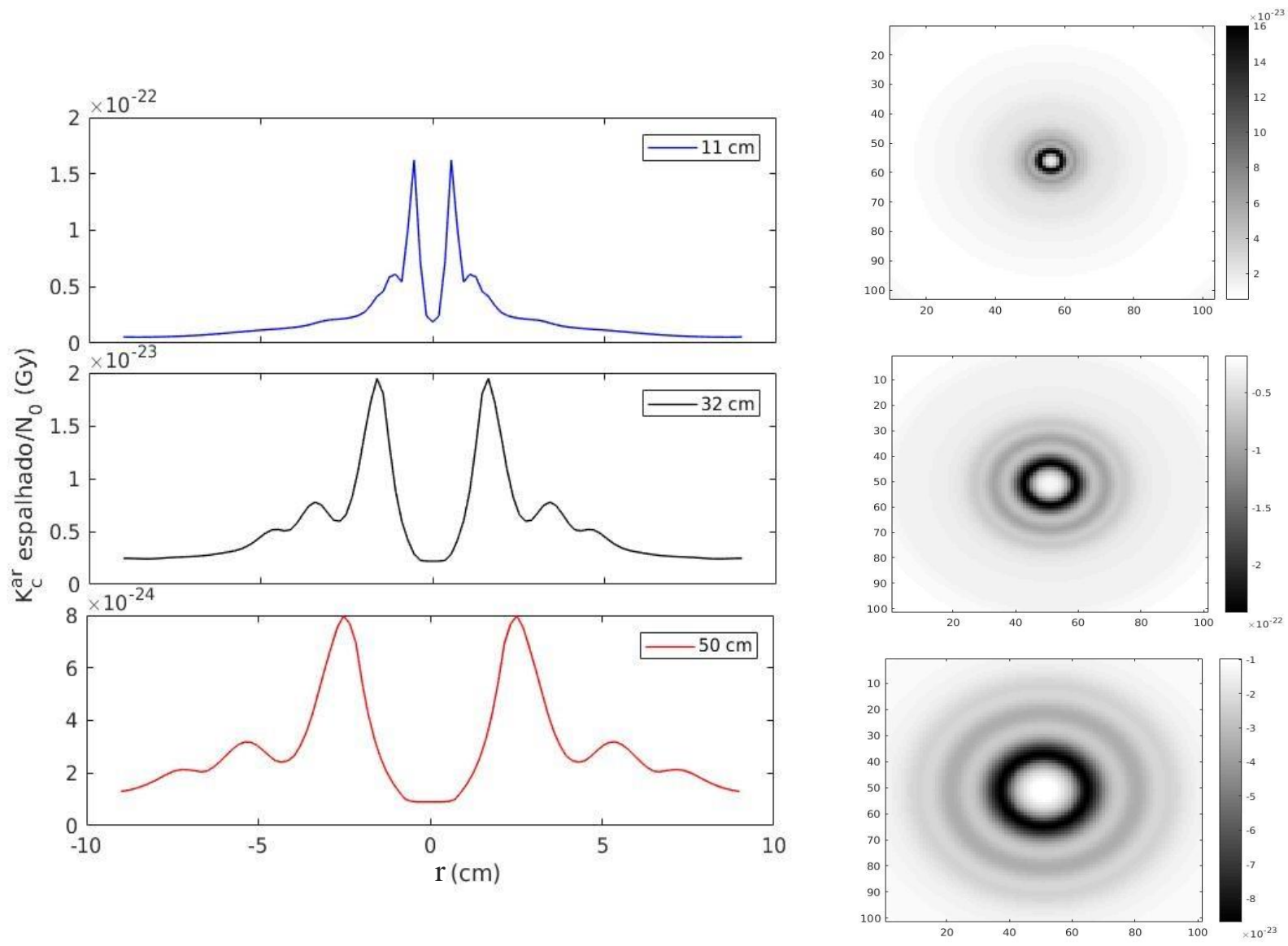

Fig. 4.4. Influência da distância do centro da amostra ao detector. a) Distribuição de $K_{c}^{a r}{ }_{\text {espalhado }} / N_{0}$ em função do raio ao longo de um eixo central do detector, de uma imagem $18 \times 18 \mathrm{~cm}^{2}$, em distâncias de 11,32 e $50 \mathrm{~cm}$ do centro da amostra de PMMA $\left(2 \times 2 \times 2 \mathrm{~cm}^{3}\right)$ ao plano do detector. b) As imagens planares referentes aos perfis radiais em a).

de uma amostra de dimensões $2 \times 2 \times 2 \mathrm{~cm}^{3}$ de PMMA com centro localizado à $11 \mathrm{~cm}, 32 \mathrm{~cm}$ e $50 \mathrm{~cm}$ de distância do detector plano, irradiada por um feixe de $40 \mathrm{keV}$. 
As posições dos picos principais foram de $0,6 \mathrm{~cm}$ em $11 \mathrm{~cm}, 1,6 \mathrm{~cm}$ em $32 \mathrm{~cm}$ e $2,5 \mathrm{~cm}$ em $50 \mathrm{~cm}$, mostrando um deslocamento em direção ao feixe primário conforme a proximidade da amostra ao detector. Em relação aos picos principais dos perfis radiais intrínsecos (Fig. 4.5a), as diferenças encontradas foram de 5,4\% em $11 \mathrm{~cm}, 1,8 \% \mathrm{em} 32 \mathrm{~cm}$ e 1,5\% em $50 \mathrm{~cm}$; as FWHM aumentaram em 84,1\% em $11 \mathrm{~cm}$, enquanto que para $50 \mathrm{~cm}$ estas diferenças geradas na FWHM, diminuíram em 10,7\% relativa à $20 \mathrm{~cm}$. Estes comportamentos observados nas variações dos picos principais e FWHM são provocados pelas diferenças no ângulo sólido de

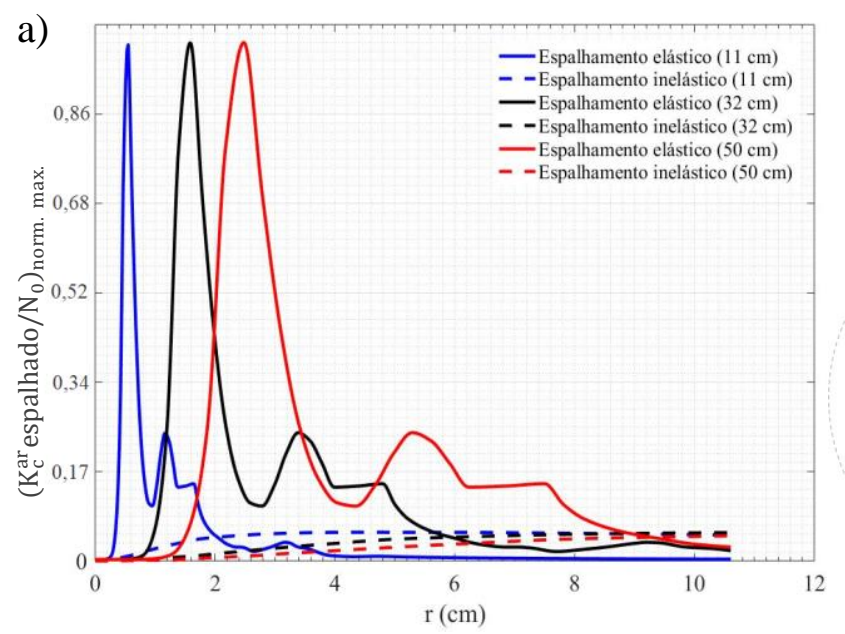

b)

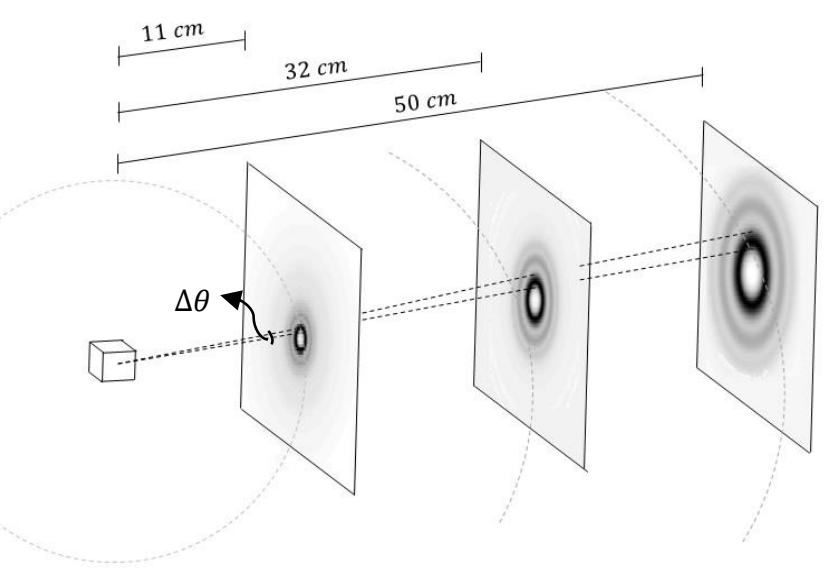

Fig. 4.5. Influência da distância do centro da amostra ao detector nas imagens. a) Variações nos perfis radiais intrínsecos de $2 \times 2 \times 2 \mathrm{~cm}^{3}$ de PMMA, conforme o aumento da distância do centro da amostra ao detector, utilizando um feixe de $40 \mathrm{keV}$. b) Ilustração das diferenças encontradas no plano da imagem e os deslocamentos causados nos picos de maior intensidade e FWHM, para um mesmo intervalo $\Delta \theta$ de espalhamento em distâncias do centro da amostra ao detector de $11 \mathrm{~cm}$, $32 \mathrm{~cm}$ e $50 \mathrm{~cm}$.

acordo com a variação na distância da amostra ao detector, associados também às dimensões dos elementos de área ou pixels do detector. A figura 4.5b ilustra de maneira mais clara as mudanças ocorridas nas imagens utilizando a componente espalhada dos raios $\mathrm{X}$ em consequência do ângulo sólido. Neste caso, o centro espalhador pode ser interpretado aproximadamente como uma fonte que emite radiação isotrópicamente, de modo que para um mesmo intervalo $\Delta \theta$ uma maior área é atingida no detector conforme o aumento da distância, resultando em um deslocamento dos picos principais e um aumento na FWHM, consequentemente, aumentando o raio do anel de maior intensidade.

Os valores de $K_{c}^{a r}$ espalhado $/ N_{0}$ dos picos principais, na Fig 4.4, diminuem aproximadamente com a lei do inverso do quadrado da distância. Esta aproximação é válida 
para as distâncias estudadas, possuindo diferenças relativas de apenas 7,8 \% em $11 \mathrm{~cm}, 2,9$ \% em $30 \mathrm{~cm}$ e $0,1 \%$ em $50 \mathrm{~cm}$.

A figura 4.6a mostra as incertezas máximas $\Delta r$ ao longo do raio do detector devido às variações na distância do centro da amostra ao eixo central do detector. Em relação aos perfis

a)

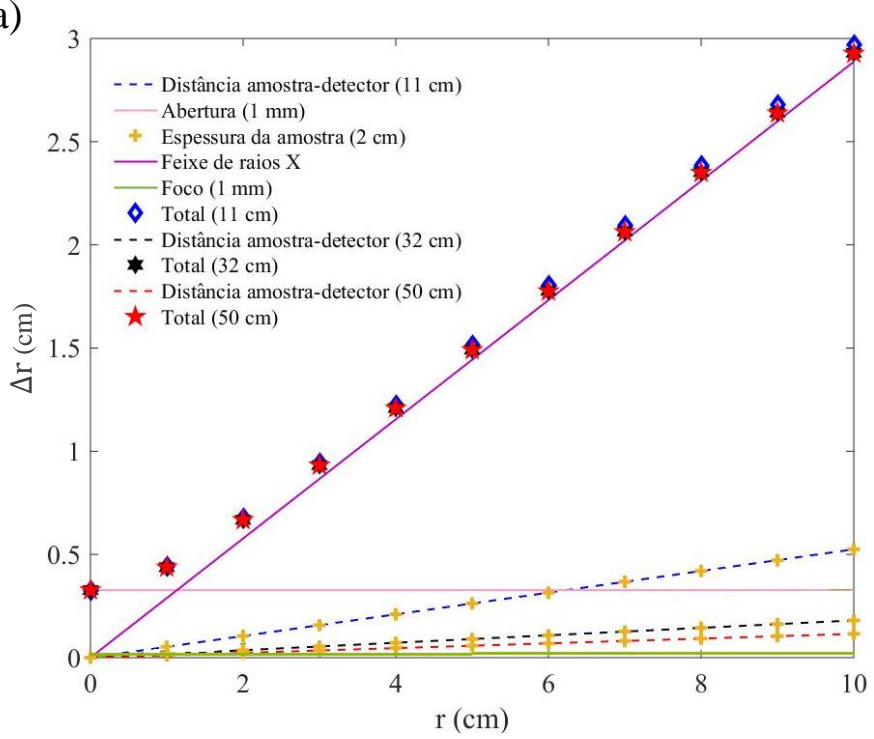

b)

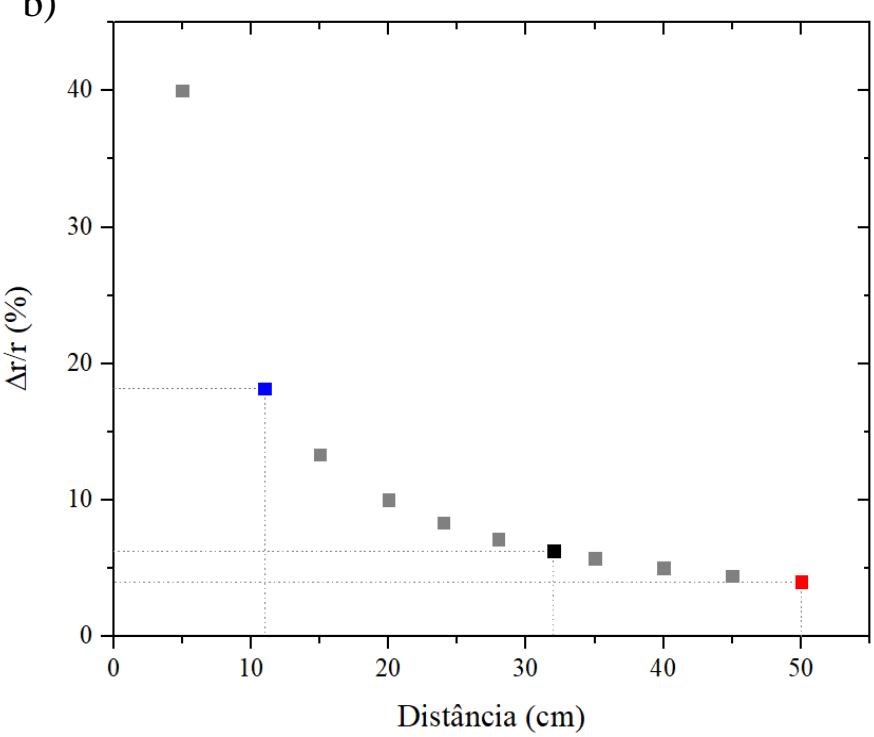

Fig. 4.6. a) Resolução espacial ao longo do raio do detector, variando a distância da amostra ao detector $(11 \mathrm{~cm}-\diamond, 32 \mathrm{~cm}-\star$ e $50 \mathrm{~cm}-\star)$, para um feixe de $40 \mathrm{keV}$ e abertura de $1 \mathrm{~mm}$, e b) o comportamento da resolução espacial relativa conforme a variação da distância entre o centro da amostra ao eixo central do detector.

radiais intrínsecos, os resultados apresentaram variações máximas nas posições $r$ dos picos principais e FWHM de 35,4 \% e $177 \%$ em $11 \mathrm{~cm} ; 17,9 \%$ e 86,6 \% em $32 \mathrm{~cm}$; e $16 \%$ e 81,6 \% em $50 \mathrm{~cm}$, mostrando uma diminuição nas variações máximas das posições $r$ dos picos principais e FWHM em 2,2 vezes em $50 \mathrm{~cm}$ comparado à $11 \mathrm{~cm}$. As curvas resultantes da soma dos quadrados de todos $\Delta r$ dos parâmetros (equação (3.15)), representadas pelos símbolos ( $\diamond$ referente à $11 \mathrm{~cm}, *$ referente à $32 \mathrm{~cm}$ e $\star$ referente à $50 \mathrm{~cm}$ ), apresentaram diferenças máximas de apenas $1,1 \%$ e $0,1 \%$ em $11 \mathrm{~cm}$ e $50 \mathrm{~cm}$, comparadas à $32 \mathrm{~cm}$. No entanto, as grandes variações nos picos principais e FWHM em relação aos perfis radiais intrínsecos são provocadas por $\Delta r$ relativas ao raio, conforme alteram-se as distâncias do centro da amostra ao detector, como observado na Fig 4.6b. Em uma determinada distância, como por exemplo, em $11 \mathrm{~cm}$ um $\Delta \theta$ é subdividido conforme as dimensões dos elementos de área ou pixels do detector, as quais permanecem fixas. De acordo com o aumento na distância (por exemplo, em $50 \mathrm{~cm}$ ), neste mesmo $\Delta \theta$, uma maior área total é atingida no detector, consequentemente, uma maior 
quantidade de pixels é contida neste intervalo comparada à distância de $11 \mathrm{~cm}$, fazendo com que aumente as subdivisões de $\Delta \theta$, causando uma diminuição de 4,5 vezes na incerteza $\Delta r$ relativa à $r$ em $50 \mathrm{~cm}$ comparada à $11 \mathrm{~cm}$. A incerteza $\Delta r$ relativa ao raio em $32 \mathrm{~cm}$ resultou em um valor 3 vezes menor comparado à $11 \mathrm{~cm}$.

Apesar dos resultados positivos na resolução espacial da imagem por espalhamento de raios X em $50 \mathrm{~cm}$, foi visto que o $K_{c}^{a r}$ espalhado $/ N_{0}$ da imagem decresce com aproximadamente o inverso do quadrado da distância, ou seja, o $K_{c}^{\text {ar }}$ espalhado $/ N_{0}$ em $32 \mathrm{~cm}$ resulta em uma intensidade de aproximadamente 2 vezes maior comparada à $50 \mathrm{~cm}$, e as diferenças nas incertezas $\Delta r$ relativa ao raio em $50 \mathrm{~cm}$ e $32 \mathrm{~cm}$ foram apenas $2,2 \%$.

Portanto, devido aos resultados encontrados nas resoluções espaciais e intensidades das imagens por espalhamento de raios $X$ de acordo com a variação na distância do centro da amostra ao detector, os resultados das seções a seguir foram realizados utilizando uma distância de $32 \mathrm{~cm}$ do centro da amostra ao detector.

\subsubsection{Influência da espessura das amostras nos perfis radiais da imagem}

A figura 4.7 apresenta as distribuições do kerma no ar espalhado sob o detector normalizado pelo número de fótons incidentes $\left(N_{0}\right)$ sob o máximo, em função da posição ao longo de um eixo central em uma imagem $18 \times 18 \mathrm{~cm}^{2}$. Os perfis radiais são adquiridos em
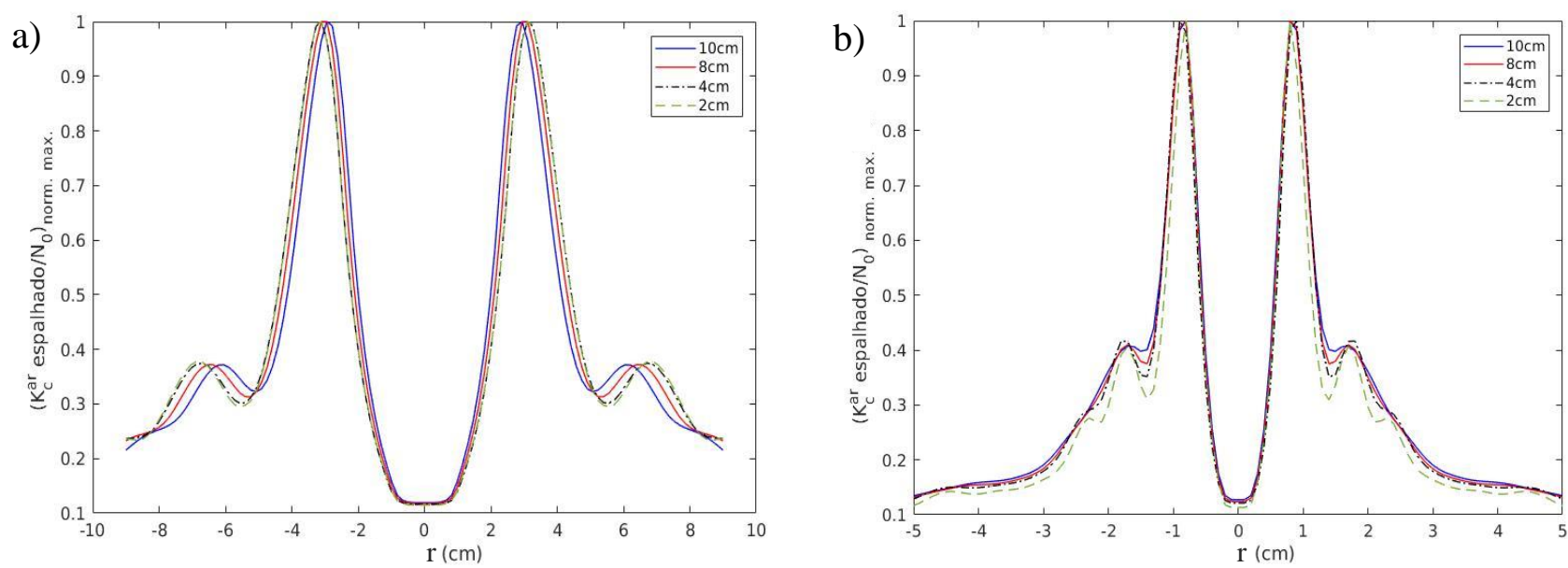

Fig. 4.7. Influência da espessura das amostras compostas por PMMA, irradiadas por um feixe monoenergético de a) $20 \mathrm{keV}$ e b) $80 \mathrm{keV}$. A abertura do colimador foi de $1 \mathrm{~mm}$ e as amostras estão distanciadas a $32 \mathrm{~cm}$ do detector. 
diferentes espessuras de uma amostra composta por PMMA, para um feixe de $20 \mathrm{keV}$ e $80 \mathrm{keV}$ (figura 4.7a e b, respectivamente).

O pico principal do PMMA em $20 \mathrm{keV}$ deslocou-se levemente em direção ao feixe incidente conforme aumento da espessura, com diferenças relativas de apenas 5,3\%, para a espessura de $2 \mathrm{~cm}$ comparada à de $10 \mathrm{~cm}$, e se encontram em torno de $3 \mathrm{~cm}$ no raio do detector. Em $80 \mathrm{keV}$, não apresentaram diferenças significativas, e os picos principais estão localizados em aproximadamente $0,8 \mathrm{~cm}$ do feixe incidente, contudo, a FWHM aumentou cerca de 35,7 \% ao modificar a espessura de $2 \mathrm{~cm}$ para $10 \mathrm{~cm}$.

Em relação ao perfil radial intrínseco (Fig. 4.8), os picos principais apresentaram uma

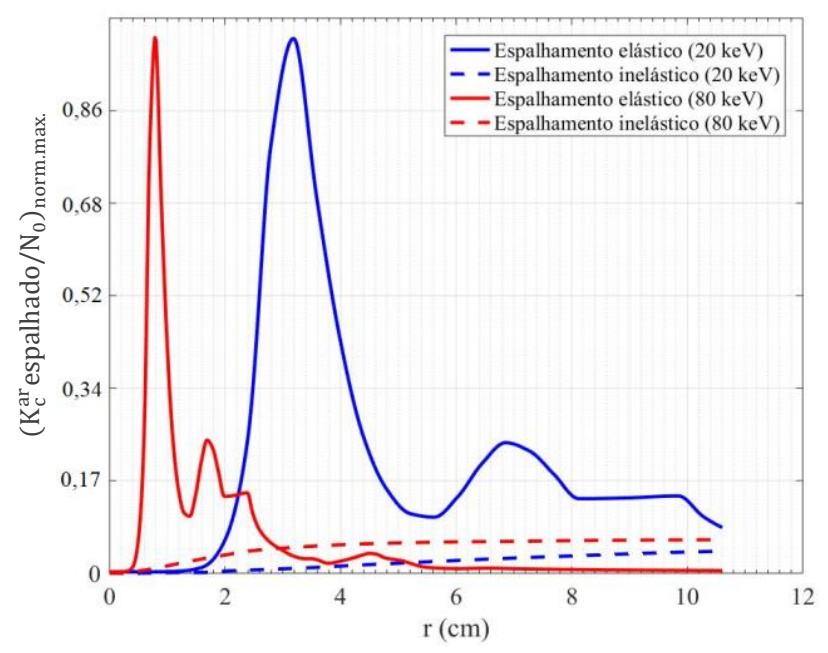

Fig. 4.8 Variações nos perfis radiais intrínsecos de material PMMA, conforme variação na energia de $20 \mathrm{keV}$ e $80 \mathrm{keV}$. Os perfis radiais intrínsecos normalizados são idênticos para todas as espessuras.

variação de 2,2 \% em $2 \mathrm{~cm}$ e 7,3\% em $10 \mathrm{~cm}$, para o feixe monoenergético de $20 \mathrm{keV}$; e uma variação de 2,56\% em $2 \mathrm{~cm}$ e $10 \mathrm{~cm}$, para o feixe monoenergético de $80 \mathrm{keV}$. As FWHM possuem diferenças de $11 \%$ entre as espessuras de $2 \mathrm{~cm}$ e $10 \mathrm{~cm}$ em $20 \mathrm{keV}$, e diferenças de $41,9 \%$ entre as espessuras de $2 \mathrm{~cm}$ e $10 \mathrm{~cm}$ em $80 \mathrm{keV}$, em relação à FWHM intrínseco. Em uma determinada espessura uma faixa de ângulo é selecionada por um elemento de área no detector, definida pelos extremos da amostra com os extremos do elemento de área. Conforme o aumento da espessura da amostra, uma maior faixa de ângulo é selecionada, consequentemente, uma maior variação na seção de choque diferencial de espalhamento é vista pelo detector. Entretanto, as deformações nos perfis radiais causadas pelo efeito do borramento angular, aparamentemente, possui uma forte dependência com a energia utilizada. A dependência destas deformações com a energia está diretamente ligada à faixa de momento 

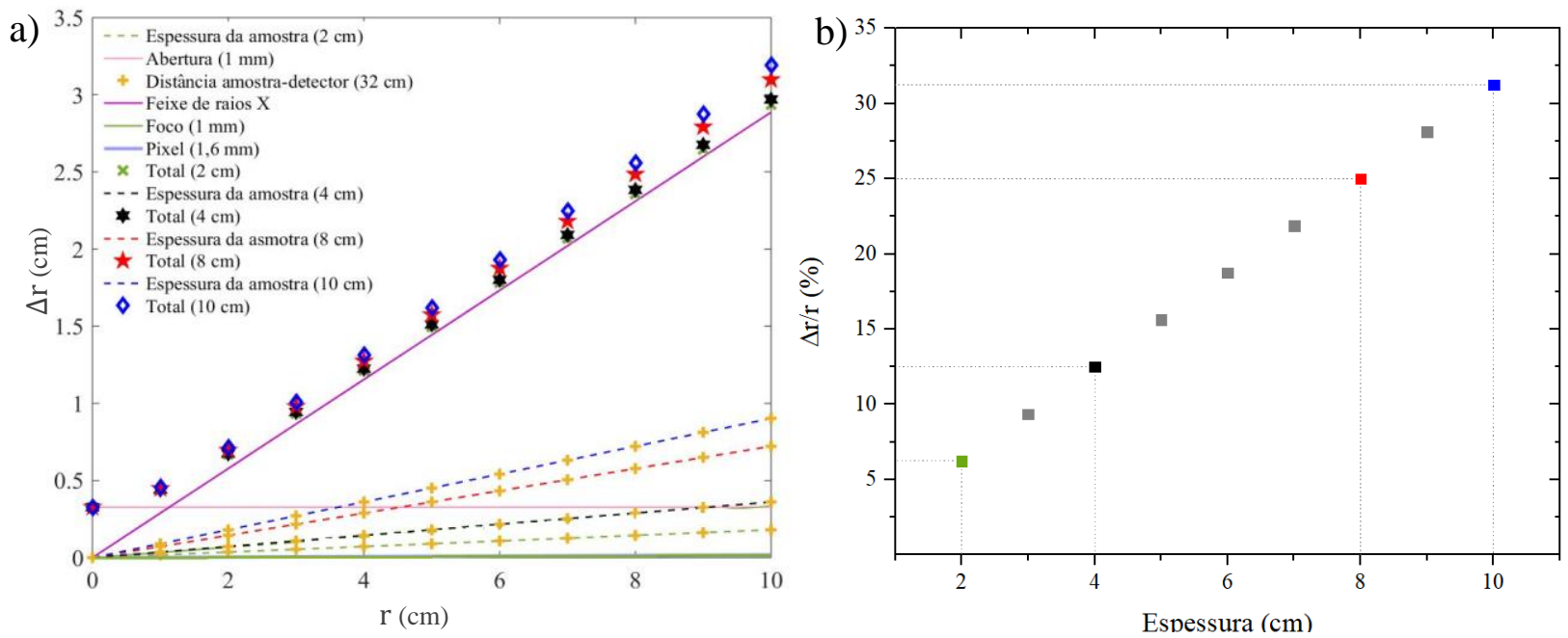

Fig. 4.9. a) Resolução espacial ao longo de todo raio do detector, variando a espessura da amostra $(2 \mathrm{~cm}-\mathbf{X}, 4 \mathrm{~cm}-\star, 8 \mathrm{~cm}-\star$ e $10 \mathrm{~cm}-\diamond)$ e b) a resolução espacial relativa em função da espessura, utilizando uma distância da amostra ao detector de $32 \mathrm{~cm}$.

transferido, a qual seleciona o intervalo na seção de choque diferencial de espalhamento por ângulos sólido, uma vez que esta não depende somente do ângulo, mas também da energia. Estes fatos explicam as diferenças encontradas nos perfis radiais da imagem de acordo com o aumento na espessura e energia.

A figura 4.9a apresenta o comportamento da incerteza $\Delta r$ ao longo de todo o raio do detector, variando as espessuras de PMMA. Em relação aos perfis radiais intrínsecos, os resultados apresentaram incertezas $\Delta r$ nos picos principais e FWHM de 15,4 \% e 76,33 \% em $2 \mathrm{~cm}$, e $16,6 \%$ e 82,4 \% em $10 \mathrm{~cm}$, para $20 \mathrm{keV} ; 32 \%$ e 133,5\% em $2 \mathrm{~cm}$, e 33,3\% e 137,1\% em $10 \mathrm{~cm}$, para $80 \mathrm{keV}$, mostrando um $\Delta r$ dos picos principais e FWHM maiores em $80 \mathrm{keV}$, em decorrência de um aumento na faixa de momento transferido, gerando maiores incertezas (seção 4.1.5).

A figura $4.9 \mathrm{~b}$ mostra o comportamento de $\Delta r$ relativas ao raio conforme alteram-se as espessuras da amostra. Os resultados mostraram que a utilização de uma espessura de $10 \mathrm{~cm}$ resulta em uma incerteza $\Delta r$ relativa de 5 vezes maior comparada à espessura de $2 \mathrm{~cm}$.

$\mathrm{Na}$ faixa de espessura testada, os resultados e análises apresentados sobre a influência que a espessura exerce sob perfis radiais das imagens por espalhamento de raios $\mathrm{X}$ mostraram que a resolução espacial é significantemente prejudicada conforme o aumento da espessura. À nível de estudo, os resultados mostrados a seguir foram realizados utilizando uma espessura de $2 \mathrm{~cm}$. 


\subsubsection{Análise da influência do espectro incidente nos perfis radiais da imagem}

\section{i. Feixes monoenergéticos}

A figura 4.10 apresenta as distribuições do kerma no ar espalhado sob o detector normalizado pelo número de fótons incidentes $\left(N_{0}\right)$ em função da posição ao longo de um eixo central em uma imagem $18 \times 18 \mathrm{~cm}^{2}$. Os perfis radiais são adquiridos em diferentes energias do feixe incidente de $30 \mathrm{keV}, 40 \mathrm{keV}$ e $50 \mathrm{keV}$ utilizando amostras compostas por PMMA e água (figura 4.10a e b, respectivamente).
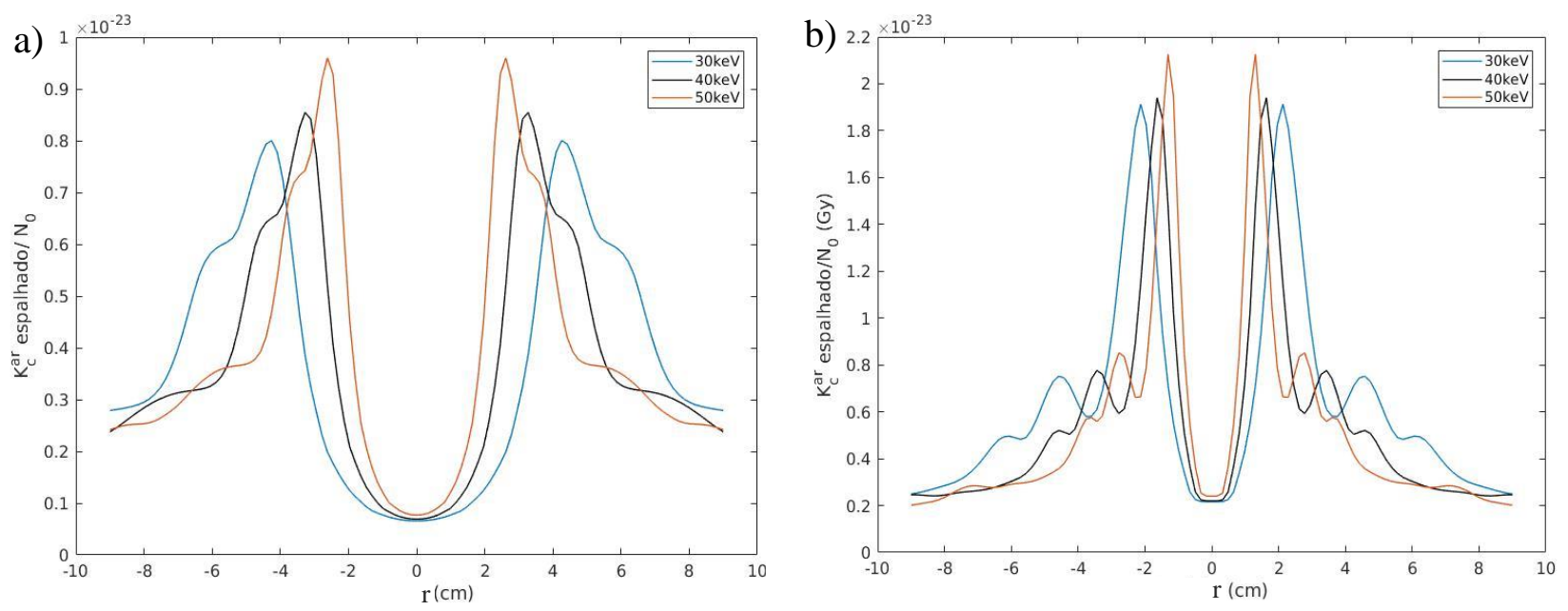

Fig. 4.10. Distribuição de $K_{c}^{a r}$ espalhado $/ N_{0}$ em função da posição ao longo de um eixo central do detector, de uma imagem $18 \times 18 \mathrm{~cm}^{2}$, em feixes monoenergéticos de 30,40 e $50 \mathrm{keV}$, para a) água e b) PMMA. A abertura do colimador foi de $1 \mathrm{~mm}$ e as amostras, ambas de $2 \times 2 \times 2 \mathrm{~cm}^{3}$, estão distanciadas a $32 \mathrm{~cm}$ do detector.

Os perfis radiais da imagem apresentam picos principais em 4,3 $\mathrm{cm}(30 \mathrm{keV})$, $3,2 \mathrm{~cm}(40 \mathrm{keV})$ e 2,5 $\mathrm{cm}(50 \mathrm{keV})$ para a água e em 2,1 cm $(30 \mathrm{keV}), 1,6 \mathrm{~cm}(40 \mathrm{keV}) \mathrm{e}$ 1,2 cm (50 keV) para o PMMA. Conforme a energia aumenta, em ambos os materiais, ocorreu um deslocamento dos picos principais em direção ao feixe primário e uma diminuição nas FWHM em até 60,6 \% e 50,5 \% para a água e PMMA, respectivamente, em relação ao feixe de $30 \mathrm{keV}$. Os valores de $K_{c}^{a r}$ espalhado $/ N_{0}$ dos picos principais aumentaram em até $11,14 \%$ e 19,94 \% para o PMMA e água, respectivamente, de acordo com o aumento da energia de $30 \mathrm{keV}$ à $50 \mathrm{keV}$. Estes comportamentos dependem fortemente da faixa de momento transferido que atingem o detector, uma vez que influenciam a faixa de seção de choque selecionada. 


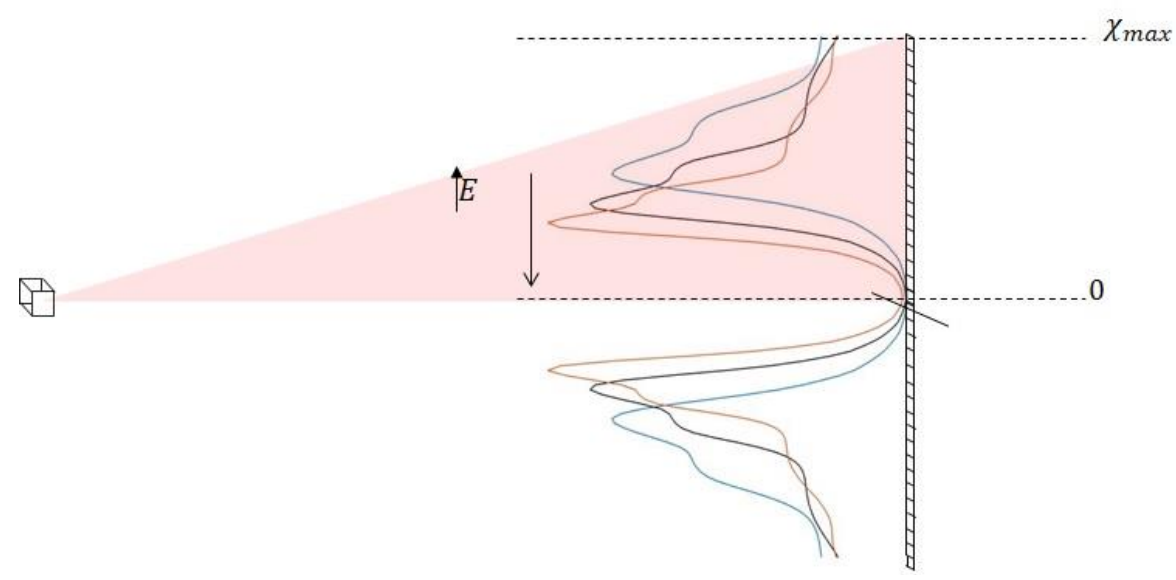

Fig. 4.11. Comportamento dos perfis radiais de acordo com o aumento na energia do feixe incidente.

Uma análise pode ser feita associando $\chi$ e a posição do detector, motivada ao fundamento de que os picos apresentam $\chi$ característicos dos materiais, e o ângulo de espalhamento $\theta$ pode ser escrito em função da posição do detector. Deste modo, a posição do pico principal resulta em aproximadamente $D_{2} \operatorname{tg}\left[2 \operatorname{arcsen}\left(\frac{\chi h c}{E}\right)\right]$, mostrando a sua proporcionalidade com a energia em $\alpha \operatorname{arc} \operatorname{sen}\left(\frac{1}{E}\right)$, justificando o seu deslocamento em direção ao feixe primário em energias maiores, e consequentemente, uma diminuição nas FWHM. A figura 4.11 ilustra de maneira mais clara estes comportamentos nos perfis radiais da imagem sob uma linha no eixo central do detector. Uma modificação em $E$ faz com que se altere o valor de $\chi_{\max }=\frac{E}{h c} \operatorname{sen}\left(\frac{\theta_{\max }}{2}\right)$, alterando a faixa de momento transferido $\left(0<\chi<\chi_{\max }\right)$, em consequência, os perfis radiais são deslocados.

\section{ii. Espectros de energia retangulares}

A figura 4.12a apresenta os espectros de energia retangulares representados pela fluência em energia normalizada em função da energia, estes espectros foram utilizados para a aquisição dos perfis radiais em 4.12 b representados pelo kerma no ar espalhado sob o detector normalizado pelo número de fótons incidentes $\left(N_{0}\right)$ em função da posição ao longo de um eixo central, para uma imagem $18 \times 18 \mathrm{~cm}^{2}$. Os perfis radiais são adquiridos em diferentes larguras do espectro de energia, para uma amostra de PMMA com dimensões $2 \times 2 \times 2 \mathrm{~cm}^{3}$, distanciada a $32 \mathrm{~cm}$ do detector plano. 

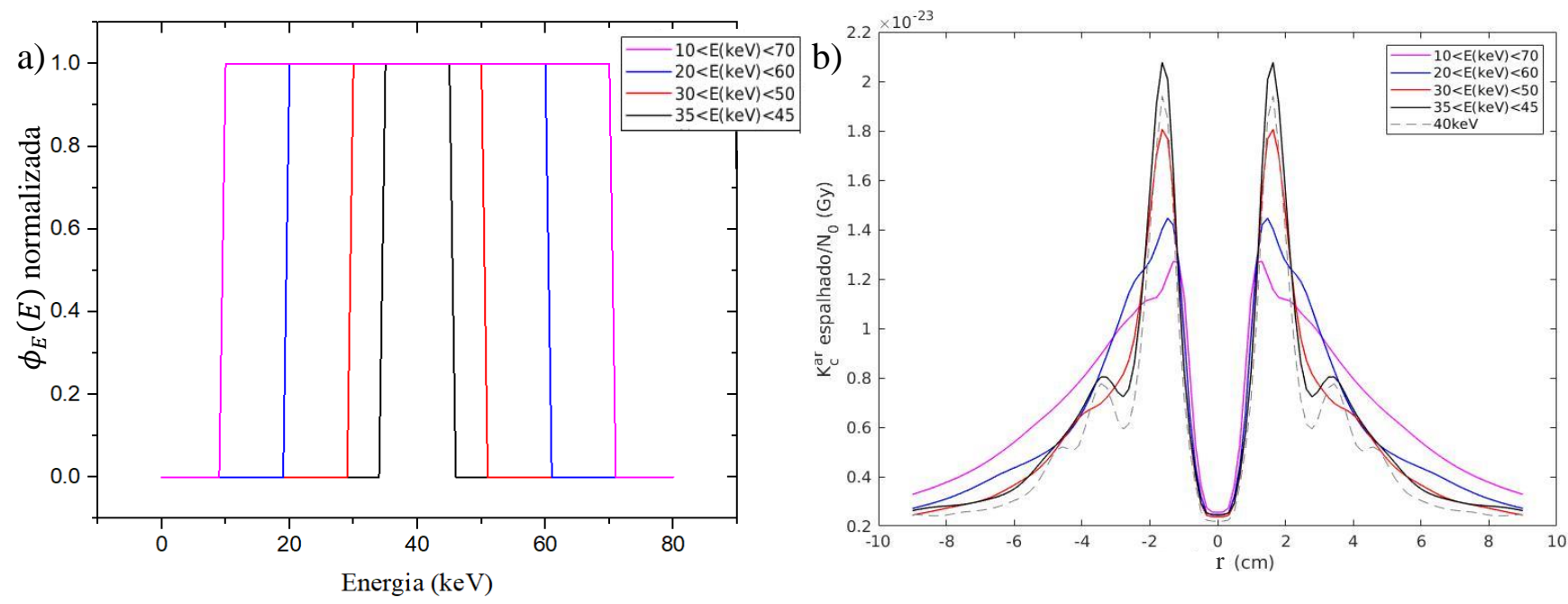

Fig. 4.12. Influência de espectros retangulares no perfil radial da imagem. Em a) a fluência do número de fótons em energia normalizada em função da energia do espectro, para diferentes larguras espectrais. Em b) a distribuição de $K_{c}^{\text {ar }}{ }_{\text {espalhado }} / N_{0}$ em função da posição ao longo de um eixo central do detector, de uma imagem $18 \times 18 \mathrm{~cm}^{2}$ e material da amostra de PMMA, para os espectros retangulares mostrados em a) comparado a um monoenergético de $40 \mathrm{keV}$.

Em espectros mais largos, como por exemplo, $10<E(\mathrm{keV})<70$ e $20<E(\mathrm{keV})<60$ $(\Delta E=16,6 \mathrm{keV}$ e $16,2 \mathrm{keV})$, verificou-se nos perfis um deslocamento dos picos principais em direção ao feixe primário, em $1,2 \mathrm{~cm}$ e 1,4 cm, respectivamente, devido à influências das energias mais altas do espectro; e um aumento na FWHM em 3,6 e 2,3 vezes comparado ao feixe monoenergético de $40 \mathrm{keV}$ de acordo com a largura espectral. As intensidades do $K_{c}^{a r}$ espalhado $/ N_{0}$ utilizando estes espectros foram 1,54 e 1,34 vezes menor comparado ao pico principal do feixe monoenergético de $40 \mathrm{keV}$.

Individualmente, cada energia corresponderá a diferentes faixas da seção de choque diferencial de espalhamento por ângulo sólido do material estudado, a qual depende juntamente com a faixa de ângulo vista por um elemento de área do detector, de modo que a resultante será o somatório de todas estas contribuições em cada energia do espectro. Este fenômeno que origina deformações nos perfis radiais da imagem por espalhamento de raios $\mathrm{X}$, devido às diferentes faixas da seção de choque selecionadas em diversas energias, é conhecido e demominado por borramento espectral (LECLAIR e JOHNS, 1999) (JOHNS, LECLAIR e WISMAYER, 2002) (WESTEMORE, FENSTER e CUNNINGHAM, 1996) (BATCHELAR e CUNNINGHAM, 2002).

A figura 4.13 apresenta o comportamento da incerteza $\Delta r$ ao longo de todo o raio do detector, variando as larguras espectrais. As curvas resultantes da soma dos quadrados de todos 


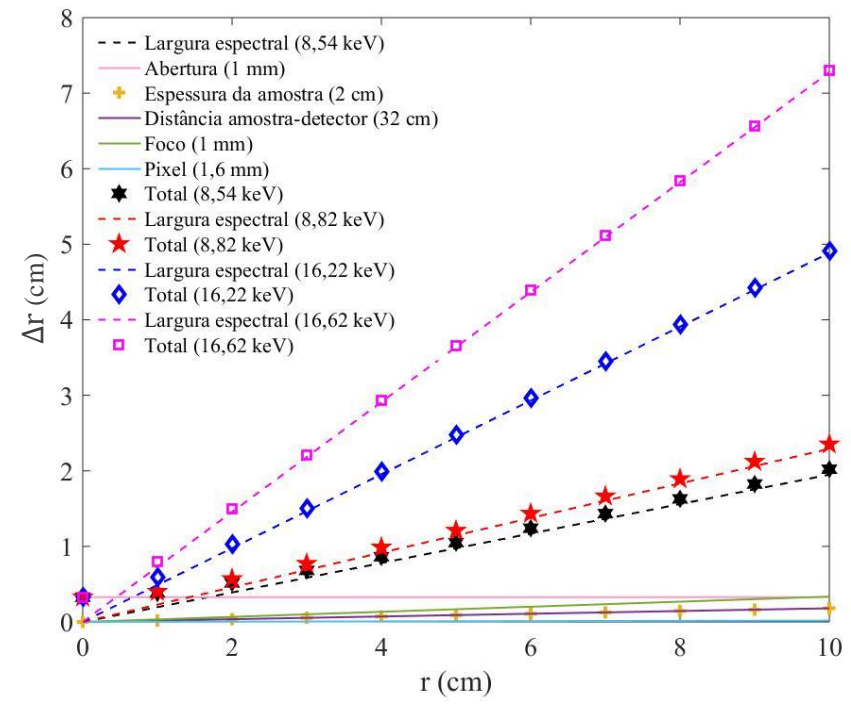

Fig. 4.13. Resolução espacial ao longo do raio do detector, variando a largura do espectro de raios $\mathrm{X}(8,5 \mathrm{keV}-*, 8,82 \mathrm{keV}-\star, 16,2 \mathrm{keV}-\diamond$ e $16,6 \mathrm{keV}-\square)$, para uma amostra espessura de $2 \mathrm{~cm}$ distanciada à $32 \mathrm{~cm}$ do detector.

$\Delta r$ dos parâmetros (equação (3.15)), representadas pelos símbolos (* referente à $\Delta E=$ $8,54 \mathrm{keV} ; \star$ referente à $\Delta E=8,82 \mathrm{keV} ; \diamond$ referente à $\Delta E=16,22 \mathrm{keV}$; e $\square$ referente à $\Delta E=$ $16,6 \mathrm{keV})$, exibiram grandes variações conforme o aumento na largura espectral, apresentando uma diferença máxima relativa de $265 \%$ em $\Delta E=16,6 \mathrm{keV}$ comparada à $\Delta E=8,54 \mathrm{keV}$. De acordo com a diminuição da largura do espectro, evidentemente, verifica-se uma menor influência na resolução espacial, consequentemente, resultando em menores distorções nos perfis radiais da imagem, como observado pela Fig. 4.12, de modo que os demais picos do material começam surgir. Portanto, estes espectros mais estreitos se mostraram mais viáveis no quesito caracterização do material, comparados à espectros mais largos.

\section{iii. Espectros de energia triangulares}

A figura 4.14a apresenta três espectros de energia triangulares utilizados para a aquisição dos perfis radiais em $4.14 \mathrm{~b}$, representados pelo kerma no ar espalhado sob o detector normalizado pelo número de fótons incidentes $\left(\mathrm{N}_{0}\right)$ em função do raio ao longo de um eixo central, para uma imagem $18 \times 18 \mathrm{~cm}^{2}$. Os perfis radiais são adquiridos em diferentes distribuições do espectro, para uma amostra de PMMA com dimensões $2 \times 2 \times 2 \mathrm{~cm}^{3}$, distanciada em $32 \mathrm{~cm}$ do detector plano. 

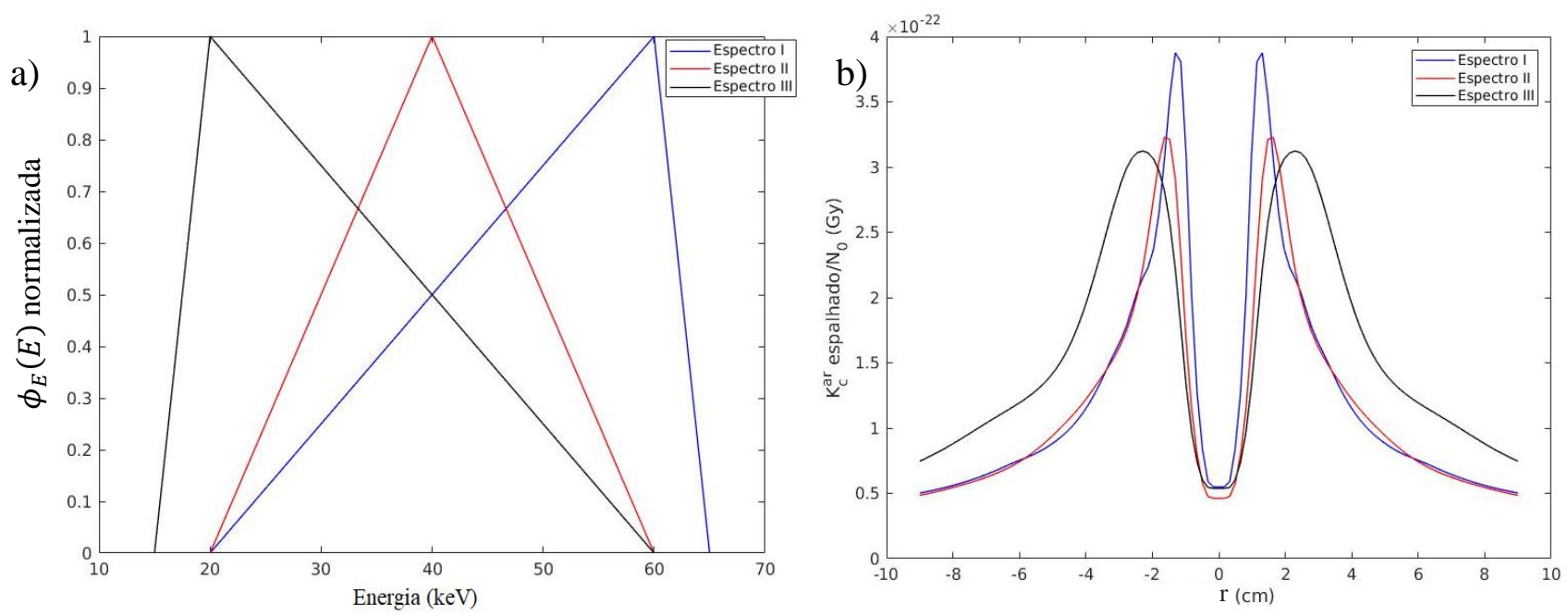

Fig. 4.14. Influência de espectros triangulares no perfil radial da imagem. Em a) a fluência do número de fótons em energia normalizada pelo máximo em função da energia do espectro, para diferentes larguras espectrais. Em b) a distribuição de $K_{c}^{a r}$ espalhado $/ N_{0}$ em função da posição ao longo de um eixo central do detector, de uma imagem $18 \times 18 \mathrm{~cm}^{2}$ e material da amostra de PMMA, para os espectros triangulares mostrados em a).

O espectro I, cuja distribuição apresenta maiores fluências em altas energias, exerce influência sob o perfil radial, de modo que o pico principal se encontra mais próximo do eixo central do detector, em $1,2 \mathrm{~cm}$, comparado aos outros perfis radiais provenientes dos demais espectros triangulares (II e III). Contudo, conforme a diminuição da energia média do espectro, ou seja, maiores fluências em mais baixas energias, houve um deslocamento nos perfis radiais em raios maiores em relação ao eixo central do detector, assumindo posições em $1,6 \mathrm{~cm}$ e 2,3 cm, utilizando os espectros II e III, respectivamente.

Os resultados mostraram uma forte dependência nos comportamentos dos perfis radiais da imagem por espalhamento de raios $\mathrm{X}$ de acorco com as mudanças na energia média do espectro. Os comportamentos são similares aos observados utilizando feixes monoenergéticos, e seguem a mesma lógica em relação ao deslocamento nos perfis radiais de acordo com as mudanças em energia. No entanto, os perfis são alargados, de maneira que os outros picos do PMMA observados em feixes monoenergéticos, não são visualizados, em decorrência do borramento espectral.

\section{iv. Influência da forma do espectro nos perfis radiais da imagem}

A figura 4.15 apresenta os perfis radiais da imagem por espalhamento de raios $\mathrm{X}$ adquiridos utilizando espectros de energia triangular e retangular, ambos com $\Delta E=5,5 \mathrm{keV}$ e 
mesma energia média $(36,4 \mathrm{keV})$. Os picos principais dos perfis radiais, utilizando ambos os espectros, apresentaram a mesma posição no raio do detector em 1,6 cm no detector plano. No entanto, diferem em FWHM, resultando em 2,0 cm e 1,4 cm utilizando os espectros triangular

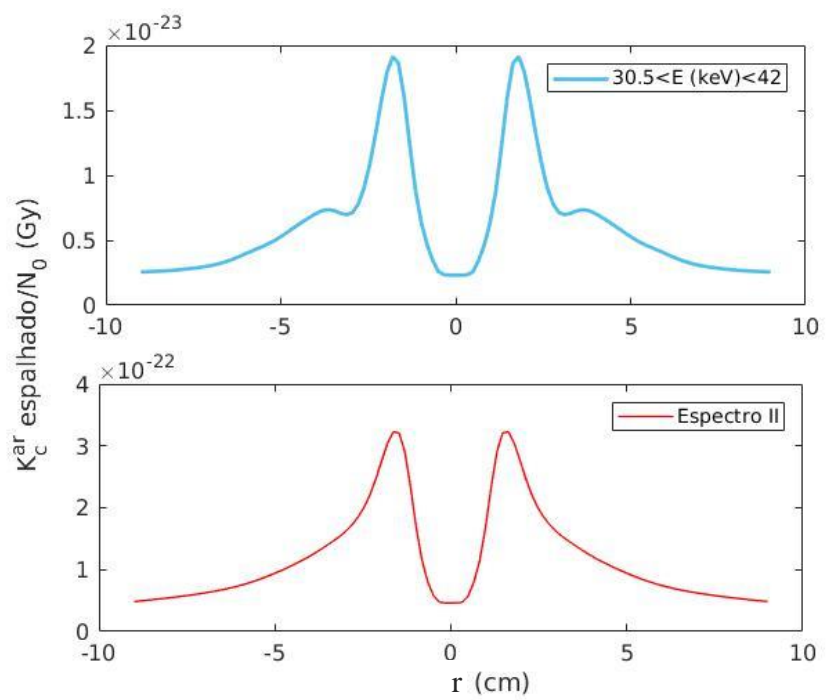

Fig. 4.15. A distribuição de $K_{S} / N_{0}$ em função da posição ao longo de um eixo central do detector, de uma imagem $18 \times 18 \mathrm{~cm}^{2}$ e material da amostra de PMMA, para os espectros retangular e triangular de mesma largura espectral $(5,5 \mathrm{keV})$ e energia média $(36,4 \mathrm{keV})$.

e retangular, respectivamente. Apesar dos espectros de energia utilizados apresentarem mesma largura espectral e energia média, os perfis radiais gerados diferem bastante ao longo do raio do detector. Uma determinada energia do espectro incidente seleciona um intervalo da seção de choque de espalhamento por ângulo sólido, ponderada por um fator, o qual depende da fluência naquela determinada energia. Estas ponderações, as quais definem a forma do espectro de raios $\mathrm{X}$, interferem na resultante da imagem e podem ser interpretadas como uma probabilidade daquele determinado evento naquela faixa de seção de choque diferencial de espalhamento por ângulo sólido ser contabilizada no pixel. Desse modo, o perfil radial utilizando o espectro retangular, o qual possui distribuição constante em um intervalo de energia e probabilidades maiores em determinadas regiões do espectro comparada ao espectro triangular, resultou em uma menor FWHM além de um outro pico do material surgir em 4,2 cm.

Em geral, os resultados mostraram que as formas dos perfis radiais não dependem somente da largura espectral e da energia média do espectro, mas também apresentou uma dependência com a distribuição do espectro em energia, influenciando diretamente nas seções de choque elástica e inelástica, ponderadas a um fator peso. 


\subsection{Estudo de imagens formadas pela componente espalhada dos raios $\mathrm{X}$ experimentalmente}

Nesta seção serão apresentados os resultados e análises de imagens adquiridas experimentalmente, utilizando a componente espalhada dos raios X. Estas análises são feitas por meio dos perfis radiais extraídos da imagem (como descrito em 3.2.3), resultado da média de três imagens adquiridas sob mesmas condições.

\subsubsection{Validação experimental}

A figura 4.16 apresenta os perfis radiais de imagens adquiridas experimentalmente e analiticamente utilizando a componente espalhada dos raios X, expressos em kerma em função do raio do detector normalizados para comparação com os resultados obtidos por King et al. (2009), em uma amostra de $1 \mathrm{~cm}$ de água irradiada por um espectro de raios $\mathrm{X}$ de $50 \mathrm{kV}$.

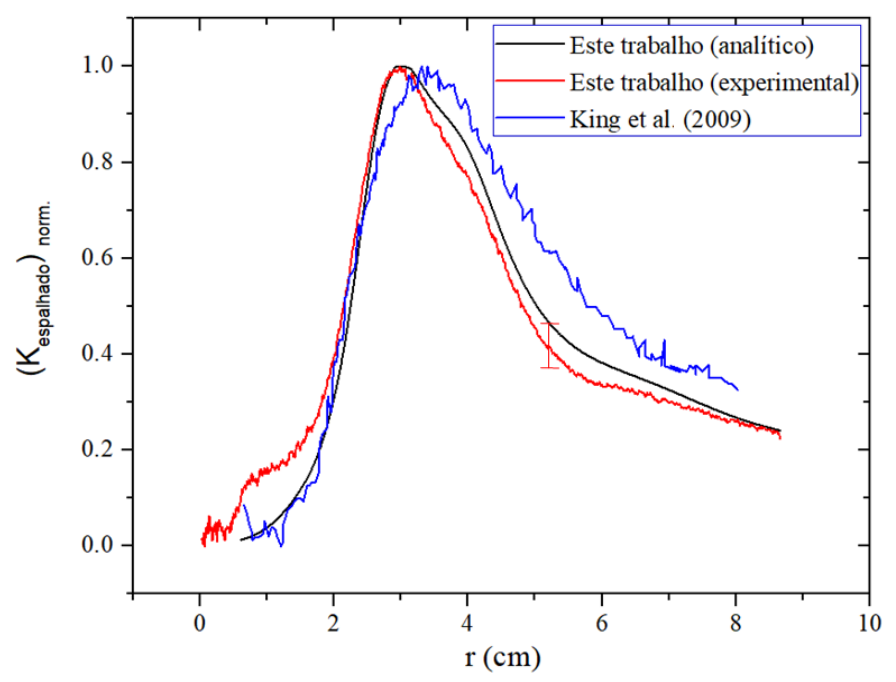

Fig. 4.16. Perfis radiais de imagens por espalhamento de raios $X$ da água, utilizando um espectro de $50 \mathrm{kV}$.

Os resultados experimentais do perfil radial da imagem por espalhamento de raios $\mathrm{X}$ apresentaram diferença relativa média de 7,9\%, em comparação com os resultados obtidos experimentalmente propostos por King et al. (2009). Em geral, apesar dos resultados adquiridos neste trabalho exibirem significantivas diferenças quando comparadas aos valores experimentais propostos pela literatura, em decorrência das diferenças nos sistemas experimentais utilizados, as formas dos perfis radiais apresentaram comportamentos similares, 
característicos da água. Os resultados do perfil radial da imagem por espalhamento de primeira ordem adquiridos analiticamente, proposto por este trabalho (seção 3.1), exibiram expressivas similaridades na forma do perfil radial da imagem adquirida experimentalmente.

Em um ponto da curva, para visualização, foi adicionada a barra de incerteza adquirida, a qual assumem valores de até 8,8 \% do valor médio nos perfis radiais das imagens. Os mesmos comportamentos foram observados para os demais resultados a seguir. Portanto, para melhor visualização das curvas, as barras de incertezas não foram adicionadas nos gráficos dos perfis radiais.

\subsubsection{Influência da espessura nos perfis radiais da imagem}

A figura 4.17 apresenta os perfis radiais de imagens adquiridas experimentalmente utilizando a componente espalhada dos raios $\mathrm{X}$, expressos em kerma normalizado por uma constante $K_{0}$ em função do raio do detector, em uma amostra de PMMA de $1 \mathrm{~cm}, 2 \mathrm{~cm}$ e $4 \mathrm{~cm}$, irradiadas por um espectro de raios X de $80 \mathrm{kV}$ e filtração adicional de 2,5 $\mathrm{mm}$ de $\mathrm{Al}$.

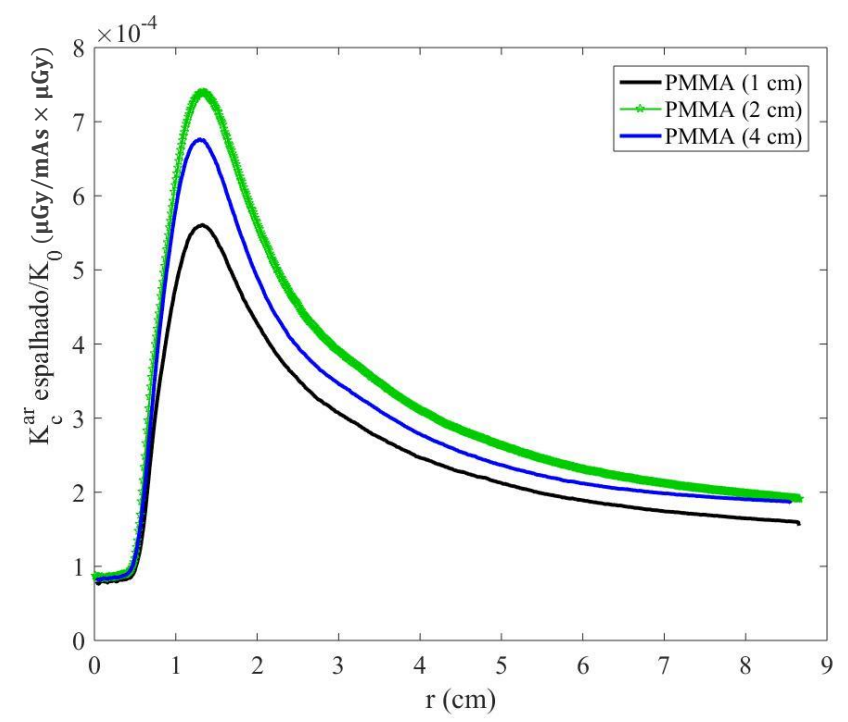

Fig. 4.17. Perfis radiais de imagens por espalhamento de raios $X$, variando as espessuras das amostras de PMMA em $1 \mathrm{~cm}, 2 \mathrm{~cm}$ e $4 \mathrm{~cm}$, utilizando um espectro de $80 \mathrm{kV}(2,5 \mathrm{~mm}$ de Al $)$.

As intensidades do perfil radial da imagem em $2 \mathrm{~cm}$ de espessura apresentaram uma diferença máxima relativa de 45,9\% e 18,9\% comparadas às intensidades do perfil radial em $1 \mathrm{~cm}$ e $4 \mathrm{~cm}$. O número de centros espalhadores é limitado pelas dimensões do volume irradiado, entretanto, são em ordem suficientes de modo que eventos de espalhamento são observados em $1 \mathrm{~cm}$. Partindo deste pressuposto, amostras de dimensões maiores deveriam 
resultar em intensidades maiores, por conta de um maior número de centros espalhadores e eventos de múltiplos espalhamentos no interior da amostra. Contudo, a amostra de $4 \mathrm{~cm}$ de espessura exibiu intensidades de até 15,9\% menores comparadas à $2 \mathrm{~cm}$, em consequência dos efeitos de autoatenuação sofridos na amostra, os quais comprometem a intensidade da imagem. Os mesmos comportamentos foram observados para os outros espectros utilizados, de $50 \mathrm{kV}$ e $80 \mathrm{kV}$ com filtrações adicionais de 2,2 $\mathrm{mm}$ de $\mathrm{Al}$ e $0,6 \mathrm{~mm}$ de $\mathrm{Cu}$.

Em âmbito de estudo da técnica de imagem por espalhamento de raios X os resultados a seguir foram feitos utilizando uma espessura de $2 \mathrm{~cm}$ compostas por materiais equivalentes ao tecido, por conta da maior intensidade observada.

\subsubsection{Imagens formadas e extração dos perfis radiais de amostras homogêneas}

A figura 4.18 apresenta as imagens utilizando a componente espalhada dos raios $\mathrm{X}$ adquiridas experimentalmente e os perfis radiais, para amostras de PMMA, nylon e água, com espessuras de $2 \mathrm{~cm}$, utilizando um feixe polienergético de $50 \mathrm{kV}$ (filtração adicional de 2,2 $\mathrm{mm}$ $\mathrm{Al}$ e $0,6 \mathrm{~mm}$ de $\mathrm{Cu})$.
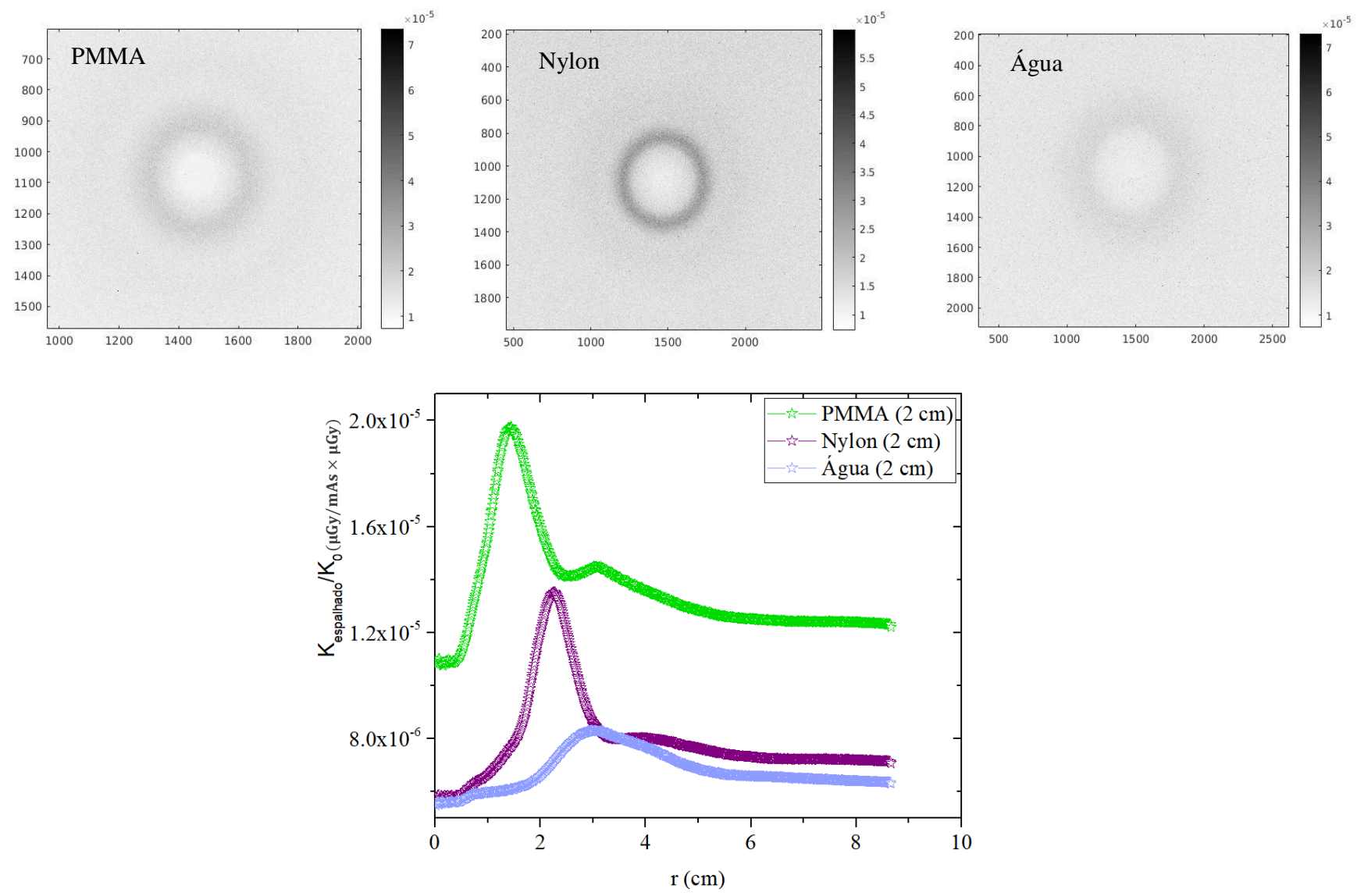

Fig. 4.18. Imagens por espalhamento de raios $X$ para amostras de $2 \mathrm{~cm}$ de PMMA, nylon e água e seus respectivos perfis radiais, utilizando um espectro de energia de $50 \mathrm{kV}(2,2 \mathrm{~mm}$ de $\mathrm{Al}+$ $0,6 \mathrm{~mm}$ de $\mathrm{Cu})$. 
Os diâmetros dos anéis e as intensidades resultantes no detector plano são característicos do espalhador e variam de acordo com a estrutura do material estudado. Estas diferenças são bastante evidentes nos perfis radiais da imagem. Os picos principais foram localizados em 1,4 cm para o PMMA, 2,2 cm para o nylon e 3,1 cm para a água.

O PMMA apresentou ao longo do raio do detector intensidades maiores comparadas aos demais materiais, resultando em intensidades $41 \%$ maiores comparadas à água. Estas diferenças encontradas são ocasionadas pelas diferenças nas seções de choque diferenciais de espalhamento por ângulo sólido, no número de centros espalhadores e nos coeficientes de atenuação de cada material ao longo de todo o espectro de energia.

As figuras 4.19 e 4.20 apresentam imagens utilizando a componente espalhada dos raios $\mathrm{X}$ adquiridas utilizando as mesmas configurações do sistema anterior, no entanto, utilizando feixes polienergéticos de $80 \mathrm{kV}$ com diferentes filtrações (filtração adicional de 2,2 $\mathrm{mm} \mathrm{Al} \mathrm{e} 0,6 \mathrm{~mm}$ de $\mathrm{Cu}$; e 2,5 $\mathrm{mm}$ de $\mathrm{Al}$ ).
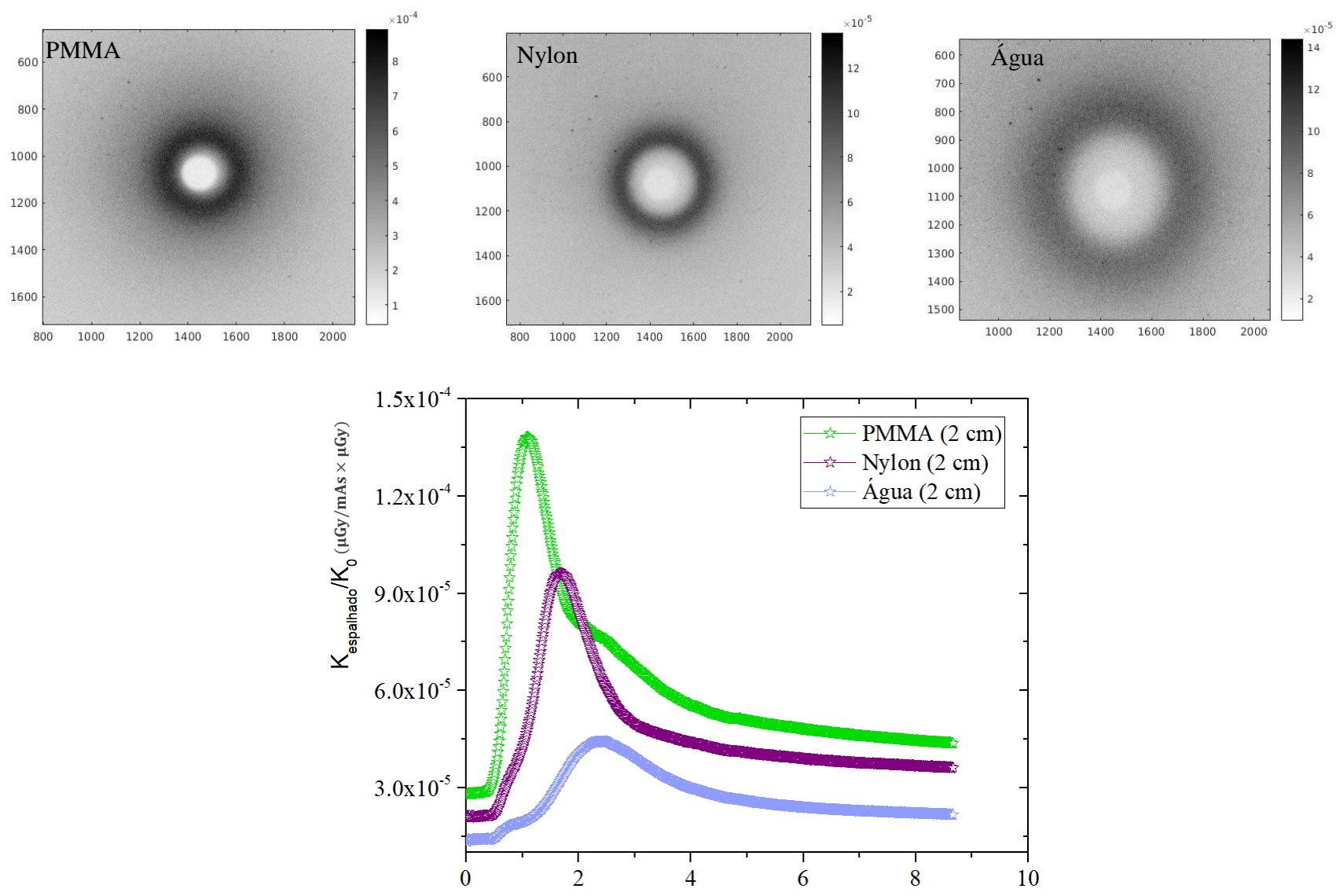

Fig. 4.19. Imagens por espalhamento de raios $X$ para amostras de $2 \mathrm{~cm}$ de $P M M A$, nylon e água e seus respectivos perfis radiais, utilizando um espectro de energia de $80 \mathrm{kV}(2,2 \mathrm{~mm}$ de $\mathrm{Al}+$ $0,6 \mathrm{~mm}$ de $\mathrm{Cu}$ ). 

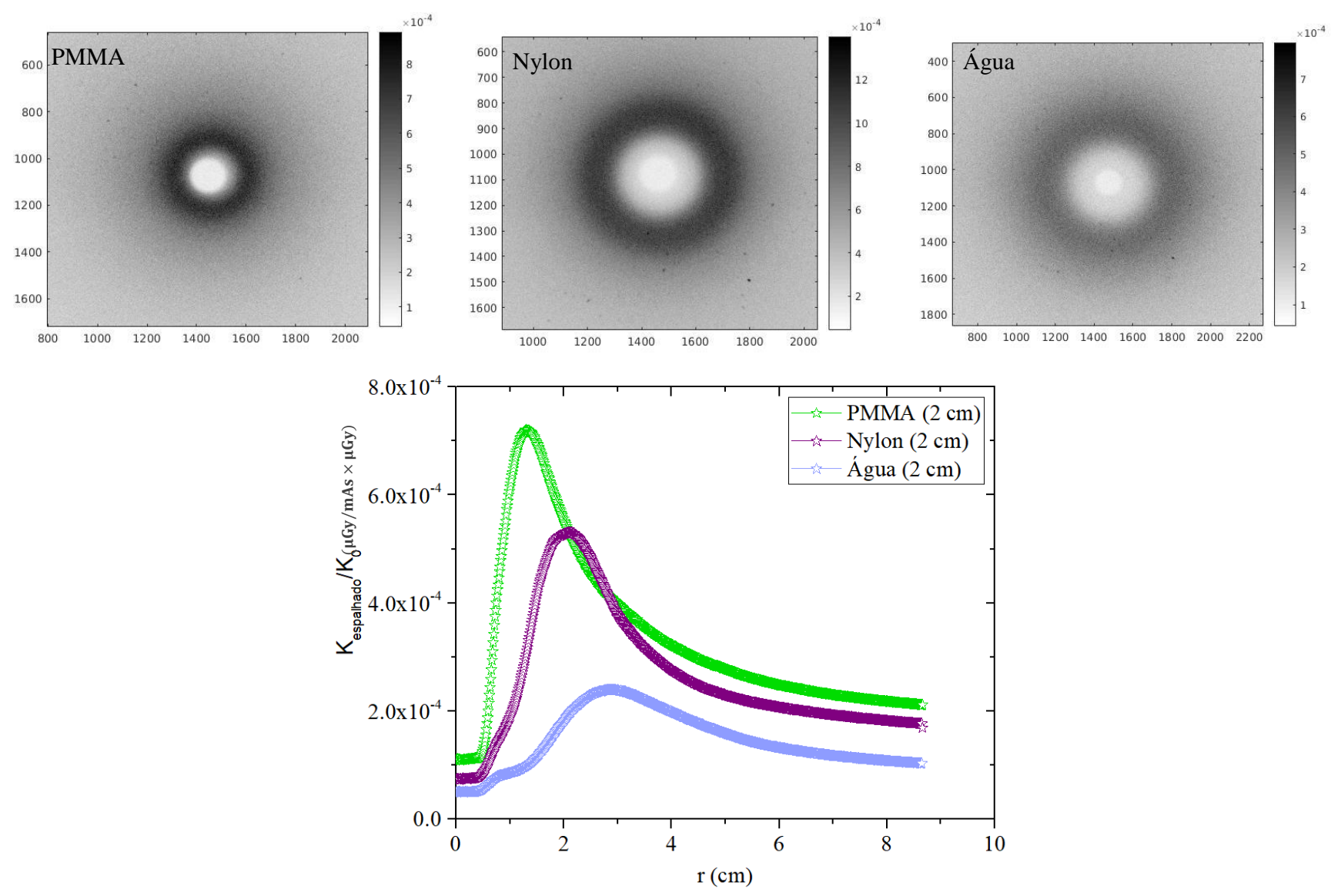

Fig. 4.20. Imagens por espalhamento de raios $X$ para amostras de $2 \mathrm{~cm}$ de PMMA, nylon e água e seus respectivos perfis radiais, utilizando um espectro de energia de $80 \mathrm{kV}(2,5 \mathrm{~mm}$ de $\mathrm{Al})$.

Os picos principais foram localizados em $1,1 \mathrm{~cm}$ e 1,3 $\mathrm{cm}$ para o PMMA, 1,7 $\mathrm{cm}$ e 2,1 cm para o nylon e 2,3 $\mathrm{cm}$ e 2,8 $\mathrm{cm}$ para a água, em $80 \mathrm{kV}$ com filtração adicional de 2,2 $\mathrm{mm}$ $\mathrm{Al}$ e 0,6 $\mathrm{mm}$ de $\mathrm{Cu}$ e $80 \mathrm{kV}$ com filtração adicional de 2,5 $\mathrm{mm}$ de Al, respectivamente. Análogo aos resultados encontrados anteriormente, as intensidades do PMMA, em ambos os espectros, foram maiores comparadas aos demais materiais, resultando em intensidades $40 \%$ e $38 \%$ maiores comparadas à água. Evidentemente, os espectros incidentes de raios X influenciam consideravelmente nas intensidades e nas formas dos perfis radiais da imagem, de modo que $\mathrm{o}$ espectro de $50 \mathrm{kV}$, o qual apresenta uma menor largura espectral, energia média e distribuição em energia pertinentes ao surgimento de um outro pico característico do PMMA, localizado à $3 \mathrm{~cm}$ do eixo central do detector.

\subsubsection{Distribuição radial do contraste e CNR em amostras heterogêneas}

A figura 4.21a, b e c apresentam os perfis radiais de imagens formadas pela componente espalhada dos raios $\mathrm{X}$ em amostras homogêneas e heterogêneas de PMMA e 
PMMA + água em $2 \mathrm{~cm}$ de espessura, o contraste e a CNR para o espectro de $50 \mathrm{kV}$ (filtração adicional de 2,2 $\mathrm{mm} \mathrm{Al} \mathrm{e} \mathrm{0,6} \mathrm{mm}$ de $\mathrm{Cu}$ ), $80 \mathrm{kV}$ (filtração adicional de 2,2 $\mathrm{mm} \mathrm{Al} \mathrm{e} \mathrm{0,6} \mathrm{mm}$ de $\mathrm{Cu}$ ) e $80 \mathrm{kV}$ (filtração adicional de $2,5 \mathrm{~mm}$ ), respectivamente.

Para raios menores que $0,5 \mathrm{~cm}$ foram observadas maiores flutuações nos resultados de contraste e CNR em decorrência da integração dos anéis possuírem uma quantidade menor de pixels conforme a diminuição do raio. Desse modo, intervalos de 0 à $0,5 \mathrm{~cm}$ do raio do detector foram desconsiderados nas análises.

Por meio dos perfis radiais da imagem por espalhamento de raios $\mathrm{X}$ foram estimados o contrate e CNR ao longo do raio do detector. As figuras em 4.21a, utilizando o espectro de $50 \mathrm{kV}$ (filtração adicional de 2,2 $\mathrm{mm} \mathrm{Al} \mathrm{e} 0,6 \mathrm{~mm}$ de $\mathrm{Cu}$ ), apresentaram valores em contraste e CNR superiores ao primário em até 1,2 e 1,6 vezes maior no intervalo de 1,2 $\mathrm{cm}$ à 1,6 $\mathrm{cm}$ e de $2 \mathrm{~cm}$ à $8,5 \mathrm{~cm}$ do raio do detector, respectivamente. Entretanto, utilizando o espectro de $80 \mathrm{kV}$ (filtração adicional de 2,2 $\mathrm{mm}$ Al e 0,6 $\mathrm{mm}$ de $\mathrm{Cu}$ ), na Fig. 4.21b, os valores de contraste e CNR foram superiores ao primário em até 2,2 vezes maior em um raio mais limitado ao longo do detector de 0,5 cm à 1,7 cm. Para o espectro de $80 \mathrm{kV}$ (filtração adicional de 2,5 mm Al), na Fig. 4.21c, os valores de contraste e CNR foram superiores ao primário em até 11,2 e 2,5 vezes maior no intervalo de $0,4 \mathrm{~cm}$ à $2,6 \mathrm{~cm}$ e de $2,9 \mathrm{~cm}$ à $5,4 \mathrm{~cm}$ do raio do detector, respectivamente.

Os resultados mostraram que além do constraste e CNR utilizando o espectro de $80 \mathrm{kV}$ (filtração adicional de 2,5 $\mathrm{mm} \mathrm{Al}$ ) resultarem em razões superiores em relação ao primário comparados aos demais espectros, as diferenças máximas relativas entre o contraste e CNR foram de 81,4\% e 14, 8 \% maiores comparadas à $50 \mathrm{kV}$ e $80 \mathrm{kV}$ (filtração adicional de 2,2 mm Al e 0,6 mm de $\mathrm{Cu}$ ), respectivamente. Estes comportamentos ocorrem devido aos deslocamentos causados nos perfis radiais da imagem em direção ao feixe primário, pelo efeito do borramento espectral. Os deslocamentos ocorrem pelas contribuições das maiores energias do espectro, as quais fazem com que se concentre maiores intensidades em raios menores do detector, associados também à distribuição em baixas energias, resultando em um aumento das intensidades em raios maiores (análago aos comportamentos observados na seção 4.1.5), fazendo com que um outro intervalo de maior contraste e CNR surja.

A figura $4.22 \mathrm{a}, \mathrm{b}$ e $\mathrm{c}$ apresentam os perfis radiais de imagens formadas pela componente espalhada dos raios $\mathrm{X}$ em amostras homogêneas e heterogêneas de PMMA e PMMA + água em $4 \mathrm{~cm}$ de espessura, o contraste e a CNR para o espectro de $50 \mathrm{kV}$ (filtração adicional de 2,2 $\mathrm{mm} \mathrm{Al} \mathrm{e} \mathrm{0,6} \mathrm{mm}$ de $\mathrm{Cu}$ ), $80 \mathrm{kV}$ (filtração adicional de 2,2 $\mathrm{mm} \mathrm{Al} \mathrm{e} \mathrm{0,6} \mathrm{mm}$ de $\mathrm{Cu}$ ) e $80 \mathrm{kV}$ (filtração adicional de $2,5 \mathrm{~mm}$ ), respectivamente. 
As figuras em 4.22a, utilizando o espectro de $50 \mathrm{kV}$ (filtração adicional de 2,2 $\mathrm{mm} \mathrm{Al}$ e 0,6 $\mathrm{mm}$ de $\mathrm{Cu}$ ), apresentaram valores em contraste e CNR superiores ao primário em até 5,5 vezes maior em raios maiores que $2 \mathrm{~cm}$. Entretanto, utilizando o espectro de $80 \mathrm{kV}$ (filtração adicional de 2,2 $\mathrm{mm} \mathrm{Al} \mathrm{e} \mathrm{0,6} \mathrm{mm}$ de $\mathrm{Cu}$ ), na Fig. 4.22b, os valores de contraste e CNR foram superiores ao primário em até 3 e 2,8 vezes maiores em um intervalo de $0,7 \mathrm{~cm}$ à 2,2 $\mathrm{cm}$ e para raios maiores que $3 \mathrm{~cm}$, respectivamente. Para o espectro de $80 \mathrm{kV}$ (filtração adicional de 2,5 $\mathrm{mm} \mathrm{Al}$ ), na Fig. 4.21c, os valores de contraste e CNR foram superiores ao primário em até 7,6 e 1,8 vezes maiores no intervalo de $0,5 \mathrm{~cm}$ à $2,6 \mathrm{~cm}$ e de $3,1 \mathrm{~cm}$ à $4,5 \mathrm{~cm}$ do raio do detector, respectivamente.

Análogo aos comportamentos observados utilizando uma espessura de $2 \mathrm{~cm}$, os resultados para amostras de $4 \mathrm{~cm}$ mostraram que além do constraste e CNR utilizando o espectro de $80 \mathrm{kV}$ (filtração adicional de 2,5 mm Al) resultarem em razões superiores em relação ao primário comparados aos demais espectros, as diferenças máximas relativas entre o contraste e CNR foram de 61,6\% maior comparada à $50 \mathrm{kV}$, entretanto, apenas $4 \%$ maior comparada à $80 \mathrm{kV}$ (filtração adicional de 2,2 $\mathrm{mm} \mathrm{Al} \mathrm{e} \mathrm{0,6} \mathrm{mm}$ de $\mathrm{Cu}$ ), respectivamente.

Em geral, os resultados em ambas as espessuras de $2 \mathrm{~cm}$ e $4 \mathrm{~cm}$ mostraram contraste $\mathrm{e}$ CNR superiores em uma larga faixa ao longo do raio do detector utilizando a componente espalhada dos raios X comparada à componente primária, e apresentaram vantagens na utilização de espectros com larguras espectrais maiores $(\Delta E=22,2 \mathrm{keV}$ para $80 \mathrm{kV}$ filtrado com $2,5 \mathrm{~mm}$ de $\mathrm{Al})$ em relação à espectros com larguras espectrais menores $(\Delta E=7,6 \mathrm{keV}$ para $50 \mathrm{kV}$ filtrado com 2,2 $\mathrm{mm}$ de $\mathrm{Al} \mathrm{e} 0,6 \mathrm{~mm}$ de $\mathrm{Cu}$ ) nos contraste e CNR das imagens.

Os resultados apresentados nos informa o intervalo o qual é gerado maiores valores de contraste e CNR, entre dois materiais de interesse. Estas informações serão úteis para definir regiões de integração dos perfis radiais da imagem, como sistematizado pelo trabalho de Nisar (2004), apresentado na Fig. 4.23. Entretanto, uma vez conhecida a região de maior contraste e CNR os quais nos geram maiores diferenciações entre os materiais, as integrais poderão ser feitas somente nestas regiões, e comporão os pixels da imagem de um objeto de dimensões reais, otimizando os intervalos de integração no raio do detector. 
a)

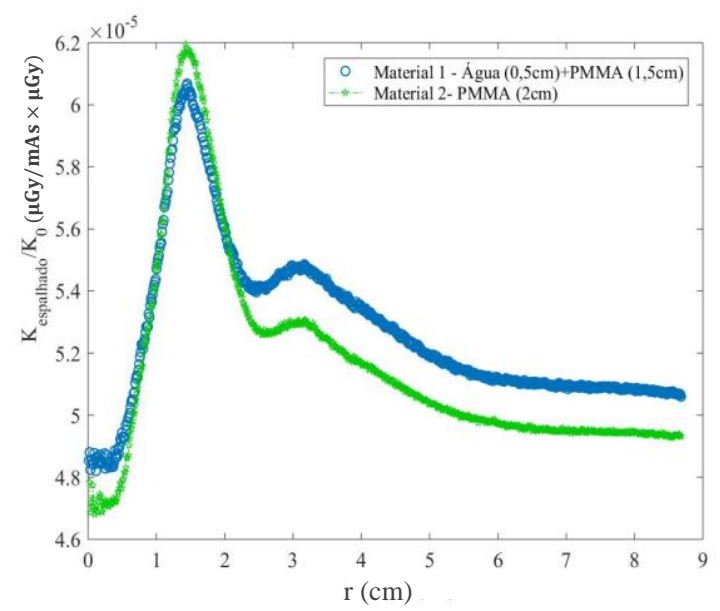

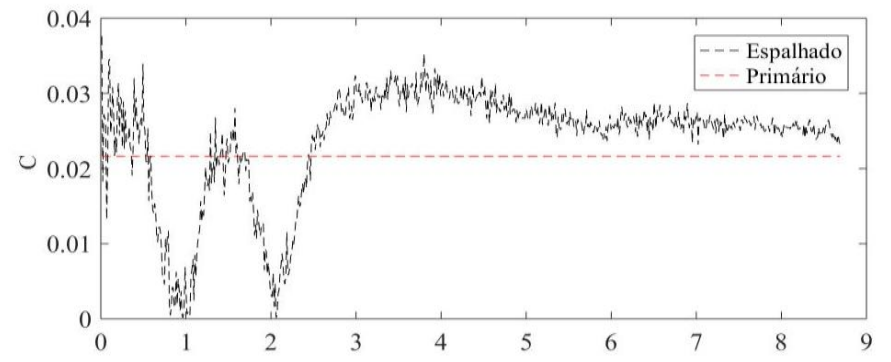

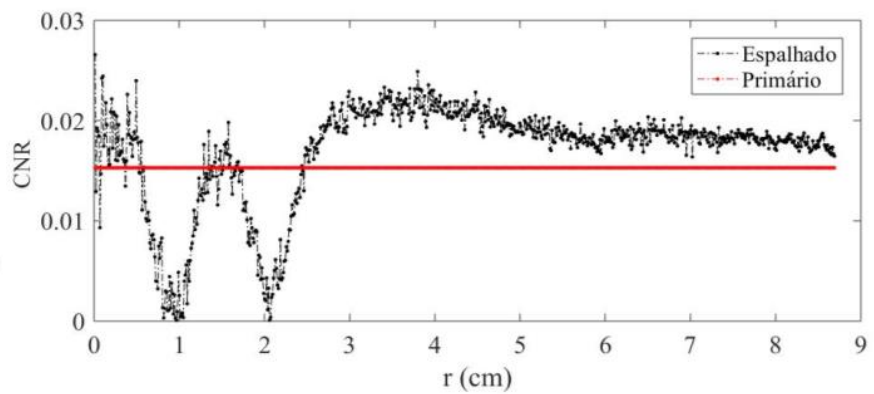

b)
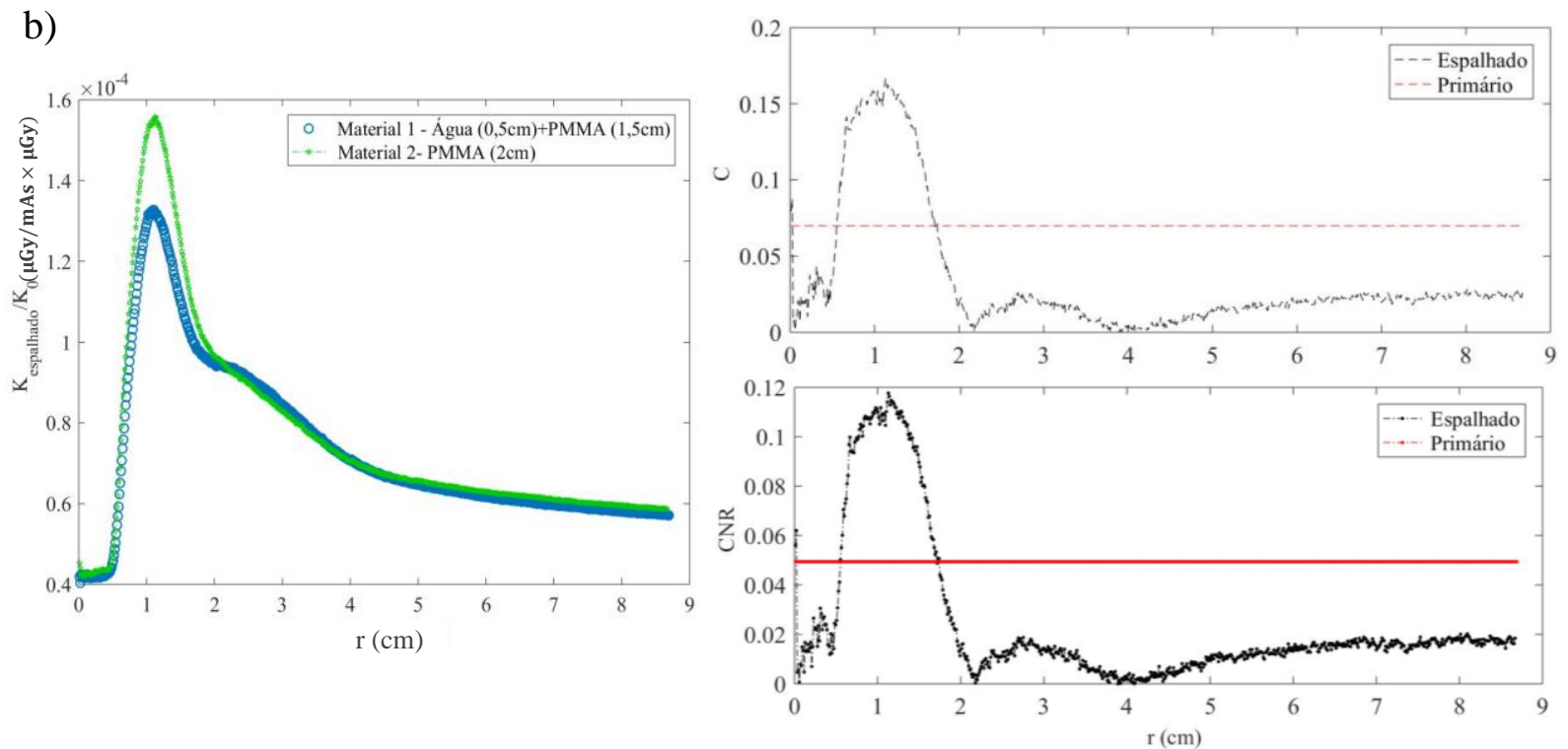

c)

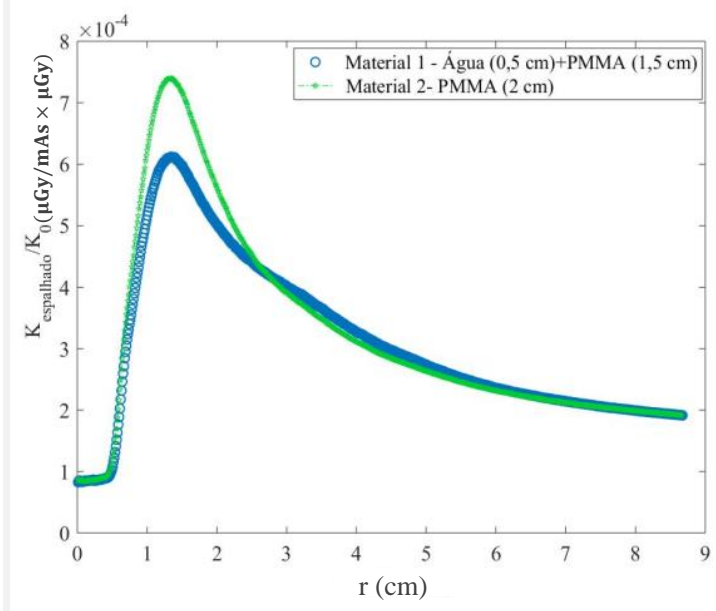

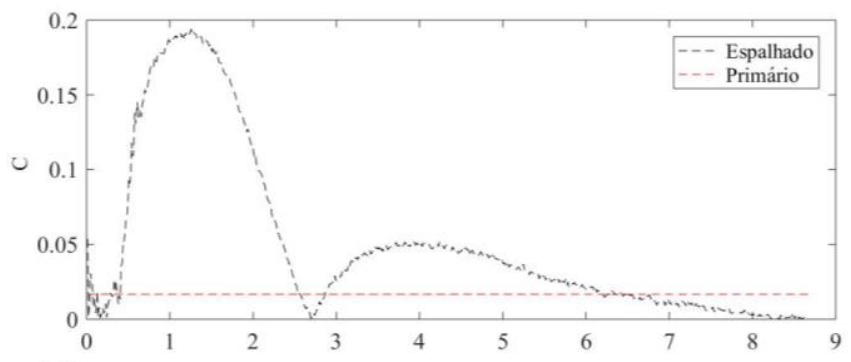

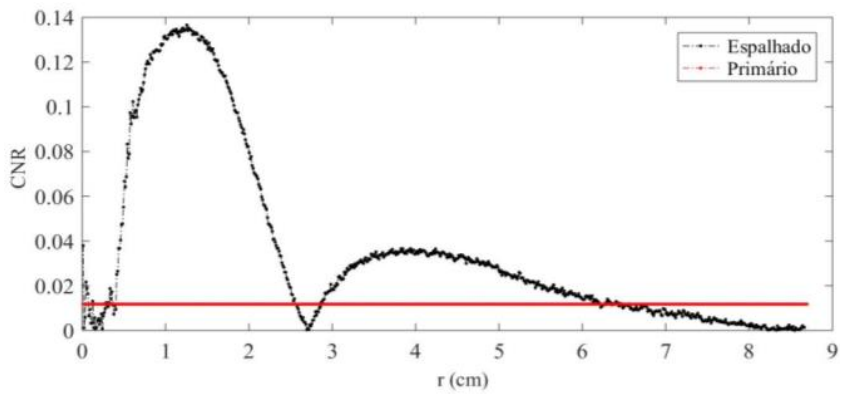

Fig. 4.21. Perfis radiais de imagens por espalhamento de raios $X$, utilizando amostras homogênea e heterogênea de PMMA e PMMA+água com espessura de $2 \mathrm{~cm}$, em análise do contraste e CNR, para um espectro de energia de a) $50 \mathrm{kV}(2,2 \mathrm{~mm}$ de Al e $0,6 \mathrm{~mm}$ de Cu $)$, b) $80 \mathrm{kV}(2,2 \mathrm{~mm}$ de Al e 0,6mm de $\mathrm{Cu}$ ) e c) $80 \mathrm{kV}(2,5 \mathrm{~mm}$ de $\mathrm{Al})$. 
a)

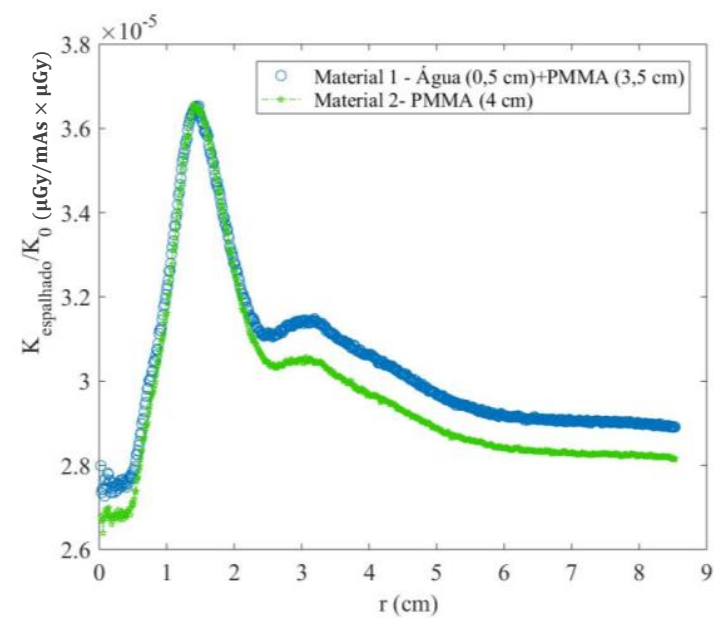

b)

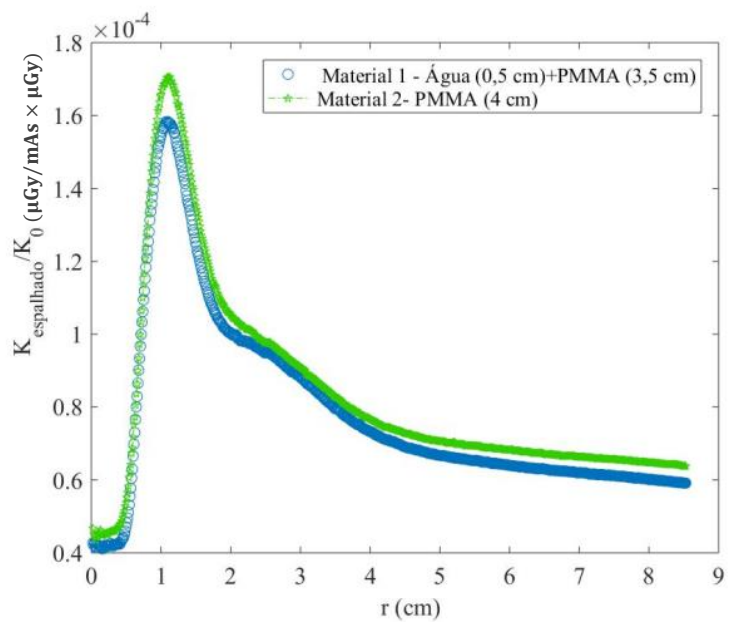

c)

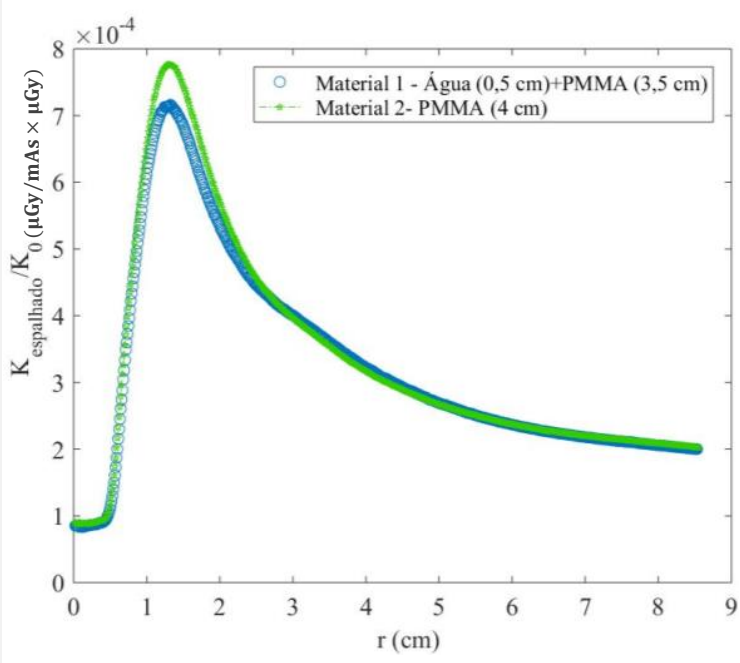

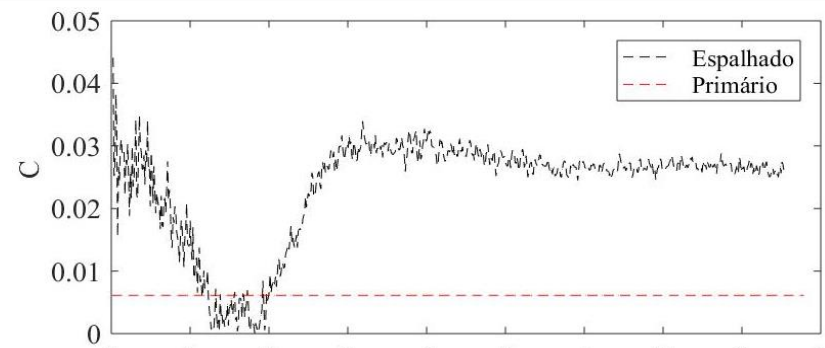
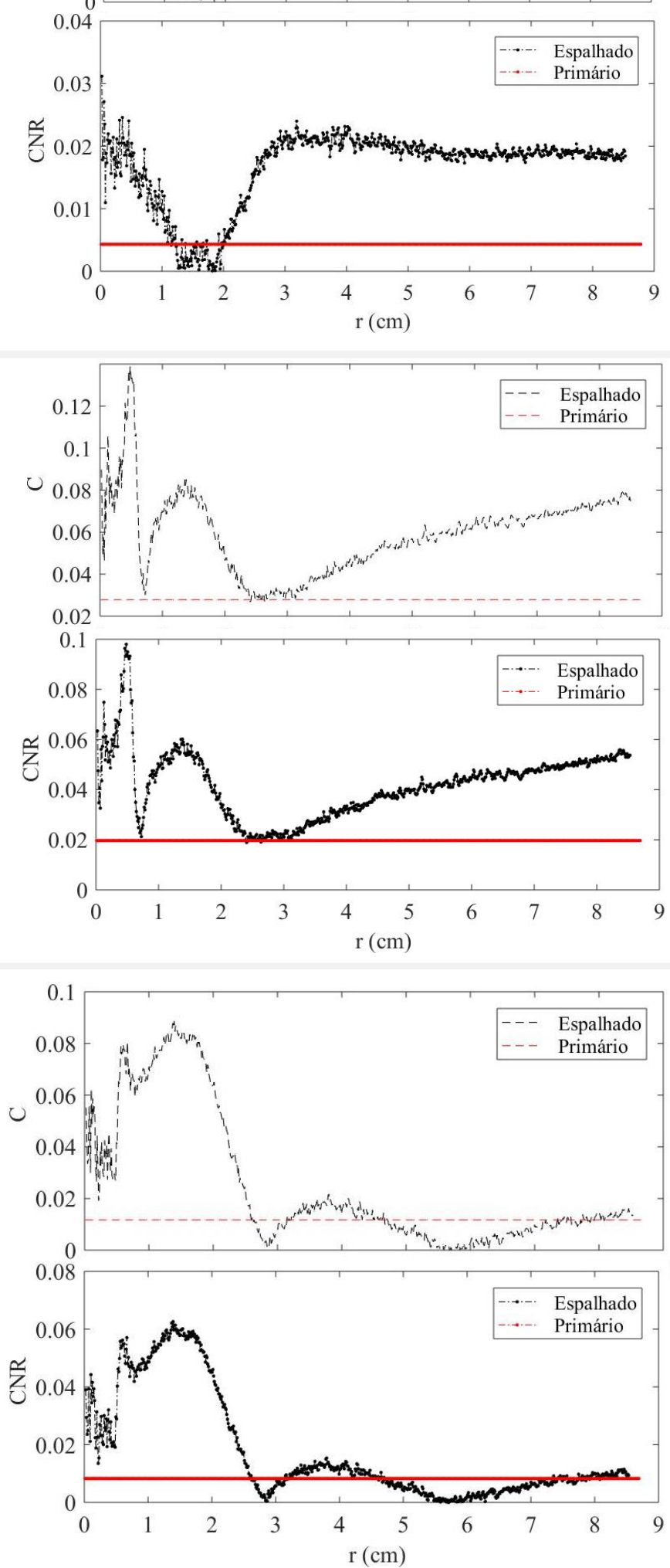

Fig. 4.22. Perfis radiais de imagens por espalhamento de raios $X$, utilizando amostras homogênea e heterogênea de PMMA e PMMA+água com espessura de $4 \mathrm{~cm}$, em análise do contraste e CNR, para um espectro de energia de a) $50 \mathrm{kV}(2,2 \mathrm{~mm}$ de Al e 0,6 $\mathrm{mm}$ de $\mathrm{Cu})$, b) $80 \mathrm{kV}(2,2 \mathrm{~mm}$ de $\mathrm{Al} \mathrm{e} 0,6 \mathrm{~mm}$ de $\mathrm{Cu}$ ) e c) $80 \mathrm{kV}(2,5 \mathrm{~mm}$ de $\mathrm{Al})$. 

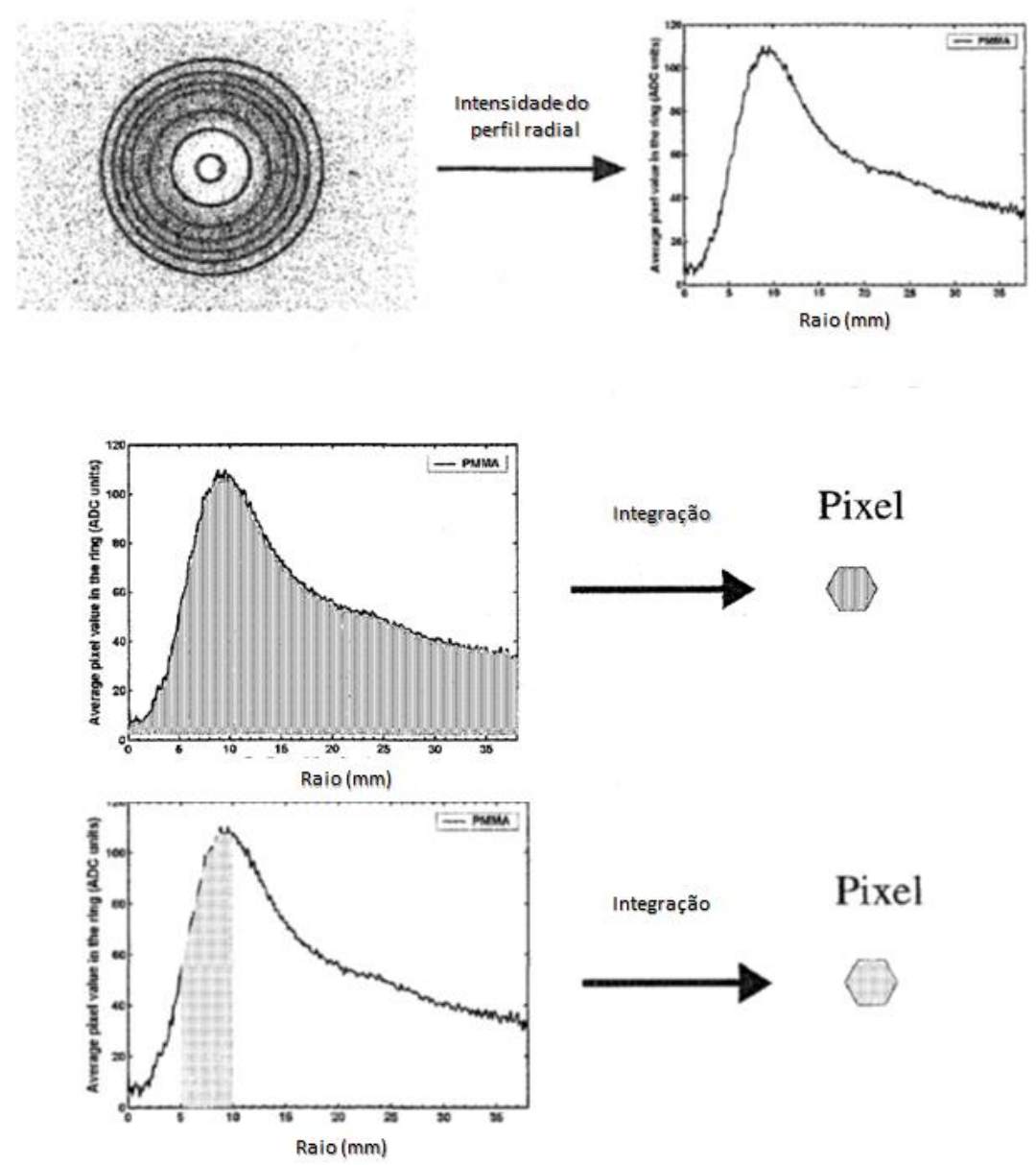

Fig. 4.23. Sistematização para a obtenção de um pixel da imagem formada pela componente espalhada dos raios X (NISAR, 2004).

\section{Conclusões e perspectivas}

\subsection{Conclusões da influência dos parâmetros geométricos e físicos}

Neste trabalho, o estudo dos parâmetros físicos e geométricos do sistema foi feito por meio do desenvolvimento, implementação e validação de um método computacional, o qual utiliza a técnica de traçamento de raios, com a finalidade de investigar os comportamentos gerados nos perfis radiais de imagens por espalhamento de raios X. Os resultados foram importantes para a construção do sistema experimental, encontrando condições nas quais a resolução espacial dos perfis radiais ao longo do raio do detector é prejudicada.

As incertezas ao longo do raio $r$ foram significantemente maiores conforme o aumento da abertura do colimador, no entanto, surtem maiores efeitos em posições do detector mais próximas ao feixe incidente, os mesmos comportamentos foram observados por Beath et al. (2009). Portanto, feixes mais colimados geram menores efeitos do borramento angular. 
Conforme a diminuição da distância do centro da amostra ao detector, são causadas maiores incertezas em $r$, devido ao aumento nos intervalos de $\Delta \theta$ definidos pelas extremidades do pixel do detector. No entanto, apesar de distâncias maiores resultarem em menores efeitos do borramento angular, devem ser levados em conta que as intensidades dos perfis radiais da imagem caem com a lei do inverso do quadrado da distância.

Conforme as espessuras das amostras aumentam maiores incertezas são geradas nos perfis radiais da imagem, devido à maiores intervalos angulares selecionados, definidos pelos extremos da amostra. No entanto, os resultados apresentaram também dependências com a energia, em decorrência da modificação na faixa de momento transferido selecionado.

O parâmetro que apresentou maior influência está relacionado ao espectro de energia incidente. As curvas resultantes da soma dos quadrados de todos $\Delta r$ dos parâmetros exibiram grandes variações conforme o aumento na largura espectral, apresentando uma diferença máxima relativa de $265 \%$ em $\Delta E=16,6 \mathrm{keV}$ comparada à $\Delta E=8,54 \mathrm{keV}$, nos espectros retangulares. Os comportamentos dos perfis radiais da imagem, em relação aos descolamentos dos picos e FWHM, são influenciados pela energia média do espectro de energia. Neste caso, foram observados comportamentos similares aos feixes monoenergéticos, ou seja, assumem picos principais mais próximos ao feixe incidente conforme o aumento da energia média do feixe. No entanto, comparando os perfis radiais gerados por espectros incidentes de mesmas $\Delta E$ e energia média, porém com distribuições distintas (retangular e triangular), os resultados apresentaram uma diferença relativa de 37 \% na FWHM do perfil radial em relação ao espectro triangular, mostrando uma forte dependência também com a forma do espectro. Deste modo, a equação (3.15) se torna insatisfeita para estimar o borramento espacial gerado nos perfis radiais da imagem, pois levam em conta somente a largura espectral e a energia média do espectro.

\subsection{Conclusões no contraste e CNR das imagens experimentais}

O sistema experimental construído e validado, proporcionou a análise dos perfis radiais de imagens obtidas experimentalmente, utilizando amostras homogêneas e heterogêneas equivalentes ao tecido, à fim de avaliar a distribuição radial do contraste e CNR entre dois materiais de interesse, apresentando valores superiores ao contraste primário em determinados intervalos ao longo do raio do detector.

Os resultados experimentais mostraram que a utilização do espectro de $50 \mathrm{kV}(\Delta E=$ 7,6 keV) geram melhores resoluções espaciais, de modo que um outro pico do PMMA pode ser 
visualizado em $3 \mathrm{~cm}$, entretanto, como já esperado, o espectro menos filtrado de $80 \mathrm{kV}(\Delta E=$ $22,2 \mathrm{keV}$ ) apresentaram maiores efeitos de borramento, indicando a potencialidade de espectros com larguras espectrais e energia média menores em caracterizar materiais em estudo. Apesar disto, para a formação da imagem por espalhamento de raios X, a análise do contraste e CNR entre os materiais PMMA e PMMA+água, ao longo do raio do detector, apresentaram valores superiores com a utilização de um espectro de $\Delta E=22,2 \mathrm{keV}$ comparado ao espectro de $\Delta E=$ 7,6 keV , indicando uma potencial aplicação das imagens por espalhamento de raios X utilizando espectros clínicos.

\subsection{Perspectivas}

Neste trabalho, ainda podem ser feitas diversas extensões de estudos das imagens por espalhamentos de raios $\mathrm{X}$, alterando o sistema de detecção para a radiografia digital (digital radiography, DR), aplamente utilizada na clínica. Outra análise deverá ser feita em relação às doses entregues, os quais se tornam imprescindíveis para aplicações médicas. Juntamente com o estudo de técnicas que minimizem o tempo de aquisições das imagens (DYDULA, BELEVB e JOHNS, 2017). 


\section{REFERÊNCIAS}

AAPM. Acceptance Testing and Quality Control of Photostimulable Storage Phosphor Imaging Systems. College Park, MD: American Association of Physicists in Medicine. 2006. p. 1-68. AAPM. An exposure indicator for Digital Radiography, College Park, MD, v. AAPM Report 116, July 2009.

ALS-NIELSEN, J.; MCMORROW, D. Elements of modern X ray physics. [S.1.]: John Wiley \& Sons, 2011.

ATTIX, F. H. Introduction to radiological physics and radiation dosimetry. $1^{\mathrm{a}}$. ed. [S.1.]: Wiley, 1986.

ATTWOOD, D. Soft X ray and extreme ultraviolet radiation: Principles and applications. $1^{\text {a }}$. ed. Bekerley, California: Cambridge University Press, 1999.

BATCHELAR, D. L.; CUNNINGHAM, I. A. Material-specific analysis using coherent-scatter imaging. Medical Physics, 29, 2002. 1651-1650.

BEATH, S. R.; CUNNINGHAM, I. A. Pseudomonoenergetic x-ray diffraction measurements using balanced filters for coherent-scatter computed tomography. Medical Physics, 36, 2009. 1839-47.

BERGER, M. et al. XCOM: Photon Cross Section Database version 1.3, Gaithersburg, MD, 2005.

BRADLEY, D. A. et al. Quantitative measurement of small-angle gamma ray scattering from water, nylon, and Lucite. Medical Physics, 16, 1989. 851-857.

BUSHBERG, J. T. et al. The essential physics of medical imaging. $2^{\mathrm{a}}$. ed. [S.1.]: Lippincott Williams \& Wilkins, 2001.

CUNHA, D. M.; TOMAL, A.; POLETTI, M. E. Diffraction enhanced breast imaging through Monte Carlo simulations. Nuclear Instruments and Methods in Physics Research Section A: Accelerators, Spectrometers, Detectors and Associated Equipment, 652, 2011. 878-882. DUVAUCHELLE, P. et al. A computer code to simulate X-ray imaging techniques. Nuclear Instruments and Methods in Physics Research B, 170, 2000. 245-258.

DYDULA, C.; BELEVB, G.; JOHNS, P. C. Accelerated x-ray scatter projection imaging using multiple continuously-moving pencil beams. Proc. of SPIE, 10132, 2017. 4J1-13.

EISBERG, R.; RESNICK, R. Física quântica: átomos, moléculas, sólidos, núcleos e partículas. 9ª ed. [S.1.]: Campus, 1994. 
EVANS, S. H. et al. Measurement of small-angle photon scattering for some breast tissues and tissue substitute materials, 36, 1991. 7-18.

FREUD, N. et al. Deterministic simulation of first-order scattering in virtual X-ray imaging. Nuclear Instruments and Methods in Physics Research Section B: Beam Interactions with Materials and Atoms, 222, 2004. 285-300.

FREUD, N. et al. Fast and robust ray casting algorithms for virtual X-ray imaging. Nuclear Instruments and Methods in Physics Research B, 248, 2006. 175-180.

FUJITA, H. et al. Basic imaging properties of a computed radiographic system with photostimulable phosphors. Medical Physics, 16, 1989.

HENDEE, W. R.; RITENOUR, E. R.; HOFFMANN, K. R. Medical Imaging Physics. 4. ed. [S.1.]: Wiley-Liss., v. 30, 2002.

HUBBELL, J. H. et al. Atomic Form Factors, Incoherent Scattering Functions, and Photon Scattering Cross Sections. J. Phys. Chern. Ref. Data, 4, 1975. 471-493.

HUBBELL, J. H.; O/VERBO/, I. Relativistic atomic form factors and photon coherent scattering cross sections. J. Phys. Chem. Ref. Data, 8, 1979.

ICRU Report 44. Tissue Substitutes in Radiation Dosimetry and Measurement, Bethesda, MD, n. $15,1989$.

IMAGE J, image processing and analysis in Java. image processing and analysis in Java, 2019. Disponivel em: <imagej.nih.gov/ij/index.html>.

INANC, F. Scattering and its role in radiography simulations. NDT\&E International, 35, 2002. 581-593.

INANC, F. Recent Development in Deterministic Radiography Simulations. AIP Conference Proceedings, 894, 2007. 523-530.

JACKSON, J. D. Classical eletrodinamics. $3^{\mathrm{a}}$. ed. Bekerley, California: John Wiley \& Sons, 1999.

JOHnS, H. E.; CUNnINGHAM, J. R. The Physics of Radiology,., Springfield, Illinois, USA. 4. ed. Springfield, Illinois, USA: ed. Charles C. Thomas, 1983.

JOHNS, P. C.; LECLAIR, R. J.; WISMAYER, M. P. Medical X -Ray Imaging with Scattered Photons. Proc. of SPIE, 10313, 2002. 355-357.

JOHNS, P. C.; YAFFE, M. J. Coherent scatter in diagnostic radiology. Medical Physics, 10, 1983. 40-50.

KING, B. W.; JOHNS, P. C. Measurement of coherent scattering form factors using an image plate. Physics in Medicine and Biology, 53, 2008. 5977-5990. 
KOSANETZKY, J. et al. X ray diffraction measurements of some plastic materials and body tissues. Medical Physics, 14, 1987. 526-532.

LANDHEER, K.; JOHNS, P. C. Synchrotron-based coherent scatter x-ray projection imaging using an array of monoenergetic pencil beams. REVIEW OF SCIENTIFIC INSTRUMENTS, 83, 2012. 095114 -1-6.

LECLAIR, R. J.; JOHNS, P. C. A semianalytic model to investigate the potential applications of x-ray scatter imaging, 25, 1998. 1008-1020.

LECLAIR, R. J.; JOHNS, P. C. Analysis of spectral blur effects in x-ray scatter imaging. Medical Physics, 26, 1999. 1811-1816.

LECLAIR, R. J.; JOHNS, P. C. Optimum momentum transfer arguments for x-ray forward scatter imaging. Medical Physics, 29, 2002. 2881-2890.

LELIVELD, C. J. et al. Monte Carlo Modeling of Coherent Scattering: Influence of Interference. IEEE Transactions on Nuclear Science, 43, 1996. 3315-3321.

LI, N. et al. Virtual X-ray imaging techniques in an immersive casting simulation environment. Nuclear Instruments and Methods in Physics Research B, 262, 2007. 143-152.

LI, N. et al. A fast algorithm for voxel-based deterministic simulation of X-ray imaging. Computer Physics Communications, 178, 2008. 518-523.

MACKENZIE, A. Validation of correction methods for the non-linear response of digital radiography systems, $81,2008.341-345$.

MARSHALL, N. W. et al. Image quality assessment in digital mammography: part I. Technical characterization of the systems. Physics in Medicine and Biology, 56, 2011. 4201-4220.

MARSHALL, N. W. et al. Image quality assessment in digital mammography: part I. Technical characterization of the systems. Physics in Medicine and Biology, 56, 2011. 4201-4220.

MARSHALL, N. W.; MACKENZIE, A.; HONEY, I. D. Quality control measurements for digital X-ray detectors. Physics in Medicine and Biology, 56, 2011. 979-999.

MORIN, L. R. M.; BERROIR, A. Calculation of x-ray single scattering in diagnostic radiology. Phys. Med. Biol., 28, 1983. 789-797.

MOTZ, J. W.; DANOS, M. Image information content and patient exposure. Medical Physics, 5, 1978. 8-22.

MUNTZ, E. P. et al. On the significance of very small angle scattered radiation to radiographic imaging at low energies. Medical Physics, 6, 1983. 319-323. 
NARTEN, A. H.; LEVY, H. A. Liquid Water: Scattering of X-Rays. In: FRANKS, F. The Physics and Physical Chemistry of Water. Water (A Comprehensive Treatise). Boston, MA: Springer, v. 1, 1972. p. 311-332.

NEITZEL, U. Status and prospects of digital detector technology for CR and DR. [S.1.]: [s.n.], 2005.

NISAR, M. Coherent scatter $\mathbf{X}$ ray imaging of plastic and water phantoms. Carleton University, thesis. Otawwa, p. 85. 2004.

OKUNO, E.; CALDAS, I. L.; ROBILOTTA, C. C. Física para ciências biológicas e biomédicas. [S.1.]: Harbra-Harper, 1986. 490 p.

PANI, S. et al. Modelling an Energy-Dispersive X-Ray Diffraction System for Drug Detection. IEEE TRANSACTIONS ON NUCLEAR SCIENCE, 56, 2009. 1238-41.

PODGORSAK, E. B. Radiation Physics for Medical Physicists. $2^{\mathrm{a}}$. ed. Montreal, Canadá: Springer, 2010.

POLETTI, M. E. et al. Precise evaluation of elastic differential scattering cross-sections and their uncertainties in X-ray. Nuclear Instruments and Methods in Physics Research B, 187, 2002. 437-446.

POLETTI, M. E.; GONÇALVES, O. D.; MAZZARO, I. X-ray scattering from human breast tissues and breast-equivalent materials. Physics in Medicine and Biology, 47, 2001. 47-63.

POLUDNIOWSKI, G. Calculation of x-ray spectra emerging from an x-ray tube. Part II. X-ray production and filtration in x-ray targets. Medical Physics, 34, 2007. 2175-2186.

POLUDNIOWSKI, G. et al. SpekCalc: a program to calculate photon spectra from tungsten anode X-ray tubes. Physics in Medicine \& Biology, 54, 2009b.

POLUDNIOWSKI, G.; EVANS, P. M.; WEBB, S. Rayleigh scatter in kilovoltage x-ray imaging: is the Independent Atom Approximation good enough? Physics in Medicine \& Biology, 54, 2009. 6931-6942.

ROWLANDS, J. The physics of computed radiography. Physics in Medicine and Biology, 47, 2002. 133-166.

SPELLER, R. Tissue analysis using x-ray scattering X ray, 28, 1999. 224-250.

TAIBI, A.; ROYLE, G.; SPELLER, R. D. A monte carlo simulation study to investigate the potential of diffraction enhanced breast imaging. IEEE TRANSACTIONS ON NUCLEAR SCIENCE, 47, 2000. 1581-1586.

TARTARI, A. et al. Updating of form factor tabulations for coherent. Physics in Medicine and Biology, 47, 2002. 163-175. 
WESTEMORE, M. S.; FENSTER, A.; CUNNINGHAM, I. A. Angular-dependent coherent scatter measured with a disgnostic $\mathrm{X}$ ray image intensifier-based imaging system. Medical Physics, 23, 1996. 723-733.

WESTMORE, M. S.; FENSTER, A. Tomographic imaging of the angular-dependent coherentscatter cross section. Medical Physics, 24, 1997. 3-10.

WINTERLE, P. Vetores e geometria analítica. $1^{\mathrm{a}}$. ed. [S.1.]: Pearson, 2000.

YAO, W.; LESZCZYNSKI, K. W. Analytical approach to estimating the first order x-ray scatter. Medical Physics, 36, 2009. 3145-3156.

ZHAN, X. et al. Simulation of Scattered Radiation with Various Anti-Scatter Grid Designs in a Photon Counting CT. SPIE Medical Imaging, 10948, 2019. 109484Q1-7.

ZHENG, Y. et al. Limit of Detection in X-ray Diffraction Measurements of Tissue Equivalent Samples. IOP Publishing, Journal of Physics: Conference Series, 637, 2015. 1-4. 